\title{
The use of unmanned aerial vehicles (UAVs) for engineering geology applications
}

\author{
Daniele Giordan ${ }^{1}$ - Marc S. Adams ${ }^{2}$ - Irene Aicardi ${ }^{3,4}$ - Maria Alicandro ${ }^{5}$ - Paolo Allasia ${ }^{1}$. Marco Baldo ${ }^{1}$. \\ Pierluigi De Berardinis ${ }^{5}$. Donatella Dominici ${ }^{5}$. Danilo Godone ${ }^{1}$ - Peter Hobbs ${ }^{6}$ • Veronika Lechner ${ }^{2}$. \\ Tomasz Niedzielski ${ }^{7} \cdot$ Marco Piras $^{3} \cdot$ Marianna Rotilio $^{5} \cdot$ Riccardo Salvini $^{8} \cdot$ Valerio Segor $^{9} \cdot$ Bernadette Sotier $^{2}$. \\ Fabrizio Troilo ${ }^{10}$
}

Received: 28 October 2019 / Accepted: 25 February 2020 / Published online: 1 April 2020

(C) The Author(s) 2020

\begin{abstract}
This paper represents the result of the IAEG C35 Commission "Monitoring methods and approaches in engineering geology applications" workgroup aimed to describe a general overview of unmanned aerial vehicles (UAVs) and their potentiality in several engineering geology applications. The use of UAV has progressively increased in the last decade and nowadays started to be considered a standard research instrument for the acquisition of images and other information on demand over an area of interest. UAV represents a cheap and fast solution for the on-demand acquisition of detailed images of an area of interest and the creation of detailed 3D models and orthophoto. The use of these systems required a good background of data processing and a good drone pilot ability for the management of the flight mission in particular in a complex environment.
\end{abstract}

Keywords UAV $\cdot$ Orthophoto $\cdot$ Debris flow $\cdot$ Drone $\cdot$ Earthquake $\cdot$ Engineering geology $\cdot$ Hydrology $\cdot$ Landslide $\cdot$ Structure from motion

\section{Introduction}

This paper represents the result of the IAEG C35 Commission "Monitoring methods and approaches in engineering geology applications" workgroup. The work of the Commission is aimed to present a general overview of UAVs and their potentiality in the field of engineering geology. The use of UAV has progressively increased in the last decade and nowadays started to be considered a standard research instrument for

Daniele Giordan

daniele.giordan@irpi.cnr.it

1 National Research Council, Research Institute for Geo-Hydrological Protection, Turin, Italy

2 Department of Natural Hazards, Austrian Research Centre for Forests (BFW), Innsbruck, Austria

3 Department of Environmental, Land and Infrastructure Engineering, Politecnico di Torino, Turin, Italy

4 PoliTO Interdepartmental Centre for Service Robotics (PIC4Ser), Politecnico di Torino, Turin, Italy

5 Department of Civil, Construction-Architectural and Environmental Engineering, University of L'Aquila, L'Aquila, Italy the acquisition of images and other information on demand over an area of interest. The possible field of activity of these systems has progressively expanded and now ranges from archaeological applications (Rinaudo et al. 2012; Nex and Remondino 2014; Nikolakopoulos et al. 2017b), to smart farming (Zhang and Kovacs 2012), to the management of natural hazards (Gomez and Purdie 2016; Giordan et al. 2018). It is possible to find different names or acronyms to describe the same object: an aerial drone. RPAS (remote pilot

6 British Geological Survey, Environmental Science Centre, Nicker Hill, Keyworth, Nottingham, UK

Department of Geoinformatics and Cartography, Faculty of Earth Sciences and Environmental Management, University of Wrocław, Wrocław, Poland

8 Department of Environment, Earth and Physical Sciences and Centre of GeoTechnologies, University of Siena, San Giovanni Valdarno, Italy

9 Struttura assetto idrogeologico bacini montani, Quart, Regione Autonoma Valle d'Aosta, Italy

10 Fondazione Montagna Sicura, Courmayeur, Italy 
aircraft system), UAV (unmanned aerial vehicle), and UAS (unmanned aerial system) are the most common acronyms, but we have also to consider all national definition, where the name is translated in the national language. In this paper, we decided to use "UAV" to identify an unmanned aerial system, which is able to have an autonomous flight with or without an engine, to be remotely controlled, and to be able to collect some data. Usually, these systems are employed with imaging sensors but not only. Nowadays, UAV and drone are familiar words, and the commercial and smaller version can be found on the shelf, in all electronic shops or in a normal mall with a very low prices. Considering the low price and the very friendly use of the system, these systems are now considered suitable for an incredible number of potential application fields even where the users are not particularly skilled in aeronautics system such as geomatics, geology, cultural heritage, archaeology, survey, mining, environmental applications, and astronomy. In next sections, we will provide a more detailed description of the main characteristics of UAV, their main components, and the possibility to carry on a payload that can be constituted by a system able to acquire a specific dataset-like images, 3D point clouds, or other physical parameters like radiations or air quality. The paper is organized in the first part focused on the description of UAV, their main characteristics, and several best practice suggestion for a correct use, and a second part with a sequence of scenarios where the use of UAV can be considered very useful for engineering geology applications.

\section{Recent UAV developments}

The first exemplar of modern UAV, in term of the aerial vehicle with the capability to have an autonomous flight even with long range and a wireless link to the ground station, has been developed in 1944, during the Second World War and it was the V-1 system. Traditionally, UAV systems were used for military goals and applications and only recently became system used for civilian use. Even though UAV systems were developed for military purposes (and this is still now a key topic), the availability of low-cost sensors and platforms has laid the foundations for an increasing interest also in the civil field (Juul 2015; NASA 2015). In geomatics, Przybilla and Wester-Ebbinghaus (1979) carried out the first application. Even if UAVs were not initially designed and realized for geomatics or other applications, commercial solutions have been progressively adapted to fulfill different geomatics fields of applications and operative requests (Piras et al. 2017a, b; Chiabrando et al. 2013; Aicardi et al. 2016a, b). Thanks to new technologies, innovative solutions and sensors have been recently developed even for civilian application, allowing to improve the flexibility (less restriction in term of sensor's installation), performance (more duration, better aerodynamics profile, better navigation system), and planning tool (new tools have been developed for planning and control the UAV operations).

For civilian purposes, the most significant recent improvements are the development of low-cost flight controller systems (Chao et al. 2010), and the great diffusion of structure from motion (SfM) applications that allows the creation of a 3D model from a sequence of images captured from different points of view (Westoby et al. 2012).

These two recent signs of progress have pushed the great current diffusion of cheap systems that has exponentially increased the number of people that are using UAV also for professional purposes. Unfortunately, most of them do not have a proper background for their correct use. In particular, the acquisition of a photo sequence required by structure from motion applications seems to be a simple operation, but if the high accuracy (both in terms of geographic positioning and resolution) of the final model is required, the use of these systems cannot be managed as a black box without respecting few essential rules. On the other hand, one of the actual limitations is that these "friendly" systems give the impression that could be used without any specific competences creating a real risk of having poor results and working in un-safety conditions.

\section{UAVs classification}

It is quite challenging to define a summary table about the UAV classification because each modern UAV is full of technology, and it is complicated to compare different systems between themselves. A possible tentative, considering some general factors as the duration of the flight, range, and payload, is shown in Table 1.

Over the short-range category, there are other larger UAV systems, but they are rarely employed for civilian applications, and for this reason, they are not mentioned in Table 1.

Another possible classification could be made considering the weight with respect to the air propulsion system (with or without engines or propellers). Considering this approach, it is possible to distinguish several kinds of systems. Balloons, kites, and paraglides are systems without their own propulsion. On the opposite side, multirotors, fixed wings, airship, and helicopters are the UAV based on electric or combustion engine. In Table 2, the main characteristics of these categories are summarized and compared.

According to recent development of UAV for civilian purposes, the most widespread applications for UAV are generally the following: (i) photogrammetry and remote sensing (Colomina and Molina 2014) to extract information from images and produce 3D data; (ii) 3D modeling (Wefelscheid et al. 2011) to reconstruct the 3D shape of buildings or areas; (iii) surveillance (Semsch et al. 2009), both in civil and military fields; (iv) inspection (Zhang et al. 2012), especially when human interventions can be dangerous; (v) disaster response 
Table 1 UAV classification (UAS Yearbook 2011)

\begin{tabular}{llllll}
\hline Category & & Range $(\mathrm{km})$ & Flight height $(\mathrm{m})$ & Duration $(\mathrm{h})$ & MTOW $(\mathrm{kg})$ \\
\hline Nano & $\eta$ & $<1$ & $<100$ & $<1$ & $<0.025$ \\
Micro & $\mu$ & $<10$ & 250 & 1 & $<5$ \\
Mini & Mini & $<10$ & $150-300$ & $<2$ & 150 \\
Close range & $\mathrm{CR}$ & $10-30$ & 3000 & $2-4$ & 150 \\
Short range & SR & $30-70$ & 3000 & $3-6$ & 200 \\
\hline
\end{tabular}

and monitoring (Boccardo et al. 2015), to map the situation after catastrophic events or before an expected one and to provide new updated information. In this case, UAVs can be easily and quickly used; (vi) forest and agriculture and geological investigations (with thermal and multispectral sensors (Saari et al. 2011) are emerging fields that UAV can provide high-resolution and repetitive data fundamental for monitoring purposes. Another possible classification has been proposed by the NASA (2015) that divides the UAV missions into four different groups:

- Land management missions: these are performed to obtain geospatial information on specific areas for monitoring or management purposes. They can be particularly suitable in dangerous areas (for example, after disasters and emergencies) and their civil applications may include fields such as the following: agricultural forestry, firefighting, geological investigations, communication networks, surveying, and mapping. This kind of use is particularly suitable to have prior knowledge of some areas before building and construction projects and to provide updated digital terrain models (DTMs) and orthophoto data.

- Commercial: these type of missions are mostly related to precision agriculture since in this specific case, the use of UAVs can save time and cost to acquire a large amount of data. In particular, the capability to house thermal and near-infrared sensors onboard suggests that unmanned system will significantly modify the general perspective in the agriculture field. On the other hand, they can be flexible and repeatable tools to acquire environmental parameters about air pollution and quality;

- Earth science missions: the goal of these missions is to monitor some areas of the earth, measuring the geophysical processes associated with natural hazards on a larger scale than the land management one. The general idea is that these missions would replace the satellite observations in the future (for example, for earthquakes, landslide, and volcanoes);

- Homeland security: these missions concern the monitoring of restricted areas for security or surveillance operations and they are included under the category of "NonMilitary Governmental."

Traditionally, in the more significant part of the activities done in the environmental field, the most used systems are fixed wings and multirotor thanks to their flight duration and operability. Unfortunately, there is not a unique system for all kind of practical problems and, in each case, it is fundamental a careful preventive evaluation of the mission characteristics aimed to define the best solution and sensors that should be installed on. Furthermore, in almost operations, it is fundamental to pay attention to the planning of data acquisition that represents a fundamental aspect to be considered in the definition of the survey. It is important to point out that when we consider a UAV, we have to know that the complete system is composed not only by the aerial vehicle but also by the ground control station (GCS). The GCS is very important and mandatory, in order to work in safe condition, and to verify in realtime the operative state of the UAV during the flight (e.g., telemetry, temperature of the battery, power, temperature of the propellers). One of most important actions that should be done before the flight is to verify the quality and the stability of the data link and the communication system, because it is fundamental to have always a good connection between UAV, pilot, and GCS.

Even if almost recent UAVs are able to fly autonomously following a predefined mission plan, it is fundamental to remember that there is always the possibility that some element
Table 2 UAV comparison (1, low-5, high)

\begin{tabular}{lllll}
\hline UAV & Range & Duration & Wind influence & Operability \\
\hline Balloon & 1 & 4 & 4 & 2 \\
Airship & 3 & 3 & 4 & 3 \\
Kite & 2 & 2 & 4 & 2 \\
Fixed wings & 5 & 5 & 2 & 4 \\
Helicopter (mini) & 4 & 4 & 3 & 5 \\
Multirotor (with 4-8 propellers) & 4 & 3 & 2 & 5
\end{tabular}


in the mission planner cannot work correctly. In this possible critical situation, the pilot has to take direct control of the UAV and land it in safety conditions. For this reason, the skill of the pilot is a fundamental element for the correct management of UAV operations.

\section{UAV main components analysis and comparison}

As mentioned before, the most used UAV for non-military applications are mini- and micro-UAV (payload $<30 \mathrm{~kg}$ ). Fixed wings and multirotors are the preferred solutions for their ease of use, low cost, transportability, and the capability of performing surveys in different areas. On the other hand, their small size requires specifically designed sensors that have to be both reliable and lightweight enough to respect the limits of the payload.

This section aims to provide the reader an overview of the essential components of conventional UAV. A more detailed analysis of possible payloads is presented in the "UAV payload sensors" section.

\section{Principal UAV components}

Aerial vehicles are complex systems made by hardware and software structures. The improvement of electronics allowed the development of navigation and control systems more and more available on the market.

The main components of a UAV can be divided into three main categories: (i) the aerial platform, which includes the airframe, the navigation system, the power system, and the payload; (ii) the ground control station (GCS), which allows the human control from a remote emplacement; and (iii) the communication system, which supports the communication between the other two components.

The aerial platform is composed of different components whose purpose is to allow the flight and carry some sensors in the air for the data acquisition:

The airframe is the main structure of the UAV. Its structure has to consider the weight regarding, in particular the power and the communication and control systems onboard. Moreover, the airframe needs to be adequately designed to withstand the forces that can occur during the flight and not cause deformation and vibration. As presented in Fig. 1, fixed wings are mainly made of polystyrene or plastic; common multirotors airframes are made of aluminum or carbon fiber (in such a way as to be lightweight and resistant), and the number of arms is a function of the expected payload and the number of engines.

The navigation system is the main component of the avionics is the autopilot that allows autonomous or semiautonomous flights through hardware and software components. The specification of the autopilot for a UAV can be summarized as reported in Table 3. The navigation system is composed of flight control, GPS/GNSS, and inertial system.

The flight control is the "core" of the navigation system. This board manages the flight planning and can verify in realtime the theoretical trajectory with respect the real one. It is possible to connect on this board several sensors, to synchronize the data acquisition using the GPS time. In some case, a small digital memory car is housing, with a purpose to collect and store several information as a trajectory (log file), telemetry, and images or another kind of data.

The GPS/GNSS board is another fundamental element of modern UAVs. Usually, a single-frequency and dualconstellation (GPS and GLONASS) system is installed onboard. In some configurations, even a dual-frequency multiconstellations receiver could be available. Traditionally, the receiver is only used to define the UAV position in stand-alone (st. dev. $=3-5 \mathrm{~m}$ ), potentially with EGNOS or WAAS solution (st. dev. $=1-3 \mathrm{~m}$ ). Raw data (pseudo-range and carrier phase) are not usually saved, but in some recent commercial systems, it is possible to do it, to realize a PPK (post-processing kinematic) positioning. Even RTK (real-time kinematic) positioning is allowed in some new commercial systems;

The inertial system is commonly the last component of the navigations system. Nowadays, a MEMS (micro-electro-mechanical systems) inertial measurement unit (IMU) is installed on board, with the purpose to control the UAV's attitude. Usually, IMU is not able to collect the raw data, even in the most recent ones. The range of the precision in the estimation of the angle of common IMU used for mini or micro-UAV is around $1-4^{\circ}$.

The power system is another fundamental element of UAV aimed to provide energy to the system. According to the selected airframe, different power systems can be adopted: Wankel rotary engines, fuel cells, and electric solutions are the most common. With multirotor systems, the most adopted solution is lithium polymer (LiPo) batteries.

The payload is composed of sensors or instruments carried by the UAV and used to acquire some specific data or
Fig. 1 Different airframes. From the left: polystyrene, plastic, aluminum, carbon fiber
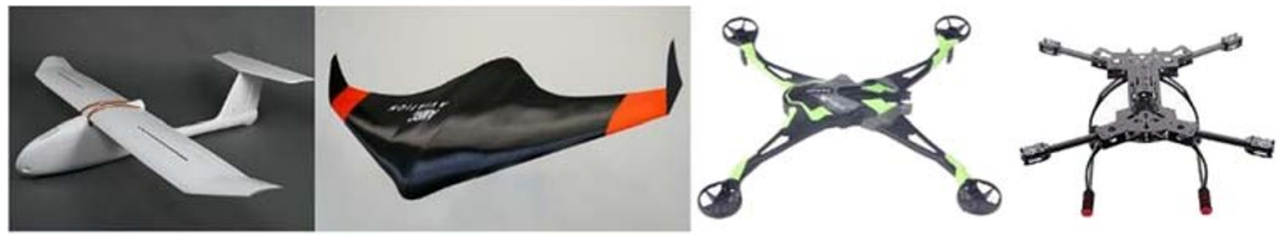
Table 3 Autopilot main specifications

\begin{tabular}{lll}
\hline $\begin{array}{l}\text { Physical } \\
\text { specifications }\end{array}$ & Sensor specifications & Autopilot functions \\
\hline Size & Operative temperature & Waypoints navigation \\
Weight & Max angular rate & Auto takeoff and landing \\
Power consumption & Max acceleration & Altitude hold \\
Required voltage & Max angular velocity & Servo control rate \\
Required CPU & Max altitude & Telemetry rate \\
Memory & Operative airspeed & Fail-safe \\
\hline
\end{tabular}

parameter (e.g., RGB/multispectral camera, video-camera, thermal or other kinds of sensors).

The other components of payload could be instruments needed for the onboard equipment and the device activation. Especially in the case of cameras, a fundamental component is a gimbal, a support that allows the rotation of the payload along one or more axes often equipped with servos that can adjust or stabilize the orientation of the sensor. According to the sensor, the gimbal can be fixed, stabilized, and controllable from the ground.

The ground control station (GCS) ensures a permanent and interactive remote control of the UAV informing the pilot about the progress of the autonomous flight. A computer or a tablet able to plan the flight and control its execution usually is the base configuration for a GCS. The pilot should be equipped with a remote control that can be used in emergency cases or to perform the takeoff and landing if the UAV is not entirely autonomous. One or more people are responsible for the management and control of UAV parameters during the flight. The major parts of commercial UAVs have their dedicated mission planner or it is possible to use open-source software developed by the scientific community. Mission planners are applications where it is possible to define a sequence of navigation waypoints or to set a photogrammetric flight defining the area of interest, the camera parameters, and other photogrammetric parameters (e.g., side and frontal overlap, ground sampling distance).

The last UAV component is the communication system that is the radio connection between the ground and the vehicle. To command and control a UAV, radio communication is mandatory also to assure a continuous link for emergency operations. Radio frequencies (RF) in the range of $30 \mathrm{MHz}$ to $3 \mathrm{GHz}$ are generally the RF bandwidth in which small multirotors operate.

\section{UAV navigational sensors}

Navigation systems have become widespread in recent years and adopted on vehicles, smartphones, and other numerous operative solutions. In most cases, these systems use not only one or more GNSS receivers but also an IMU that is necessary to provide the vehicle setup information for each epoch and to assist the GNSS system in estimating the position of the vehicle. The use of these sensors for UAV, however, requires the resolution of a series of problems linked for example to their synchronization and calibration. Typically, these problems can be solved by developing appropriate hardware and software tools, able to analyze and compensate systematic errors (bias) and sensor drift(s). The ultimate goal of this suite is a navigational solution sufficiently accurate about the type of final application of the system. The accuracy of the UAV position is not only an important element for the management of the flight but also a crucial point for the possible application of direct photogrammetry (Chiabrando et al. 2013).

Different operative solutions can be available on UAV, mainly based on these possible configurations: (i) single/ multi-frequency GPS/GNSS receivers; in this case there is often the possibility to improve the solution with the usage of the L2 frequency; (ii) single/multi-constellation antennas and GPS/GNSS receivers: the availability of more than one constellation can improve the final positioning solution; (iii) GPS/GNSS RTK (real-time kinematic) approach which allows the possibility of improving the position accuracy estimated in real-time with the correction from a master or a permanent station; (iv) integrated GNSS and IMU sensors; in this configuration, the GNSS position can be improved using the data from the inertial platform.

The market offers many low-cost GPS or GNSS receivers, often available as an OEM card. In other cases, some developer kits are available, as the u-blox receivers. u-blox can be considered an example of low-cost GNSS receiver capable of receiving four single-frequency GNSS constellations. Due to its limited cost, it can be considered an interesting solution with minimum overall dimensions and an easy interface. The presence of the communication port requires only preparing a data storage on micro PC and SD card (or similar) and the transfer of raw data to a processing center. Among the "medium-high" level receivers, some multi-frequency and multi-constellation OEM cards could be mentioned. These cards should be engineered and could constitute a low-cost solution but with centimeter precision suitable also for real-time. These receivers are usually set up for RTK acquisitions, and they may have options that are not always included in normal receivers such as 1PPS (pulse per second), to issue the recording command from the receiver to an external instrument, and "Event Marker" to record an external event (for example, the measurement time of another sensor) in the GNSS time scale.

The IMU consists of a set of sensors, generally accelerometers and gyroscopes, necessary to allow the estimation of all the navigation states at a high frequency. Since these are electro-mechanical sensors, the measurements carried out could often be affected by systematic errors like measurement bias, scaling factors or non-orthogonality of the sensor triplets, and accidental errors generally due to noise. 
IMU can be used for the following: (i) The estimation of the position often integrated with GNSS receivers. In this case, they can determine the displacement with a double integration while the orientation takes place with three gyroscopes on the three coordinate axes. (ii) The estimation of the attitude angles, by measuring the components on the three axes. Measurements can be static or dynamic.

GNSS and IMU can be integrated into the navigation board of UAV or mounted as external sensors and connected to the navigation board.

\section{UAV navigation sensors evaluation tests}

In order to understand the behavior of common UAV, the investigation of the main components of the navigation system is a crucial aspect. In particular, the performance of navigator sensors (IMU and GNSS) has a great impact on the final performance of the system. To define the system precision considering different possible configurations for better management of the missions, several tests of navigation sensors (onboard and external) have been carried on. The employed system was a hexacopter that weighs about $2.2 \mathrm{~kg}$ including batteries, and that can lift a payload of up to $1.5 \mathrm{~kg}$.

The test of navigation sensors is based on reference data extracted from topographic measurements done using a total station (TS). Two different solutions, mainly based on the same kind of approach, are proposed: (i) positioning sensor's evaluation, aimed to define the performance of GNSS sensors, is based on the use of a single prism and a total station; (ii) angle's estimation, designed to the evaluation of IMU performance, is based on the use of two prisms and two total stations.

The first test is focused on positioning systems. For this test, a retro-reflector target composed by three small prisms was housed on board on the UAV under the gimbal. The retroreflector target assures a continuous auto-tracking of the total motorized station that can follow the UAV flight paths and autonomously measure both distance and angles with accuracies of $2 \mathrm{~mm}$ and $1 \mathrm{~s}$ within an operative range of $1 \mathrm{~km}$. The UAV is equipped with an onboard GPS and an external GNSS receiver that acquire simultaneously the position of the drone. The tested external GNSS receiver was a Novatel OEM 615 dual-frequency $(\mathrm{L} 1=1575.42 \mathrm{MHz}$ and L2 $=1227.60 \mathrm{MHz}$ ) equipped with the antenna ANTCOM ID L1L2 1215 A2, which can receive GPS, GLONASS, and Galileo constellations. The drone was manually piloted in a dedicated airfield where cross flights of $200 \mathrm{~m}$ were performed flying at a speed of $3 \mathrm{~m} / \mathrm{s}$.

After the synchronization, to have comparable sets of data, the track extracted from the onboard and external positioning sensor can be compared with that one obtained from the data of the total station, considered as reference. The difference between the two sets of data is used to evaluate the reliability of positioning systems considering the accuracy of the proposed methodology based on total station measurements and the differences between the two sets of data.

Tables 4 and 5 show the result of the analysis of internal and external GNSS accuracy, in terms of minimum, maximum and mean values with the evaluation of the standard deviation $(\sigma)$ which measures the dispersion of the data. For the internal GPS, Table 4 shows the comparison between the acquired track of GPS and of the total station. In particular, the south-north-south path was used to evaluate the accuracy in the $X$ direction and the east-west-east path for the $Y$ direction (Table 4). The same approach was used to analyze the vertical component.

Presented results demonstrate that the performance of the internal GPS receiver is consistent with a low-cost single-frequency GPS receiver in stand-alone positioning using EGNOS correction, with an accuracy of few meters, with the vertical component four times worse than the horizontal one (Bulusu et al. 2000). Furthermore, the analysis of the standard deviation shows that the acquired data are very noisy and the sensor is not, therefore, reliable. For the significant part of the geomatic applications (photogrammetry, thermal analyses, radio-frequency measurements, etc.), centimetric positioning is required. For this reason, the introduction of an external GNSS receiver on the UAV was investigated to evaluate the eventual positive effect in positioning accuracy. The storage of the GNSS receiver raw data has been realized by making a direct connection between the GNSS OEM and a dedicated Ardulog data logger. The GNSS raw data (pseudo-range and carrier phase), were recorded in a text file using a sample rate of 5 . For a protection of the system during the flights, a special box was realized with the $3 \mathrm{D}$ printer and housed below the airframe in the gimbal. The box also houses the battery for the GNSS receiver, and two switches allow to activate the receiver and the antenna. The entire system is shielded, and a LED light is mounted outside the box to signalize when the ambiguity phase is fixed as it is fundamental that the system is initialized before beginning the flight. The external antenna was mounted on a dedicated support designed to protect the system also against interferences, and the entire system was calibrated to know the lever arm.

The data recorded by the external receiver were processed with a PPK (Post Processed Kinematic) approach (Gao and Wojciechowski 2004; Stempfhuber and Buchholz 2011) to define the UAV positions respect to a master station on the ground. The accuracy and completeness of the positioning solution through the GNSS external receiver has been assessed using the total station as a reference. The UAV position was tracked two times along a rectangular path to evaluate the position accuracy, and then, the positions estimated from the external GNSS receiver during the same flight were processed with a PPK technique considering the master station on the ground and the receiver onboard as a moving point.

Obtained results (Table 5) demonstrate that estimated GNSS positions follow the total station trajectory and have 
Table 4 Internal GPS accuracy evaluation compared with robotized total station results

\begin{tabular}{lllll}
\hline Component & Min value $(\mathrm{m})$ & Max value $(\mathrm{m})$ & Mean value $(\mathrm{m})$ & Std \\
\hline Horizontal component & -3.310 & 5.340 & 0.414 & 0.875 \\
Vertical component & -15.342 & 19.332 & 1.66 & 2.175 \\
\hline
\end{tabular}

an accuracy of few centimeters. This is an acceptable value according to the nominal precision of the PPK positioning.

The presented test shows the good performance of the external GNSS receiver. A more detailed analysis of obtained results pointed out that higher differences between GNSS results a TS measures are referred to the first part of the test (especially for the vertical component). The cause of these is the GNSS initialization phase, the time necessary to fix the phase ambiguity. To avoid this inconvenient, some recommendations can be proposed: (i) the receiver should be turned on about 2-3 min before starting the flight and it has to stay on the initial flight point; (ii) after takeoff, UAV must stay on air on the first waypoint for a few seconds; (iii) then, the flight can be performed with a maximum speed of about $5-7 \mathrm{~m} / \mathrm{s}$; (iv) finally it is important to wait $2-3 \mathrm{~min}$ on the ground after landing before turning off the receiver. This strategy allows having centimetric accuracies for the entire mission.

Another aspect that has been investigated is the reachable precision of the external receiver using different GNSS constellations (Pupillo et al. 2015) and, in particular, considering only GPS and GPS-GLONASS. Results (Table 6) demonstrated that the usage of the GLONASS constellation has a strong influence on the final solution. Without the GLONASS, the estimated precision is about $40 \mathrm{~cm}$. On the contrary, the use of both constellations can improve the precision to $1-3 \mathrm{~cm}$. Multi-constellation antennas are more and more available, and their dimension and weight are compatible with UAV. Since their cost is now quite acceptable, and the procedure to use their data to obtain precise position is well established, in precise positioning surveys, the use of multi-constellation antennas is recommended.

The second presented test is aimed to evaluate the performance of IMU. Using the same approach of the previous test, the onboard sensors data, and a reference solution acquired from the ground were obtained and compared. In this test, the adopted strategy involved the use of two total stations and two retro-reflector targets mounted on the UAV. The retro-reflector target consists of the combination of three smaller prisms. A bar with two retro-reflector targets was installed onboard to guarantee the acquisition of the UAV position and attitude. To track the flights, two total stations (Leica Image and Smart
Station) were used in the position tracking mode. One of the used instruments can also be synchronized with the GPS time by using an external receiver that can be placed on the instrument and update the total station time according to the GPS. Finally, the same sampling rate of $0.2 \mathrm{~s}$ was used for the two instruments. During the flights, each total station can follow one prism because of the track mode of the instrument, and it is then possible to relate the two measurements. Using the same approach used for GNSS, the test of IMU considered internal and external solutions. The adopted external IMU was a low-cost Microstrain sensor, the 3DM-GX3-35 model.

The UAV attitude during the flight and the reliability of the recorded data from the internal sensors were evaluated by taking particular attention to the compass component. This is important to assess whether it is necessary to install an external IMU to have a precise compass component. For the internal IMU, different flights (especially linear and cross) were performed to test the recorded attitude of the UAV. During the linear path, the UAV flew along the direction between the two total stations (with an angle of about $35^{\circ}$ respect to the North) instead during the cross path the chosen direction was $0^{\circ}$.

The flights were scheduled using a special application developed in MATLAB able to generate a text file that contains the waypoints positions that can be managed by the navigation software.

The test is based on the estimation of the UAV compass as an angle between the two measured prisms and its comparison with the data recorded from the UAV. The different sampling rates of the two total stations and their synchronization need to be considered during the processing step. Each total station has an internal clock, but the two times are not the same, and the acquisition interval was not the same. For this reason, a specific MATLAB script was developed to process these data. The developed code is partitioned in three main steps:

1. angles estimation from the data of the two total stations:

a. total stations need to be previously mutually synchronized (also according to the GPS time);

b. the coordinates of each point recorded by the TSs have to be extracted;
Table 5 Evaluation of the positioning results of the external GNSS receiver

\begin{tabular}{lllll}
\hline Component & Min value $(\mathrm{m})$ & Max value $(\mathrm{m})$ & Mean value $(\mathrm{m})$ & $\sigma$ \\
\hline Horizontal component & -0.124 & 0.130 & 0.010 & 0.002 \\
Vertical component & -0.182 & 0.213 & 0.032 & 0.008 \\
\hline
\end{tabular}


Table 6 Standard deviations of different GNSS solutions related to satellite constellations

\begin{tabular}{|c|c|c|c|c|c|c|c|c|c|c|}
\hline \multirow{2}{*}{$\begin{array}{l}\text { GPS } \\
\text { No. }\end{array}$} & \multirow{2}{*}{$\begin{array}{l}\text { GLONASS } \\
\text { No. }\end{array}$} & \multicolumn{3}{|l|}{$\sigma_{\mathrm{X}}(\mathrm{m})$} & \multicolumn{3}{|l|}{$\sigma_{\mathrm{Y}}(\mathrm{m})$} & \multicolumn{3}{|l|}{$\sigma_{\mathrm{Z}}(\mathrm{m})$} \\
\hline & & Min & Max & Mean & Min & Max & Mean & Min & Max & Mean \\
\hline 8 & 0 & 0.006 & 0.520 & 0.180 & 0.005 & 0.430 & 0.130 & 0.015 & 1.420 & 0.420 \\
\hline 10 & 11 & 0.014 & 0.036 & 0.016 & 0.015 & 0.025 & 0.017 & 0.016 & 0.041 & 0.031 \\
\hline
\end{tabular}

c. the angles between two corresponding points can be estimated;

2. angles extraction from the data recorded by the internal IMU platform (that is already synchronized with the GPS time);

3. comparison between the angles determined with the TSs data and that recorded by the internal UAV platform.

Here it is reported an example of the performed tests, a cross path.

The first required step was the total stations synchronization and interpolation. The data acquired by the two TSs differ in:

- absolute time;

- $\quad$ interval step between two consecutive measurements

In an ideal case, the instruments synchronization should be the following: $N_{1}(t)+b_{\mathrm{N}}=N_{2}(t)$ where $b_{\mathrm{N}}$ is the bar length in the North direction between the two prisms; however in the real case, measurements estimation uncertainties are introduced: $N_{1}(t+\Delta t)+b_{\mathrm{N}}+\Delta b_{\mathrm{N}}=N_{2}(t)$

To align the data, one TS was considered the reference, and the data from the other one were translated and interpolated to have the measurements at the same time and interval steps. Starting from an approximate offset time, an iterative procedure was used to obtain the best fit between the two sets of data. A linear interpolation was used at this step to have the same number of measurements.

When the two set of data were finally synchronized, it was possible to estimate the compass as the angle between two measured targets (each one acquired from a TS). The calculated result is shown in Fig. 2 (red component).

Data acquired by the internal sensors of the UAV are stored in the microSD in a log file. A script (gpx reader) able to read these data was written in MATLAB, and it includes positioning (from the internal GPS) and attitude information (from the internal IMU). The same synchronization procedure was applied to overlap the UAV data recorded from the internal sensors with that acquired by the TS. The TS was adopted as a reference, and the UAV data were temporally translated and interpolated to have the same sampling rate. The compass component of the UAV can now be overlapped (Fig. 2) and compared with the TS measurements. To better understand the behavior, the difference between the two data was evaluated (magenta in Fig. 2), and some statistical values were also estimated:

$-\quad$ mean $=-0.022^{\circ}$
$-\quad$ standard deviation $= \pm 0.910^{\circ}$
- $\quad$ median $=-0.073^{\circ}$

The obtained results have a mean value very close to the zero with a small standard deviation, and they demonstrated that, using this UAV, the angles could be estimated with precisions acceptable for our investigations.

The use of an external IMU was also evaluated to assess if it is possible and useful to improve accelerometers, magnetometers, and gyroscopes data to enhance positioning and attitude information housing on board an external IMU platform. We made some analyses using the low-cost sensor of Microstrain, the 3DM-GX3-35 model (Table 7) because of its low weight and size.

This sensor has an internal GNSS receiver (u-blox) that allows a row metrical position and performs the synchronization of the data including accelerometers, gyroscopes, and magnetometers that can be independently acquired by the instrument, but it is not able to retrieve an integrated solution based on the loosely coupled Kalman filter (Kalman 1960). The sensor was previously analyzed by the Geomatic's group of the Politecnico di Torino (Piras and Dabove 2016) to assess its behavior.

For our implementation on the UAV, the IMU sensor was directly connected to a mini PC installable onboard, in particular, a PicoPc (Pico83016) with Windows operating system and with the possibility to directly install the management software of the Microstrain. The whole system was installed onboard, the IMU was housed directly on the gimbal, and the antenna has been locked on the top of the UAV. To evaluate the platform were performed two different tests with the UAV with the engines off and placed on the table and during a flight.

Figure 3 shows the comparison of the data obtained in the two evaluated cases.

During the flight test, the information acquired before the flight (before the red line) when the UAV engines were turned on is easily recognizable. For all the graphs, the same axis 
Fig. 2 Cross flight estimated angles: measured with TS (red) and internal sensor (blue). The angles differences are in magenta

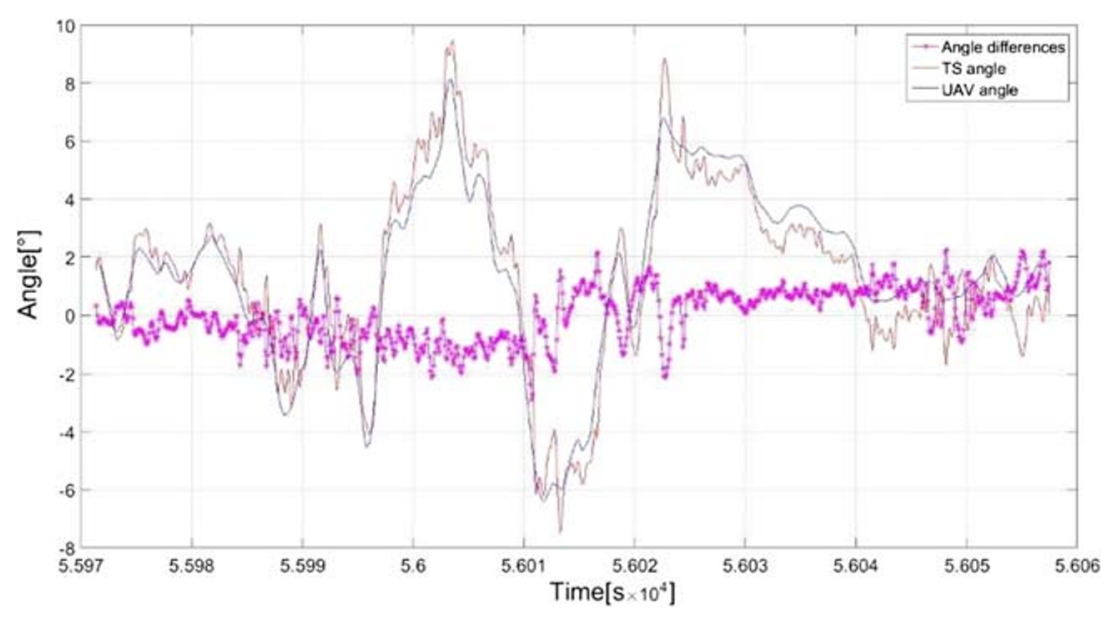

scale is used to read the data easily and different colors represent different directions $(x, y, z)$. The recorded data in the three directions shows a significant noise for all the IMU components. The sensor betrays the UAV vibrations due to flight movement, and the magnetic component can have large interferences from the operation of the engine. A further test was done trying to filter out this noise. In particular, through the MATLAB Wavelet Analyzer, the signal was filtered with the Daubechies 3 level 7. In the case of the two sets of data (on the table and during the flight), the accelerometers, gyroscopes and magnetometers signals were filtered, but after the filter, it has remained a clear difference between the signal acquired in static and that recorded in dynamic.

According to these tests, we can conclude that a detailed knowledge of the onboard available navigational sensors is crucial to understand UAVs behavior and to test their performance. This need has been investigated with the development of a specific methodology to evaluate GNSS and IMU platforms, and particular flights were adopted to analyze the performance of the sensors in comparison with well-established topographic techniques. The analysis strategy employed for the onboard navigation sensors (GNSS receiver and IMU) allowed to assess the metrical position achievable through the low-cost devices installed on board. On the other hand, it was demonstrated that, if a real-time knowledge of the precise

Table 7 Microstrain 3DM-GX3-35 main specifications

\begin{tabular}{llll}
\hline & Accels & Gyros & Mags \\
\hline Measurement range & $\pm 5 \mathrm{~g}$ & $\pm 300^{\circ} / \mathrm{s}$ & \pm 2.5 Gauss \\
Non-linearity & $\pm 0.1 \% \mathrm{fs}$ & $\pm 0.03 \% \mathrm{fs}$ & $\pm 0.4 \% \mathrm{fs}$ \\
In-run bias stability & $\pm 0.04 \mathrm{mg}$ & $18^{\circ} / \mathrm{h}$ & ---- \\
Initial bias error & $\pm 0.002 \mathrm{~g}$ & $\pm 0.25^{\circ} / \mathrm{s}$ & \pm 0.003 Gauss \\
Scale factor stability & $\pm 0.05 \%$ & $\pm 0.05 \%$ & $\pm 0.1 \%$ \\
Noise density & $80 \mu \mathrm{g} / \sqrt{\mathrm{Hz}}$ & $0.03^{\circ} / \mathrm{s} / \sqrt{\mathrm{Hz}}$ & $100 \mu \mathrm{Gauss} / \sqrt{\mathrm{Hz}}$ \\
In-run bias stability & $\pm 0.05^{\circ}$ & $\pm 0.05^{\circ}$ & $\pm 0.05^{\circ}$ \\
Sampling rate & $30 \mathrm{kHz}$ & $30 \mathrm{kHz}$ & $7.5 \mathrm{kHz} \max$ \\
\hline
\end{tabular}

position of the UAV during the flight is not required, it is possible to use an external GNSS receiver. The processing of the acquired data was also analyzed to obtain precise knowledge of the system position along with the flight. Considering these strategies, it is possible to reconstruct the UAV position with a centimeter-level of detail, which is the required level for precise geomatics analyses and direct photogrammetry scenarios.

The use of an external IMU platform was also investigated, but the used sensors suffered too much from vibrations and interference, and it was not possible to assess improvement in the definition of the angle since it must be very well shielded and protected from vibrations to work well. This means introducing other weights, but the limited payload carried by UAV usually hampers this possibility.

\section{UAV payload sensors}

The use of mounted sensors exploits UAV potential. Their payload is, in fact, the core of the system that allows their user to collect various kinds of data for further processing and analyses (Pajares 2015). In addition to sensors, there is also accessory equipment allowing the correct positioning of the acquired datasets in three-dimensional spatial coordinates (De Agostino et al. 2010). These features are mandatory when UAV data are used in conjunction with other geocoded data, and when the investigated topics deal with earth science issues (Schulz 2007).

Focusing the attention on UAV's payload, various acquisition systems, and related supporting equipment like gimbals, can be mounted on board. These sensors can mainly include the following categories: (i) digital cameras, (ii) thermal detectors, (iii) multispectral cameras, (iv) LiDAR (light detection and ranging), (v) sensors for the air quality evaluation. In engineering geology applications, the first four categories are the most used, and for this reason, they are presented and discussed in this section. The acquired payload dataset can 

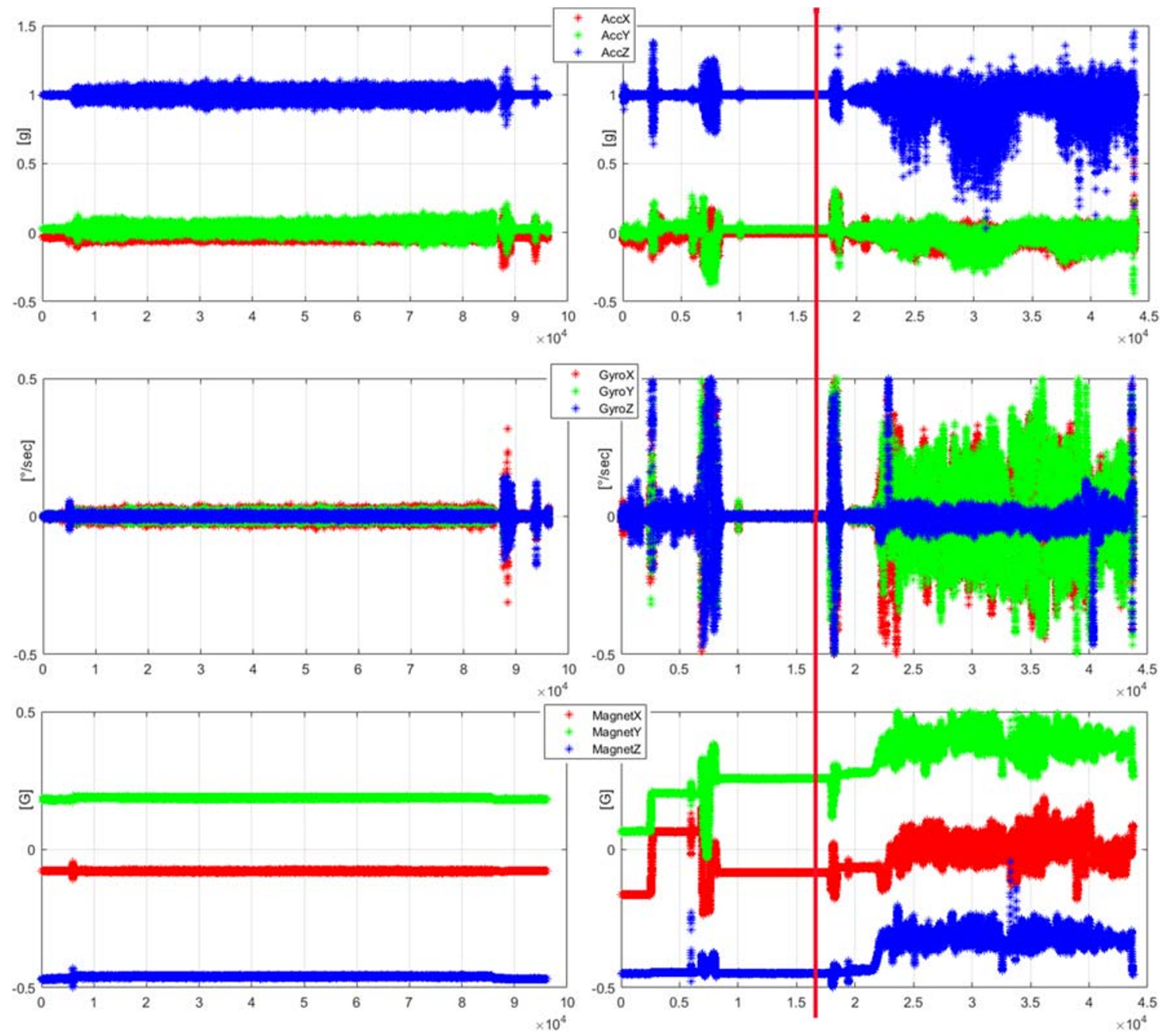

Fig 3 Microstrain 3DM-GX3-35 accelerometers, gyroscopes and magnetometers behavior on the table (left) and during the flight (right); in the right plot, the vertical red line is the propellers switch on

be merged with IMU and GNSS receivers installed on the UAV to measure its position and attitude, in real-time and post-processing, along with the flight for navigation and data processing purposes (Cramer 2001).

\section{Digital cameras}

The most common use for UAV is acquisition of images and videos for monitoring (Gonzalez et al. 2016), photogrammetry (Eisenbeiß 2009), filming, security (Mademlis et al. 2018), and any kind of documentation (Nageli et al. 2017), also for geological applications (Bemis et al. 2014; Giordan et al. 2018). Different categories of cameras are now available for this kind of applications: professional, semi-professional, and action cams. For each category, the lens calibration is required to ensure the quality of the final result (Casella et al. 2004; Clarke and Fryer 1998; Hemayed 2003).

One of the most critical points in the use of RGB cameras is the identification and measurement of the shooting position to perform the image orientation (Remondino et al. 2012). Nowadays, many commercial navigation systems can manage the acquisition of image and store UAV's position (GNSS) and attitude (IMU) simultaneously (Zongjian 2008; Carbonneau and Dietrich 2017). In the post-processing phase, the GNSS position can be stored in the EXIF file of the acquired image or coupled in dedicated software. Concerning the image processing phase, the most employed technique is the "structure from motion" (SfM) (Braunstein 1990; Clapuyt et al. 2016) which allows the three-dimensional reconstruction of the surveyed object for further processing and analyses. This approach has been satisfactorily applied in geosciences and engineering geology as well (Westoby et al. 2012; Lucieer et al. 2014; Mancini et al. 2013; Ryan et al. 2015).

\section{Thermal detectors}

Thermal detectors are a class of sensors capable of remotely measuring the object's temperature. They provide, as a result, 
an image with temperature values stored in raster's digital numbers (Cetas 1978). The process, defined as thermography, is based on the acquisition of the thermal infrared radiation of the electromagnetic spectrum $(1.3-15 \mu \mathrm{m})$. Thermal imagery is then represented in grayscale, from white depicting areas emitting maximum radiation to black at the opposite end of the thermal scale. To ease image interpretation or highlight particular temperature intervals, false colors could be suddenly added.

Often, thermal detectors are coupled with an RGB camera with the same field of view to allow a better interpretation of acquired imagery by adding the visible bands to the thermal one.

The uses of these sensors on UAV are various (Vasterling and Meyer 2013), ranging from search and rescue missions (e.g., Rudol and Doherty 2008) to precision agriculture (e.g., Turner et al. 2010) and earth science applications, as in Fig. 4, or volcanology (Nishar et al. 2016; Amici et al. 2013).

Concerning currently available sensors, the following is a non-exhaustive list of manufacturers: DJI, FLIR Flytron, Thermoteknix, Yuneec, Workswell WIRIS. FLIR is a renowned manufacturer producing a vast array of thermal cameras, including UAV-borne ones - thermal or coupled with a visual one. They are also provided with preassembled kits, usually featuring DJI drones. Several companies offer this kind of products as DRONExpert or DSLRPros. DJI itself produced a dual sensor (thermal and RGB) featuring several advanced functions to maximize thermal survey productivity. Workswell WIRIS creates an integrated system composed by a thermal camera, RGB camera, and a built-in control unit.

Moreover, the upper limit of measured temperature range could be extended, on request when purchased, to $1500{ }^{\circ} \mathrm{C}$. Workswell also provides ready-to-fly kits composed by their system and a drone. Flytron manufactures, based on a FLIR sensor core, a compact and low-cost thermal sensor allowing small drones to include in their payload a thermal camera. Yuneec, on the other hand, proposes an integrated kit including, in addition to the thermal sensor, a low light visual camera and the gimbal. Lastly, Thermoteknix offers a compact, new generation thermal camera featuring a shutter-less technology allowing an uninterrupted view of the target and the removal of moving parts. Thanks to these characteristics, it is used in security applications, including counter UAV drones (C-UAV) as a part of the targeting equipment. Table 8 summarizes some features of the described sensors.

\section{Multispectral cameras}

In addition to RGB cameras, multispectral ones can capture image data in the non-visible sector of the light spectrum. They are equipped with an array of sensors, each one acquiring a specific wavelength interval. In some cases, the intervals mimic those featured by well-known satellite missions mounting multispectral sensors. To perform multi-band analyses and indices computation also visible bands are acquired. If the camera is dedicated to a particular task, only part of the visible spectrum could be considered. On the other hand, generalpurpose ones are capable of acquiring all of the visible bands (i.e., RGB).

Cameras are also connected to external components which allow the correct positioning of the acquired images, like GNSS antennas and calibration sensor detecting the incident solar radiation during image acquisition thus correcting each one, according to the sunlight influence. Concerning sensor calibration, cameras are often provided with a calibrated panel, which has to be scanned at the beginning and the end of the flight. The panel acquisition ensures a more accurate generation of the data by taking into account the incident light conditions during the UAV mission.

The result of a multispectral survey is exploited, particularly, by the computation of indices that are linear combinations of bands processed by raster algebra (Shapiro and Westervelt 1994). Among the various indices proposed in the literature, the most used is the NDVI (normalized difference vegetation
Fig 4 Thermal image captured by Sensefly Albris camera $(80 \times$ $60 \mathrm{px}$ ) highlighting an inflow and wetlands in Candia Lake $\left(45^{\circ} 20^{\prime}\right.$ $\left.\mathrm{N} ; 7^{\circ} 53^{\prime} \mathrm{E}\right)$

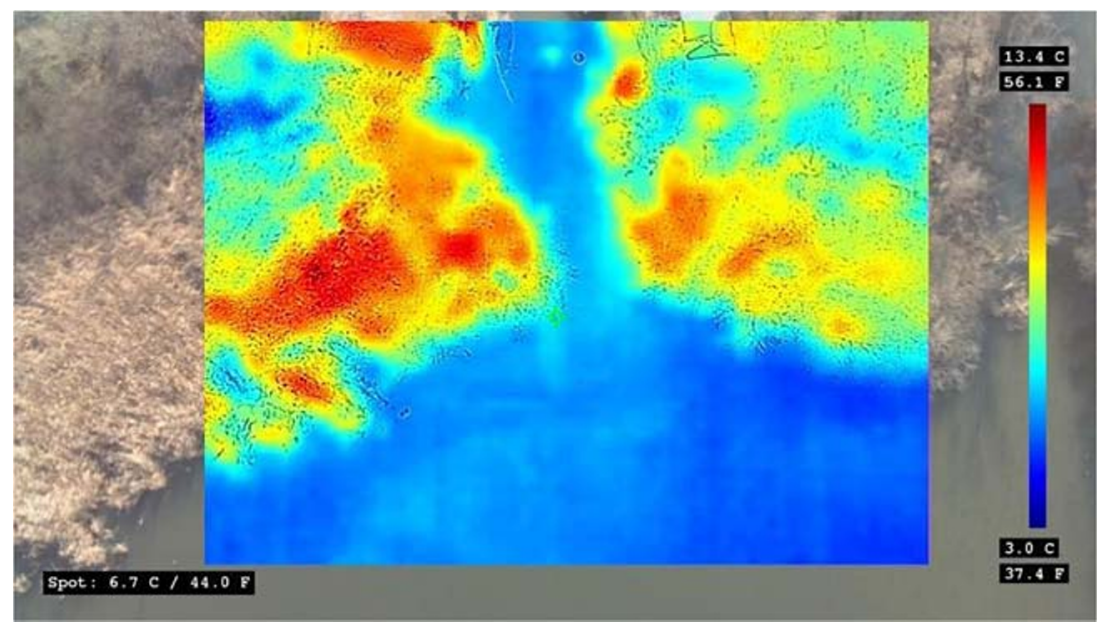


Table 8 Comparison between the most used thermal sensors

\begin{tabular}{|c|c|c|c|c|c|c|c|}
\hline & $\begin{array}{l}\text { FLIR Vue } \\
\text { Pro R }\end{array}$ & FLIR DUO & $\begin{array}{l}\text { DJI } \\
\text { ZENMUSE } \\
\text { XT }\end{array}$ & $\begin{array}{l}\text { WORKSWELL } \\
\text { WIRIS }\end{array}$ & $\begin{array}{l}\text { FLYTRON } \\
\text { DRONETHERMAL } \\
\text { v3 }\end{array}$ & $\begin{array}{l}\text { THERMOTEKNIX } \\
\text { MICROCAM } 3\end{array}$ & $\begin{array}{l}\text { YUNEEC } \\
\text { CGOET }\end{array}$ \\
\hline Sensor size (px) & $640 \times 512$ & $160 \times 120$ & $640 \times 512$ & $640 \times 512$ & $80 \times 60$ & $384 \times 288$ & $160 \times 120$ \\
\hline Measure range $\left({ }^{\circ} \mathrm{C}\right)$ & $-55 \div 95$ & $-20 \div 60$ & $-40 \div 550$ & $-25 \div 150$ & $-40 \div+80$ & $-40^{\circ}+70$ & -10 to 180 \\
\hline Measure precision (\%) & $\begin{array}{c} \pm 5^{\circ} \mathrm{C} \text { or } \\
\pm 5 \%\end{array}$ & $\begin{array}{c} \pm 5^{\circ} \mathrm{C} \text { or } \\
\pm 5 \%\end{array}$ & $\pm 5^{\circ} \mathrm{C}$ or $\pm 5 \%$ & $\pm 2{ }^{\circ} \mathrm{C}$ or $\pm 2 \%$ & $\pm 5{ }^{\circ} \mathrm{C}$ or $\pm 5 \%$ & NA & NA \\
\hline Weight $(\mathrm{kg})$ & 0.015 & 0.084 & 0.270 & 0.390 & 0.003 & 0.030 & 0.278 \\
\hline
\end{tabular}

index) obtained by calculating the ratio between the difference and the sum of NIR and red bands. NDRE (normalized difference red edge) is similar to the previous one, and the only difference is the Red Edge band use instead of the red band (Li et al. 2013). Both of them are used in order to spot differences in vegetation health status (Fig. 5) and soil water availability (Eitel et al. 2010), also for inferring slope failures and instability triggers as in satellite remote sensing application of the same methodologies (Fiorucci et al. 2011; Mondini et al. 2011; Guzzetti et al. 2012).

Manufacturers offer different sensors, featuring various characteristics and acquired bands. Sentera offers multiple solutions concerning multispectral cameras, the most advanced is the multiSPEC 4 with six bands (RGB + multispectral) and automatic computation of vegetation indices (NDVI, NDRE). Sentera also proposes a ready-to-use version of the sensor capable of yielding RGB and vegetation indices or only vegetation indices as results. The camera is provided as it is or included in a ready-to-fly kit compatible with various drones with fixed or rotary wings. Sequoia, manufactured by Parrot, is supplied with four bands and an RGB camera; it is also equipped with GPS, IMU, and magnetometer, so it is entirely autonomous and compatible with any drones. Tetracam produces the lighter sensor, called ADC Micro, allowing its deployment also on small UAVs. Its bands are equivalent to Landsat Thematic Mapper bands TM2, TM3, and TM4. MicaSense manufactures RedEdge sensor, which, in addition to the RGB bands, captures Red edge and near-IR. Lastly,
AIRINOV multiSpec 4C acquires four different spectral bands: green, red, red edge, and NIR. They are corrected in real-time by an onboard lux meter; the recording of date, time, and position is available for each shot. Table 9 summarizes some technical characteristics of the listed sensors.

\section{Light detection and ranging}

Light detection and ranging (LiDAR) sensors are the most complex and also valid for the acquisition of a 3D model of the studied area. These devices can be very helpful during the night or in low light conditions, with clouds or shadows and especially in dense tree-covered areas. LiDAR is an active sensor that emits a signal to the target object; then, it measures the time of flight and the intensity of the returned signal (Baltsavias 1999; Wehr and Lohr 1999).

The system is not only composed by the laser emitter but also equipped with a receiver that detects the reflected energy of the pulse, and its positioning (IMU) and navigation (GNSS) systems. From the late 1990s (Miller and Amidi 1998), many different LiDAR sensors (firstly experimental and then for commercial purposes) specially designed for UAV applications were developed.

Primary limitations on these sensors are naturally represented by their weight, their dimensions, and power consumption. Nowadays, there are various LiDAR models commercially available for use on a UAV system having suitable load capacity in terms of payload and dimensions. The first
Fig. 5 Comparison between the RGB image and the NDRE index (sensor MicaSense RedEdge, location $42^{\circ} 46^{\prime} \mathrm{N} ; 13^{\circ} 42^{\prime} \mathrm{E}$ ). The rectangle shows the presence of a swamp area, barely visible in the RGB image and depicted by the vegetation index (modified from Allasia et al. 2018).
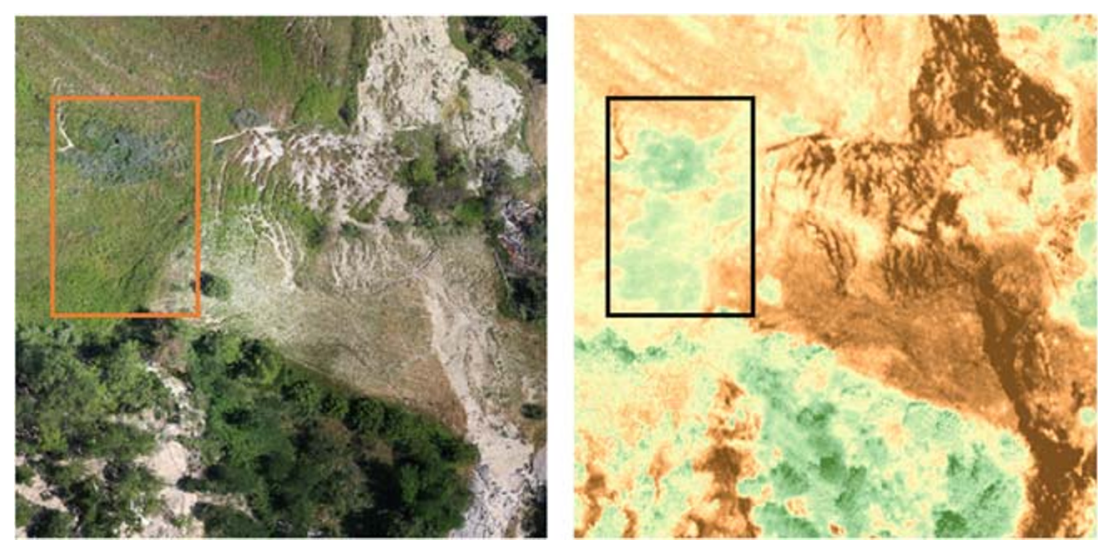
Table 9 Comparison between the most used multispectral sensors

\begin{tabular}{llllll}
\hline & $\begin{array}{l}\text { PARROT } \\
\text { SEQUOIA }\end{array}$ & $\begin{array}{l}\text { MICASENSE } \\
\text { REDEDGE }\end{array}$ & $\begin{array}{l}\text { TETRACAM } \\
\text { ADC Micro }\end{array}$ & $\begin{array}{l}\text { SENTERA } \\
\text { QUAD }\end{array}$ & $\begin{array}{l}\text { MULTISPEC } \\
\text { 4C }\end{array}$ \\
\hline $\begin{array}{l}\text { No. of spectral } \\
\text { channel }\end{array}$ & 4 & 5 & 3 & 6 & 4 \\
$\begin{array}{l}\text { Spectral range (nm) } \\
\text { Weight }(\mathrm{kg})\end{array}$ & $550-790$ & $400-900$ & $520-920$ & $450-825$ & $550-790$ \\
& 0.072 & 0.15 & 0.09 & 0.17 & 0.16 \\
\hline
\end{tabular}

applications of these sensors are forestry and vegetation mapping (Sankey et al. 2017; Sankey et al. 2018; Guo et al. 2017) but, according to "traditional" LiDAR potentialities (among others Lato et al. 2009; Dewitte et al. 2008) in engineering geology, also the UAV-borne version of LiDAR is expected to provide encouraging results.

Various systems/sensors are available with different features and capabilities. Leddar Tech provides a compact solution equipped with a solid-state fixed light source and eight independent detection elements allowing multi-object measurement. Velodyne, renowned for autonomous vehicle equipment, offers different lightweight rotating head sensors allowing $360^{\circ}$ surveys. Riegl markets a long-range system allowing an operating flight altitude of up to $350 \mathrm{~m}$ AGL.

Integrated systems are also available, like the one provided by Routescene. It is a ready-to-use system, which combines LiDAR, RTK-GNSS, inertial sensors, and control components in a unique device. Velodyne LiDAR is also included in two other solutions like Yellowscan and Geodetics, and it is integrated, like the previous one, with GNSS, inertial, and control units. Table 10 shows the main features of six different examples of systems that can be adopted by UAV.

Although similar in sizes and weight, scanning systems examined have different characteristics in terms of global performances, absolute ranging, and scanning rate. In particular, is it possible to divide them into two main categories: (i) compact sensors with approximate ranging between 40 and 100 and scan rate ranging between 50 and $300 \mathrm{KHz}$, weighting nearly $1 \mathrm{~kg}$, and (ii) advanced sensors, with multi-pulse and full-waveform technology with a weight of $4-5 \mathrm{~kg}$, ranging between $100 \mathrm{~m}$ (for corridor and power lines applications) and $900 \mathrm{~m}$ (aerial mapping).
In the second category, at the current date, is it possible to include only the RIEGL VUX, in the two versions: UAV (primary lower ranging and scan rate) and LR (long range). This sensor differs from those belonging to the first category from this concept project, comparable with a full-scale aerial LiDAR sensor, and mounted on an aerial vehicle with a pilot, but made compact and suitable for use with UAVs.

However, the two main problems of this instrumentation are its weight, which in fact constrains the type of aerial platform that can be used, with not negligible consequences on flight regulations for this type of aircraft (in particular total takeoff weight); and its price, which is more than ten times higher than other solutions represented by the first category.

It is evident that this system has a higher level of performance in comparison with other types of solutions but it remains, at least from a psychological point of view, more than one doubt about safety and reliability factor for the installation of a payload of the cost 20 times greater than the aerial vector that carries it. This sensor results in almost all cases installed on a rotating blade manned vector.

At the moment, these systems have a strong limitation, represented by the UAV flight autonomy, usually represented by a multirotor, which have a fly range of no more than 25 $30 \mathrm{~min}$. A possible solution could be the use of fixed wing solution featuring a greater flight autonomy.

Table 10 Comparison between the most used LiDAR sensors

\begin{tabular}{|c|c|c|c|c|c|c|}
\hline & $\begin{array}{l}\text { LEDDAR } \\
\text { TECH } \\
\text { VU8 }\end{array}$ & $\begin{array}{l}\text { VELODYNE } \\
\text { HDL-32E }\end{array}$ & $\begin{array}{l}\text { RIEGL } \\
\text { VUX-1UAV }\end{array}$ & $\begin{array}{l}\text { ROUTESCENE } \\
\text { LIDARPOD }\end{array}$ & $\begin{array}{l}\text { YELLOWSCAN } \\
\text { SURVEYOR }\end{array}$ & $\begin{array}{l}\text { GEODETICS } \\
\text { GEO-MMS }\end{array}$ \\
\hline Wavelength (nm) & 905 & 903 & 905 & 905 & 905 & 905 \\
\hline $\begin{array}{l}\text { Maximum range } \\
(\mathrm{m})\end{array}$ & 185 & 100 & 920 & 100 & 100 & 200 \\
\hline Accuracy $(\mathrm{cm})$ & 5 & 2 & 1 & 2 & 5 & 3 \\
\hline Field of view $\left(^{\circ}\right)$ & 100 & 360 & 330 & 360 & 360 & \\
\hline Weight $(\mathrm{kg})$ & 1.3 & 1.3 & 3.5 & 2.5 & 1.5 & 1.5 \\
\hline
\end{tabular}




\section{UAV for 3D model generation: operative rules, regulation, data collection, and processing}

In this section, we present a synthesis of the best practice for an excellent acquisition of a photo sequence that can be processed using the structure from motion applications. The main goal of this section is the introduction of most essential aspects that can be considered for proper use of UAVs, in term of operative rules, regulation, data collection, and data processing.

Sometimes, users are often convinced that the use of UAV is quite easy, practically automatic and that the data collection strategy is secondary to obtain valid and precise photogrammetric products.

In the last 20 years, a major revolution has taken place in microelectronics, battery and camera technology, and global positioning, plus a quiet revolution in photogrammetric software and its availability, based on the theory of "close-range" photogrammetry (Cooper and Robson 2001). This recent evolution has fueled developments and enabled almost any type of UAV-mounted camera to achieve reliably accurate results in terms of 3D surface models and 4D monitoring. In practice, results from UAV photogrammetry can be spliced smoothly with LiDAR-based techniques, both terrestrial and airborne, and satellite-based techniques, and are increasingly used in tandem to produce DTM (Hobbs et al. 2013; Tong et al. 2015; Peppa et al. 2016; Wilkinson et al. 2016; Mateos et al. 2017). Of course, there are limitations to the use of UAV, primary among which are weather and legislation. The former is not exclusive to UAV surveys but the latter definitely. Regulation and law for UAV is not a subject that is covered in detail in this paper as it is complex, internationally varied, and ever-changing (Stöcker et al. 2017). Current technological improvements include greater endurance, payload and range, collision avoidance, and increased sophistication of onboard IMU (UST 2018). Context-based flight controls are also emerging; that is, the UAV use of elements of Artificial Intelligence (AI) to control flight parameters onboard according to changes in its environment. Terrain recognition, either from laser scanner or from photogrammetry, combined with IMU data, provides a form of "dead reckoning" navigation and safeguard against GPS outages. This is already available in some terrestrial laser scanner systems for indoor use, but will also be applied to confined or other UAV scenarios where GPS is absent. Some requirements of landslide surveys are summarized in Table 11 and the effects of some recent and (likely) future developments given in Tables 12 and 13.

\section{Regulation}

In a built-up or air-trafficked area, a UAV survey is likely to be regulated internationally (International Civil Aviation
Organisation, ICAO) and/or nationally (national aviation authority) (Stöcker et al. 2017) which might include, for example, a "Permission for Commercial Operations" (PfCO), a "Congested Area Operational Safety Case" (CAOSC), a "Private Impact Assessment" (PIA), and insurance cover. In any event, even where not mandatory, some form of site assessment is advisable and, where applicable, contact with air traffic control (ATC), police, emergency services, etc. Besides, an assessment of weather and likely flying conditions should be carried out. These levels of regulation tend to mitigate against rapid ad-hoc UAV surveying of the kind that might be deemed necessary to achieve an effective geohazard response, for example. However, for a routine survey, such preparations would be considered advisable and most government and commercial organizations carrying out geo-surveys will have formalized health \& safety procedures covering all forms of fieldwork. At the moment, each country has a different regulation, but the European community is going to prepare a European Regulation. The goal is to have a "mandatory regulation" in June 2020.

\section{Operative rules and planning}

One of the most crucial activities that should be considered before a survey is flight planning. Nex and Remondino (2014) listed several essential elements that compose the typical workflow for the acquisition and processing of images. The published workflow is dedicated in particular to the acquisition of photo sequence that can be processed using SfM algorithms. Similar approaches can be adopted for different acquisition processes.

The most important parameters considered in the workflow that is fundamental for a correct definition of the flight planning are as follows: (i) flight parameters: ground sample distance (GSD), area of interest, camera information, and flight goals; (ii) characteristics of the available UAV: UAV platform (batteries duration, maximum distance from the ground control station) and autopilot; (iii) additional parameters like camera calibration, and availability and distribution of ground control points (GCPs).

These elements contribute to the definition of the mission planning that is propaedeutic to the acquisition of images. After the acquisition of the photo sequence, a process of image triangulation allows the generation of the digital surface model (DSM) and other products like orthoimages, 3D modeling, and the extraction of features. James et al. (2017) made a detailed analysis of how it is possible to reduce the number of GCPs, which often requires a strong field survey effort and the importance of the proper choice camera concerning the final resolution and quality of the DSM.

Even if the use of commercial UAV could seem very simple and quite friendly, it is fundamental to apply some primary mode of operation and to be able to realize correct planning of 
Table 11 Likely requirements and outcomes for a UAV landslide survey

\begin{tabular}{|c|c|c|}
\hline Requirement & Purpose & UAV photogrammetry advantage \\
\hline Safety assessment & $\begin{array}{l}\text { Communication with local authorities, emergency services, } \\
\text { and public }\end{array}$ & Rapid deployment and processing \\
\hline Reconnaissance & $\begin{array}{l}\text { Fieldwork planning, contextual mapping, and planning of } \\
\text { ground investigation. Disaster response }\end{array}$ & Rapid deployment and processing, and flexibility of scale \\
\hline 3D modeling & $\begin{array}{l}\text { Responsive visual assessment, rapid geomorphological } \\
\text { assessment and zoning of landslides, monitoring rates } \\
\text { of erosion, design of ground investigations, design } \\
\text { of TLS survey, and slope stability analysis }\end{array}$ & $\begin{array}{l}\text { Speed, repeatability, compatibility with other survey } \\
\text { methods, flexibility of scale, and lack of requirement } \\
\text { for photogrammetry expertise }\end{array}$ \\
\hline Environmental sensing & Thermal imaging, e.g., for gas escape & Wide coverage and hazardous areas \\
\hline Publicity & $\begin{array}{l}\text { Public understanding of science, education, media, and } \\
\text { marketing }\end{array}$ & $\begin{array}{l}\text { Topicality, immediacy, and engaging imagery providing } \\
\text { geographical context without map interpretation }\end{array}$ \\
\hline
\end{tabular}

the flight, to avoid collecting useless dataset. First, it is mandatory to do an investigation of the site before the flight. Aerial or satellite images are not sufficient (and updated) to detect some critical points or elements. After the decision of the UAV survey, it is essential to select the best UAV typology. As previously mentioned, the two most diffused UAV categories are multirotor and fixed wings. As suggested by Giordan et al. (2015), the topography of the target is a good point for the identification of the best UAV configuration: for steep areas (like rock walls or infrastructures), the best solution is usually a multirotor coupled with oblique images acquisition; for gentle and more extensive slopes, the best solution is often a fixed wing with nadiral images acquisition. Once that the typology of UAV has been identified, it is fundamental to keep into account the actual condition of the site, and, in particular, it is mandatory to:

Table 12 Recent UAV developments that have affected landslide studies

\begin{tabular}{ll}
\hline Development & Effect \\
\hline Electric power & $\begin{array}{l}\text { Acceptable noise levels and no need for } \\
\text { flammable liquids or starter battery } \\
\text { Auto piloting and accurate camera control } \\
\text { IMU }\end{array}$ \\
$\begin{array}{l}\text { Geo-rectifying survey and repeat monitoring } \\
\text { surveys } \\
\text { Camera/sensor control and vibration reduction }\end{array}$ \\
Gimbal & $\begin{array}{l}\text { Image quality and "true" coloration of models, } \\
\text { light weight, and radio control }\end{array}$ \\
Camera & $\begin{array}{l}\text { Portability, ability to backpack, and reduced } \\
\text { landing damage }\end{array}$ \\
Compactness & $\begin{array}{l}\text { Greater coverage and data density per flight } \\
\text { Improved inspection and reconnaissance }\end{array}$ \\
Duration & $\begin{array}{l}\text { Repeat surveys and monitoring } \\
\text { "Home" function and parachute systems } \\
\text { Route programming } \\
\text { Self-recovery }\end{array}$ \\
Legislation & $\begin{array}{l}\text { Greater safety, professional attitude, and } \\
\text { availability of professional training }\end{array}$ \\
\hline
\end{tabular}

1. Verify the possible authority restriction on this area (e.g., a location close to the airport), to ask permission (if it is possible) or not working there. Each country has different rules; therefore, it is fundamental to verify the specific one.

2. Verify the presence of electric lines or pylons or other aerial furniture. In some case, it is impossible to estimate the height or the distance between this obstacle and UAV

3. Identify the correct surface where takeoff and land. This area depends a lot by the category of used UAV. If the selected UAV is a multirotor, the required space is limited, because it is possible to realize the VTOL (vertical takeoff and landing). Using a fixed wing, it needs a broader area (at least 20-25 m), including a free space about the runways, to have the takeoff and landing ramp.

4. Check the adequate GNSS visibility, both in the upper part of the flight and on the ground, to avoid to lose the GNSS signal during the landing (very critical condition) or in the takeoff (operability is not allowed);

5. Control the presence of vegetation and other possible obstacles;

6. Verify the presence of potential electromagnetic interferences, both for the GNSS signal and for the UAV communication system;

Table 13 Future UAV developments that will affect landslide studies

\begin{tabular}{ll}
\hline Development & Effect \\
\hline Hybrid and "transitioning" UAVs & $\begin{array}{c}\text { Combined advantages of rotary and } \\
\text { fixed wing, cost reduction, and } \\
\text { wider applications } \\
\text { Autonomy and onboard reaction to } \\
\text { environment/adverse conditions } \\
\text { AI-enhanced control }\end{array}$ \\
$\begin{array}{l}\text { Golar power } \\
\text { (but less useful in the UK) }\end{array}$ \\
$\begin{array}{l}\text { Terrain recognition + } \\
\text { IMU = "dead reckoning" }\end{array}$ & $\begin{array}{c}\text { Safeguard against GPS outages } \\
\text { Swarming technology }\end{array}$ \\
\hline
\end{tabular}


7. Check the morphology of the area to survey, considering possible high slope variation or other specific issues.

Also, a critical operative step is to verify the weather condition, and to have a continuous weather forecasting bulletin, avoiding being surprised by critical visibility condition (e.g., fog) or, in a worst-case, a rainstorm. Nowadays, there are a lot of APP for smartphone (e.g., Avia Weather - METAR \& TAF), where the METAR (METeorological Air Report) is read and the main information is extracted, allowing working with the official meteorological report, generated by the Aeronautic Service. After that, it is possible to start the flight planning. This planning depends on the aim of the flight. In some case (e.g., indoor positioning or GPS not available), the flight is entirely manually made. In all other conditions (where the GPS is available), it is possible to realize an automatic flight. If the target of the flight is the acquisition of an image sequence for photogrammetry purposes, it is fundamental to shooting the images respecting the photogrammetric parameters imposed by the user. Knowing the proprieties of the digital camera (focal length, resolution, pixel size, etc.), it is possible to planning the flight, in order to respect the scale factor of the frame, the overlapping between the frames (longitudinal and transversal) and the GSD (ground sampling distance), that is the distance between two pixel in the object space. Using a traditional nadir acquisition, the schema of the flight is presented in Fig. 6 . According to Fig. 6, the scale factor of the frame is defined as:

$\frac{H}{c}=\frac{L}{l}=m_{\mathrm{b}}$

where $B$ is the distance between two shooting; $H$, the relative flight height; $c$, the focal length; $A$, the distance between two strips; $L$, the size of the frame in the object space (ground); and $l$, the size of the frame in the image space

Usually, the scale factor and the GSD depend on the precision and quality of the final products. In the nadir condition,

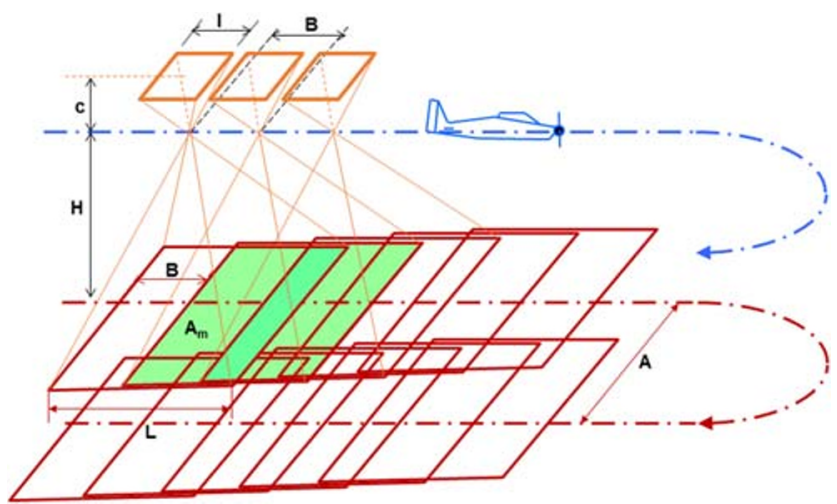

Fig. 6 Nadiral acquisition of a photo sequence. $B$, the distance between two shooting; $H$, the relative flight height; $c$, the focal length; $A$, the distance between two strips; $L$, the size of the frame in the object space (ground); $l$, the size of the frame in the image space the range of the frame overlapping could be $60-80 \%$ in the longitudinal direction and $50-80 \%$ in the transversal direction.

The minimum values of these ranges are used when a photogrammetric procedure is involved, where the collinearity equations are adopted for plotting the points (Kraus 2007). In opposite, it is better to improve the overlapping when a computer vision approach (e.g., structure from motion) is employed (Micheletti et al. 2015). In this case, the plotting is made with automatic feature extraction procedures, and the suggested value of the overlapping can achieve the $80 \%$ if the surface is characterized by a low contrast like snow or sand (Agisoft 2018).

The planning could be made or by the user, knowing precisely the relation of the photogrammetry or using some tool.

Usually, the height of flight is fixed not considering a real elevation model. In some case, flight planners are able to consider some global digital elevation models and define a flight plan with a constant distance from the ground. This is important in particular in steep areas, where the value of GSD can be very different is the flight height is constant, and the surveyed area has a great difference in altitude.

Recently, there is a new approach adopted for photogrammetry applications, which is based on the acquisition of oblique images (Fig. 7). In this case, the planning has to be completely different, and the traditional tools are not more available. The same problem arises when the image acquisition is made along a vertical façade (e.g., rock façade), where the flight is manually performed using the experience of the pilot. Moreover, the acquisition of vertical sectors often is affected by errors in the definition of the height, which is not perfectly guaranteed and stable due to the position quality estimated by the GNSS receiver. The oblique acquisition is typically based on the use of multirotor.

After the data acquisition using the UAV, images, and GCPs are used for generating several products as digital surface models (DSM) and orthophoto. Typically, there are two possible approaches for data processing: photogrammetry based or computer vision based. Actually, the high diffusion of software based on Structure from Motion (SfM) algorithms has increased the computer vision approach that is presented in the "Data processing and 3D model generation" section.

\section{Ground control points}

The use of Ground Control Points is an essential element that could have a substantial impact on the accuracy of the SfMbased DSM (James and Robson 2012; Turner et al. 2015). GCPs are points of known coordinated that can be clearly recognized in the photo sequence acquired by UAV. These points can be elements present in the field and/or artificial targets placed in the surveyed area before the UAV flight. The position of GCPs is acquired using high accuracy topographic methods like GNSS or total stations and then 
Fig. 7 Examples of different camera orientations and how a grid of section lines appears on various types of photos (modified from Gherdevich et al. 2012)

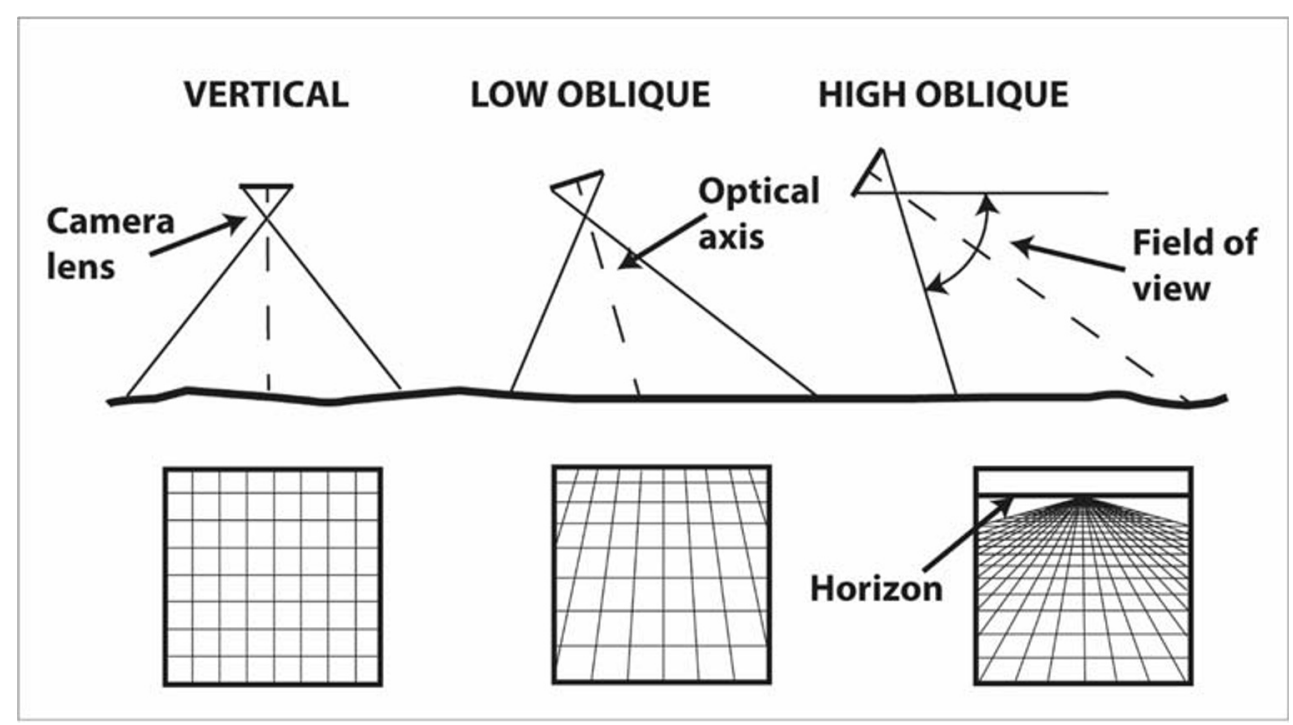

identified in the photo sequence during the SfM procedure (Harwin and Lucieer 2012).

The use and the number of GCPs depend on the required final accuracy of the positioning of the DSM and the quality of the UAV positioning system. As said before, it is possible to have on the UAV a GPS only or a multi-constellation receiver, but it is important to evaluate the combination between receiver and antenna, in order to define the final performances. In some cases, an external GNSS receiver can be installed and used to collect the raw data of the UAV path. This solution is adopted for direct photogrammetry applications (Turner et al. 2014; Eling et al. 2015; Mian et al. 2015; Gabrlik et al. 2018), where is required a high-resolution GNNS on board that reduce the importance and the impact of GCPs on the final accuracy of the DSM. The number of GCPs and their position is hard to define a priori, but some simple operative suggestions can be useful for proper distribution of these points: (i) follow the limit of the area of interest, (ii) insert other GCPs inside the area of interest considering also the elevation differences of the area. Other critical considerations that have to be evaluated during the deployment of GCPs are, according to James et al. (2017): (i) the importance of datum alignment to gravity (the distribution of targets can be carefully considered in particular if the final model can be used for modeling gradient-sensitive processes like, for example, rainfall or runoff models), (ii) the presence of vegetation at the scale of the physical control targets (that could hamper the identification of targets on images), (iii) the absolute 3D positioning.

Another important element that should be carefully considered during the definition of number and position of GCPs is the real effort that the deployment and survey of these points required. Nex and Remondino (2014) proposed an evaluation of the time effort in a typical UAV-based photogrammetric workflow. The time effort evaluation proposed by Nex and Remondino (2014) is as follows: flight planning, 5\%; image acquisition, 20\%; GCPs field measurement, 15\%; image triangulation, 15\%; DSM generation, 25\%; ortho mosaicking, $10 \%$; feature extraction, $10 \%$. Nowadays, working with the traditional photogrammetry the time usually required for the survey of GCPs is twice or more the time necessary for the UAV survey. This element should be carefully considered because the deployment of targets has to be done before the flight, and this activity can constrain the UAV flight activity that often should be done in the central part of the day to limit the influence of shadows.

Typically, it is possible to have three kinds of GCPs: natural, artificial, and coded. First ones are "natural" points which are easily detectable in the images, and their coordinates can be measured by a topographic survey (e.g., total station or GNSS). Usually, these points are corners, artifacts, pedestrian crossing lines, some natural spot, and similar. As a best practice, each GCP needs to be well defined, and it means to select a point and not a blob or an ambiguous area.

A weakness of this kind of GCPs is that not always it is possible to find some suitable points and the quality of the georeferencing could be low with respect to the use of artificial GCPs. Artificial marker (e.g., plastic or wooded panel) can be placed on the terrain and satisfy the required geometry of the distribution of GCPs. Using artificial marker, the geometry and the center is perfectly defined, and it can be correctly measured with high accuracy. In this case, it is very important to verify the color combination, because there is the risk to have a "pixel saturation" effect in the image, due to the white color.

Since a few years, artificial GCPs have been replaced by "coded" panel, such as artificial support where the top is covered by a special design, where is possible to use the code with a purpose to include some properties (e.g., name, code). In Fig. 8, codified markers are shown. 


\section{Data processing and 3D model generation}

The literature devoted to the use of UAV and the postprocessing procedures of a "typical" dataset composed by a photo sequence is very vast and variegated. Just to cite some more representative papers, Westoby et al. (2012) published a relevant article for the use of structure from motion in geosciences; Nex and Remondino (2014) published a useful review of the use of UAV for 3D mapping, and James et al. (2017) described how it is possible to optimize the structure from motion process.

The field of computer vision has evolved, allowing the human-level capability in the extraction of information from image data. There are many and diverse applications of computer vision since much of human experience are associated with images and with visual information processing.

Nowadays, the most used solution for UAV image sequence process is based on the structure from motion (SfM) algorithms. A typical SfM process workflow can be found in many articles such as Turner et al. (2014) and Ajayi et al. (2017). A full description of how the structure from motion works is out from the scope of this manuscript, which is aimed to presents the principal elements of the procedure and some operative suggestions. The number of software that are able to acquire the photo sequence and process the available data are progressively increased in last years and now are available both freeware applications and commercial solutions. The most complete software have a detailed guide that describes the sequence of processes that starts from the camera calibration and the image orientation, and that continues with the image matching technique (Westoby et al. 2012).

With an iterative procedure, this software is able to reconstruct firstly a sparse point clouds and then a dense one that is generally preferred in case of terrain/surface reconstruction. After, the dense point cloud could be interpolated, simplified, classified, and finally textured for photo-realistic visualization (Nex and Remondino 2014). The photo-realistic representation is one of the most relevant results of SfM for engineering geology applications that, for example, can be used for a
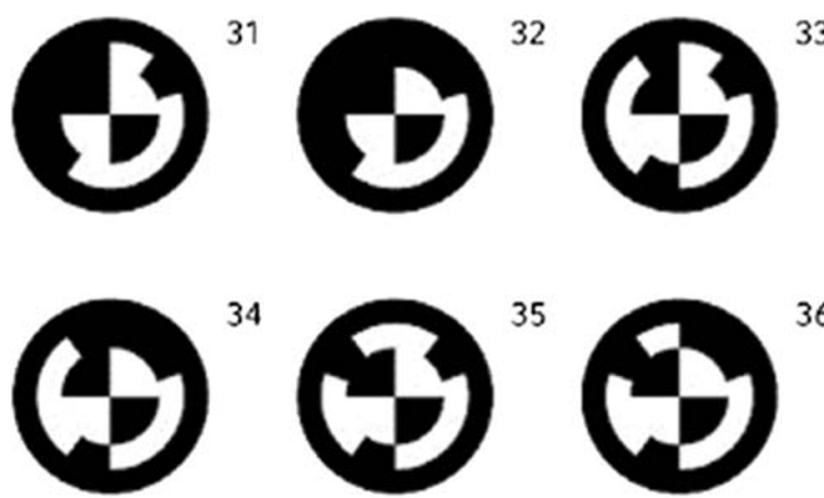

34

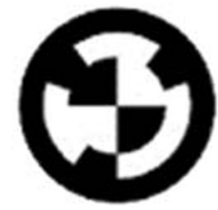

35

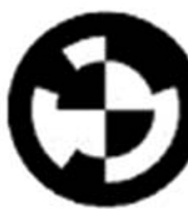

Fig. 8 Examples of artificial coded GCPs (Daftry et al. 2015) bedrock discontinuity analysis (Menegoni et al. 2019). Another significant result of the SfM procedure is the orthophoto generation of the surveyed area. A highresolution image of the studied area is fundamental in many applications like, for example, the study of landslides (Peppa et al. 2017; Fiorucci et al. 2018a, b; Cignetti et al. 2019), rivers (Tamminga et al. 2015), or coastlines (Nikolakopoulos et al. 2019).

Data processing could be based on GCPs or, in the most recent cases, working with direct photogrammetry approach, where the position and orientation of the camera are known, and it is directly possible to create the block. Nowadays, there are already on the shelf some UAV that are able to realize the direct photogrammetry, because they are able to synchronize the shutter with the GPS time and to collect the raw GNSS data, with the purpose to realize the data processing or even to directly work in RTK.

Even if direct photogrammetry approach is available, it is essential to know some milestones:

1. GCPs are still fundamental because they allow having better control of the quality of the final model in terms of precision and accuracy; it is possible to reduce the numbers working with direct photogrammetry, but they are still essential to verify the quality and to correct some local deformation.

2. RTK is available even for direct photogrammetry, but the basic of RTK positioning is still valid; therefore it is important to verify the datalink connection and the and the distance between master and rover;

3. RTK navigation is not required; hence it could be sufficient to store the raw GNSS data for data processing and then use a post-processing approach for the acquisition of high-precision images acquisition points;

4. On the shelf, there are several commercial solutions, but the cost of these systems is not cheaper considering professional solution where the internal GNSS data could be analyzed and processed.

\section{Additional remarks}

In engineering geology, high-resolution topographic reconstructions of determined area are probably one of the most common uses of UAV. That is due to the limited cost of small commercial UAV equipped with a high-resolution photo camera. The section also proposed a selection of papers that can be used by readers to improve the knowledge of these aspects, which are fundamental for a correct reconstruction of a topographic model. Additional necessary steps (e.g., battery storage and charging, UAV maintenance) are not mentioned but they are vital aspects to be considered to work in a safe condition and to obtain the best result. The last comment is 
required considering other natural issues like birds attack. It seems funny, but in some wide-areas, it is possible to be affected by a predator attack as eagle, buzzard or similar birds. Usually, they want to protect their territory by the enemy and unfortunately, the UAVs (typically small fixed wings) are detected as "enemy" and then attacked.

\section{The use of UAVs on landslides}

The International Programme on Landslides (IPL) declared in Kobe, Japan, in 2006 that "strengthening research and learning on landslides and related earth system disasters for global risk preparedness" was a key objective and will be carried forward to form the "Kyoto 2020 Commitment" (Sassa 2017). The important study of landslides has fully embraced process understanding and new technologies, including LiDAR (light detection and ranging) and UAVs (unmanned aerial vehicles), in particular, small UAVs $(<20 \mathrm{~kg})$, to good effect internationally, particularly in the last 30 years. These technologies have transformed the capabilities of engineering geologists, mapping geologists, engineers, and researchers.

For the last two decades terrestrial LiDAR scanning (TLS), or equivalent ground-based radar systems, have been available to survey landslides and other geohazards, remotely, allowing accurate Digital Elevation Models (DEM's) of the ground surface to be produced from point clouds (Miller et al. 2007; Hobbs et al. 2010; Boon et al. 2015). Vegetation can be "stripped" from 3D datasets to reveal stunning high-resolution models of the landslide beneath; in many cases, this includes landslides previously undetected and subtle features within and beyond known landslides. From these data, displacements and volumes can be calculated (Quinn et al. 2010; Hobbs et al. 2013; Chesley et al. 2017). Further, more recently, it has been possible for surveys made by Unmanned Aerial Vehicles (UAVs) or Unmanned Aerial Systems (UAS's) to replicate some of the capabilities of large and expensive aerial and satellite platforms. LiDAR scanners themselves, with the addition of hyperspectral sensors, can now be added to the UAV's onboard facilities. This section takes an overview of developments and the consequent advantages for those studying, mapping, and surveying landslides. The development history of UAV, in general, is described in Colomina and Molina (2014) and its use in other spheres of geological study in Bemis et al. (2014), Tong et al. (2015), Wilkinson et al. (2016), Jordan et al. (2016), Chesley et al. (2017), Nieminski and Graham (2017), Nikolakopoulos et al. (2017a), Madjid et al. (2018), Nikolakopoulos et al. (2018), and Nikolakopoulos et al. (2019).

In many ways, it can be argued that the small instrumented UAV is the perfect tool for the assessment of landslides, where the terrain may be remote, hazardous, and inaccessible except on foot or entirely out of bounds. The UAV photogrammetry tool, where point clouds and 3D models can be produced from overlapping photography, meets this requirement head-on, but this has only been truly the case very recently. In its simplest form we now have a small, radio-controlled, electric rotary or fixed-wing aircraft fitted with a small, but high-resolution, camera easily capable of achieving a digital elevation model (DEM) resolution of between 5 and $25 \mathrm{~cm}$ (Madjid et al. 2018). This has developed from a simple "eye in the sky" to a sophisticated photogrammetric tool but, crucially, one available to professional and non-expert alike (Niethammer et al. 2012; Lucieer et al. 2014; Stumpf et al. 2014; Eltner et al. 2015; Peppa et al. 2016). Landslides come in a variety of forms and states. They can be large or small, inland or coastal, active or inactive (Hungr et al. 2014). There have been many instances, particularly on linear infrastructure such as rail, where an apparently small, active landslide has been investigated only for it to be later identified as part of a much larger, and possibly more hazardous, landslide. For this reason, ground investigations and remedial works applicable to the "small" landslide may turn out to be totally inadequate for the "large" landslide of which it is part. For this scenario, an early UAV survey could be vital in revealing the "big picture," at least in the absence of any other "desk study" information.

\section{Examples of landslides studies in the UK using UAV}

Landslides in the UK tend to be driven by rainfall, both amount and intensity (Forster and Culshaw 2004; Pennington et al. 2015; Uhlemann et al. 2016). This can also apply to coastal cliffs, but with the additional factor of marine erosion (Poulton et al. 2006). The ability of geological formations to cope with water is a key factor. More permeable rocks/ soils are able to accept more water than less permeable ones but they may also result in more rapid landslide triggering depending on the mechanisms involved. Slopes in low permeability rocks/soils, in particular clay-rich ones, may tend towards instability over many decades. This includes man-made slopes (e.g., cuttings and embankments) where the method of construction and the drainage regime are also important.

The distinction between "active" and "inactive" states can be difficult to determine during early investigations. In some cases, for example, where an active landslide poses a chronic threat, a monitoring regime may be needed to determine which parts are active, how the activity is progressing and what effect this is having on the overall hazard; and also to monitor the response to remedial measures. Such a regime can also aid the understanding of landslide mechanisms and their complexity. Again, a UAV survey may be the ideal solution here or, at least, an important part of the solution. Georegistration of each survey in a landslide monitoring program is vital to compare individual surveys and calculate changes. Without good quality onboard GPS some form of ground control is required (Stumpf et al. 2014; Peppa et al. 2016). A 
landslide is traditionally mapped, characterized, and zoned using a small-scale, detailed "geomorphological" map; the starting point of which is some form of terrain model combined (in the last two decades) with digital input in the field via tablet PC. These can now be produced rapidly, automatically and remotely by uploading large numbers of UAV photos to proprietary software packages (Fig. 9).

A large number of photographs taken from a wide variety of viewpoints is uploaded. Specialist "metric" cameras are no longer required, and everyday digital cameras are suitable. The result is a convincing rendition of the ground surface in the form of a colored "point cloud." Point clouds are the "bread and butter" of terrestrial LiDAR surveys (TLS) and while the results of UAV photogrammetry are not equal, at least on paper (Wilkinson et al. 2016), to those of TLS (all other factors being equal) both outputs can be combined following processing, as indeed they can with full-scale (highaltitude) airborne LiDAR. It is reported that a combination of TLS and SfM (using both terrestrial and UAV platforms) provides the best result in rock slope stability surveys when linked to an independent survey control network (O'Banion et al. 2018). The coloration of the data (true RGB) itself adds hugely to the value of the survey for a geologist or geomorphologist, as this aids visualization and the identification of features. These factors amount to a powerful visualization and measurement combination when applied to landslide surveys.

UAV-mounted LiDAR has also entered the public domain in the last 5 years. This is a desirable option mainly due to its 3D capability to "strip" foliage using the 3 rd laser return to see the ground beneath and hence produce a DTM. However, it is very expensive; currently requiring a powerful $(>20 \mathrm{~kg}$ ) UAV platform and subject to additional national restrictions or outright bans worldwide. In fact, the cost is currently higher than conventional TLS. Of course, technology is moving rapidly and these, and other, tools will become commonplace in the very near future; for example, multispectral and environmental sensors, some of which will be suitable for aspects of landslide surveying. Some multispectral sensors can be used for detecting minerals and water and for distinguishing rock types (Madjid et al. 2018); a potentially useful capability for landslide investigations and geological investigations more widely (Quinn et al. 2010). "Green" LiDAR has also been developed for its ability to "see-through" water for bathymetric surveying. In the UK, much of the land has been deforested for agriculture. The remaining areas of woodland are often found to contain previously undetected landslides, particularly on escarpment slopes (this, in turn, adding to the unsuitability for farming) such as shown at the British Geological Survey "landslide observatory" at Hollin Hill, North Yorkshire (Fig. $10)$.

In the UK many landslide boundaries match woodland boundaries. Currently, UAV photogrammetry is incapable of "stripping away" tree cover as each raw image is, by definition, 2D (Bemis et al. 2014). However, the level of detail already available to LiDAR is increasingly available to UAV photogrammetry and Structure from Motion techniques. Overall images of 3D models of the unwooded part of the landslide at Hollin Hill are shown in Fig. 11 and detail of the active backscarps in Fig. 12.

The use of UAV images for coastal landslide surveying and modeling at the British Geological Survey's "coastal landslide observatory" on the Holderness coast of Yorkshire (Hobbs et al. 2020) is shown in Figs. 13 and 14. The results are fully compatible with, and complementary to, TLS survey results. One approach is to use TLS for the overall survey and UAV photogrammetry for infilling shadow (obscured) areas or for areas where greater detail is required. If a larger area is to be covered then the opposite approach may be more suitable.

The question of UAV photogrammetric accuracy has been examined, in the context of an active landslide by Peppa et al. (2016) and rock slopes (O'Banion et al. 2018), and for outcrop surveying by Wilkinson et al. (2016). The former was located at the BGS's "landslide observatory" at Hollin Hill, North Yorkshire, UK, where the authors described the accuracy as "acceptable for landslide assessment." Others have successfully used UAV for time series monitoring of similar landslides (Lucieer et al. 2014; Turner et al. 2015). This is an important consideration because landslides occur in a wide range of scales and behaviors (Hungr et al. 2014).
Fig. 9 Coastal cliff landslide surveying using a a DJI "S900" UAV with a digital camera and $\mathbf{b}$ a Mikrokopter "Hexakopter XL" (right), Aldbrough, UK (2014), BGS@UKRI[2018].

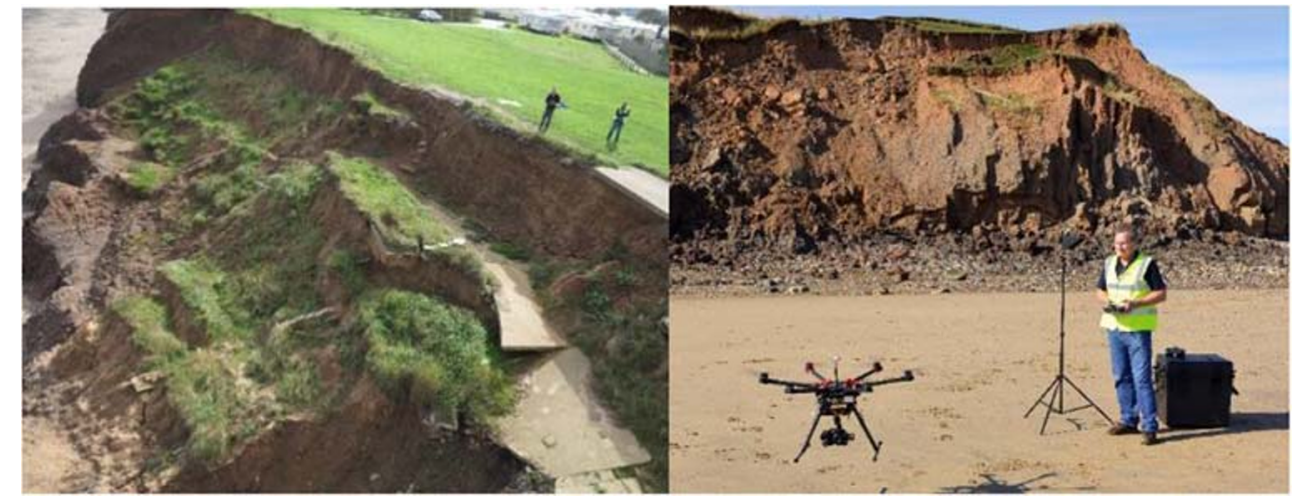


Fig. 10 Landslide complex, $\mathbf{a}$ in part revealed beneath tree cover, from airborne LiDAR-derived DTM's, and b DTM prior to "stripping out" of tree cover, Hollin Hill, UK (2012), BGS@UKRI[2018]
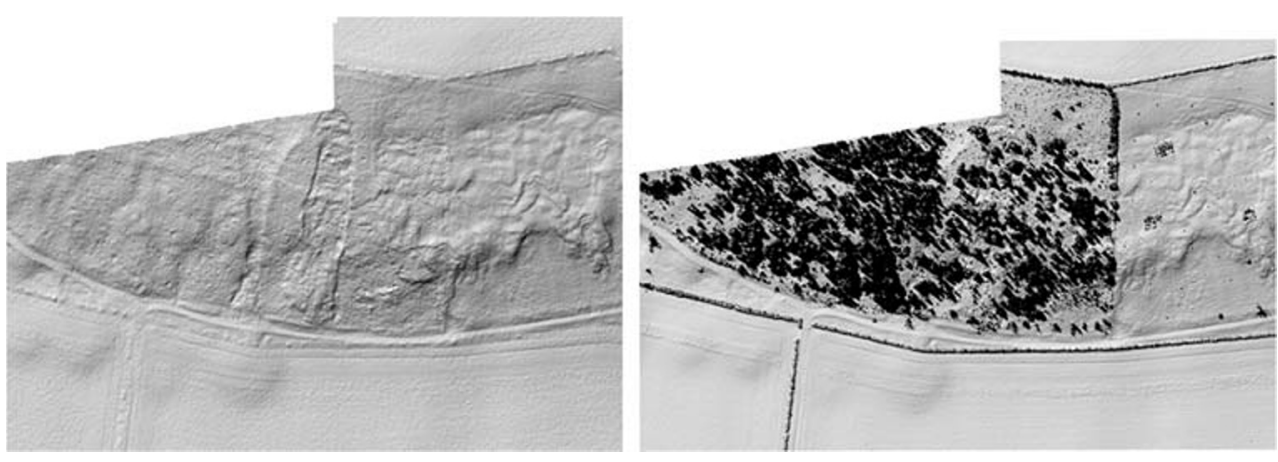

Landslides which consist of unsaturated soil or weak rock (and often both) tend to feature large-scale movements (often on moderate slopes) which can be slow-moving and non-catastrophic, whereas landslides consisting of strong rock tend to undergo small deformations before catastrophic failure (often on steep slopes). However, it could be argued that where large deformations are involved high-accuracy (geodetic-quality) surveys are neither necessary nor cost-effective. The same argument could be applied to emergency situations where accuracy may be a secondary factor in either response or outcome. Nevertheless, using a network of ground control points (GCP's), an accuracy was reported in terms of a "real terrain change equal to $9 \mathrm{~cm}$ " (Peppa et al. 2016).

\section{Challenges of using UAVs for landslide surveying}

Recurring problems encountered in landslide surveying with UAVs include the following:

- Regulation: national regulatory bodies have struggled to keep up with developments (Cracknell 2017) but are likely to restrict or even prevent UAV surveys in some countries. The international regulation situation is changing and there have been moves to clamp down on civilian use of drones. Usually, there is a requirement for commercial users to have completed a training program (Cracknell 2017; Cunliffe et al. 2017). The European Union (EU) has committed to introducing new regulations by 2019 (Dron 2017).

- Software licenses: these can be expensive and, at the higher end of geodetic-quality surveying, almost prohibitively so; particularly where complex processing and combinations of software packages are required, and also where multiple "seats" are involved. However, new generations of SfM software, in particular, are reducing the cost and complexity of image processing.

- Weather: small and micro-UAVs are usually incapable of operating in severe weather. However, many small UAVs can now deal with "TLS-tolerant" weather. The wind is the main problem for platform safety and camera stability; in particular, gusting wind. Precipitation, fog, and mist are also included, partly by virtue of damage to electronics and moving parts, but also obscuration of the landslide itself.

- Computing: UAV photogrammetry may occupy several hours of processing time, depending on survey size and laptop power. Nevertheless, the same can be said of TLS.

\section{Advantages of using UAV for landslide surveying}

Of course, problems aside, there are many advantages to the use of UAV in landslide surveys. These include the following:
Fig. 11 a Orthophoto at 1-cm resolution and $\mathbf{b}$ digital elevation model (DEM) sub-sampled at $5 \mathrm{~cm}$, from UAV imagery of unwooded part of Hollin Hill landslide, June 2014 (refer to Fig. 10), BGS@UKRI[2018]
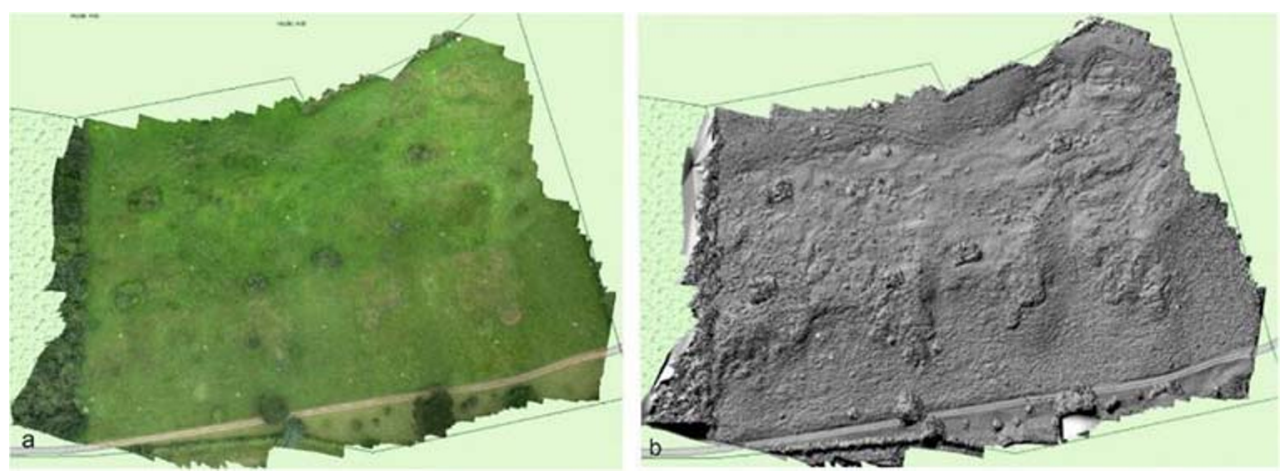
Fig. 12 a Orthophoto at $1-\mathrm{cm}$ resolution and $\mathbf{b}$ digital elevation model (DEM) sub-sampled at $5 \mathrm{~cm}$, from UAV imagery of Hollin Hill landslide (detail: fresh slumps in north-east corner of Fig. 11), June 2014, BGS@UKRI[2018]
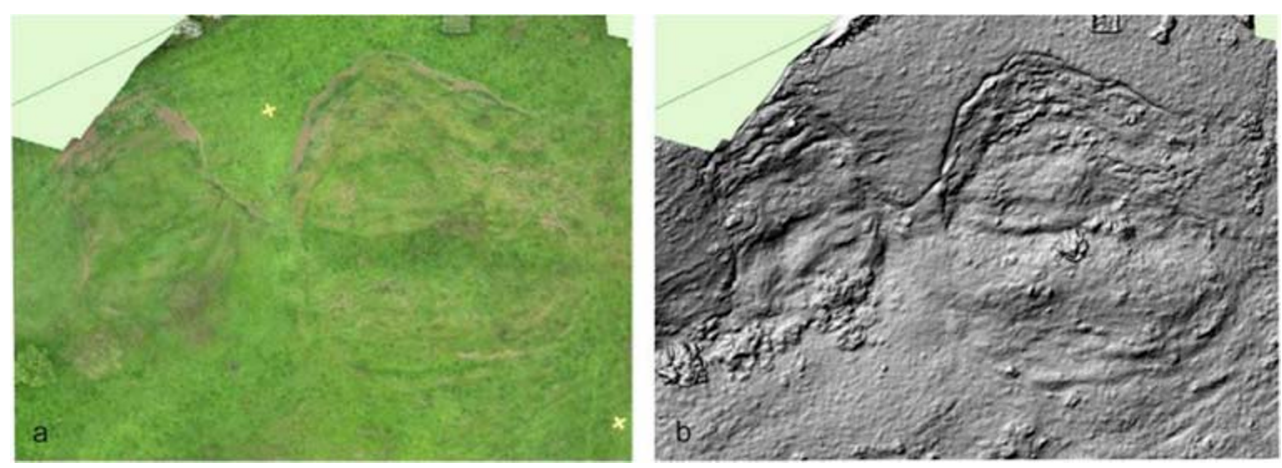

- Portability: many modern small and micro-UAVs can be back-packed to site and hand-launched and retrieved. This is an important consideration when trekking, for example through jungle, bog, or mountain, to reach a remote landslide (packing cases and launch ramps not needed).

- Rapidity: the ability to move into a potentially hazardous area and out again quickly, having assessed the situation and completed the survey. This is particularly useful in the case of landslides involving infrastructures such as road, rail, pipelines, and transmission.

- Opportunism: this is really the combined effect of portability and rapidity. A cross-country expedition of several days or even hours is likely to benefit from the ability to deploy at any point and short notice. For example, colored point clouds of landslides often reveal subtle features more effectively when photographed in sunny conditions; particularly with a low sun angle. Also, there are distinct advantages to being able to repeat a survey the same day, for example, if there are problems with visibility. This may not be possible with full-scale aircraft in remote locations.

- Proximity: a terrestrially deployed UAV survey can have an advantage over an equivalent full-scale (high altitude) airborne survey by virtue of its proximity. Rather than a blanket coverage with an average resolution, a targeted survey with a more detailed resolution can be achieved either by "loitering" over areas of interest (rotary) or by

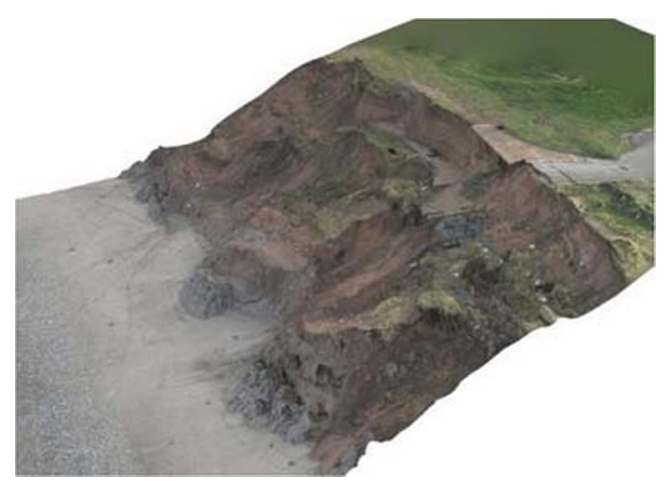

Fig. 13 Orthophoto image of coastal cliff landslide produced using UAV photogrammetry, Aldbrough, UK (2013), BGS@UKRI[2018] flying at lower altitude and speed (fixed wing). Satelliteborne remote sensing methods tend to have a oblique line of sight which may be unsuitable for cliffs and escarpments. Proximity also allows expert local observations to be made to aid interpretation of the survey results.

- Dataset size: the size of the datasets (raw + processed) is typically modest compared with equivalent TLS surveys; for example: two hundred photos of 4 to $8 \mathrm{MB}$ each, giving an overall LASer file format (.las) size of 200 MB for the small section of landslide shown in Fig. 12 , compared with $1 \mathrm{~GB}$ for an equivalent TLS.

- Cost: an off-the-shelf, ready-to-fly UAV with mounted camera is now less than $\$ 1000$ (excluding training and processing software). This also typically amounts to less than 1 h's flying time with a full-scale survey aircraft. Meanwhile, a TLS system can cost as much as $\$ 120,000$.

- Safety: the safe deployment and operation of UAVs in the field should be a normal part of the overall risk assessment for the project. Fixed-wing and rotary types both have the capability to inflict personal injury and property damage; hence the importance of regulation and the effective assessment of weather and traffic (air and ground). The UAV system should also have its own Operations Manual and logbooks for pilot and batteries. Electric power is virtually ubiquitous for small UAV and utilizes lithium polymer (LiPo) batteries; the safety aspects of which (e.g., charging and transporting) should be carefully considered.

An improved understanding of landslides and other geohazards is necessary worldwide and will have an important impact on resilience, survivability, planning, and engineering. Recent developments lead to the conclusion that "UAV photogrammetry" and "structure from motion" methods are making a significant contribution to landslide surveying, mapping, monitoring, and research, in common with many other spheres of activity in the earth sciences. New and positive experiences with UAVs are being reported at an accelerating rate, for example in the fields of agriculture, archaeology, oceanography, glaciology and virtually every other branch of observational scientific research that has an "outdoor" component. Drone video footage is now used almost universally by the media 
Fig. 14 Schematic block model of a section of coastal cliff landslide produced from UAV orthophoto, Aldbrough, UK (2013), BGS@UKRI[2018]

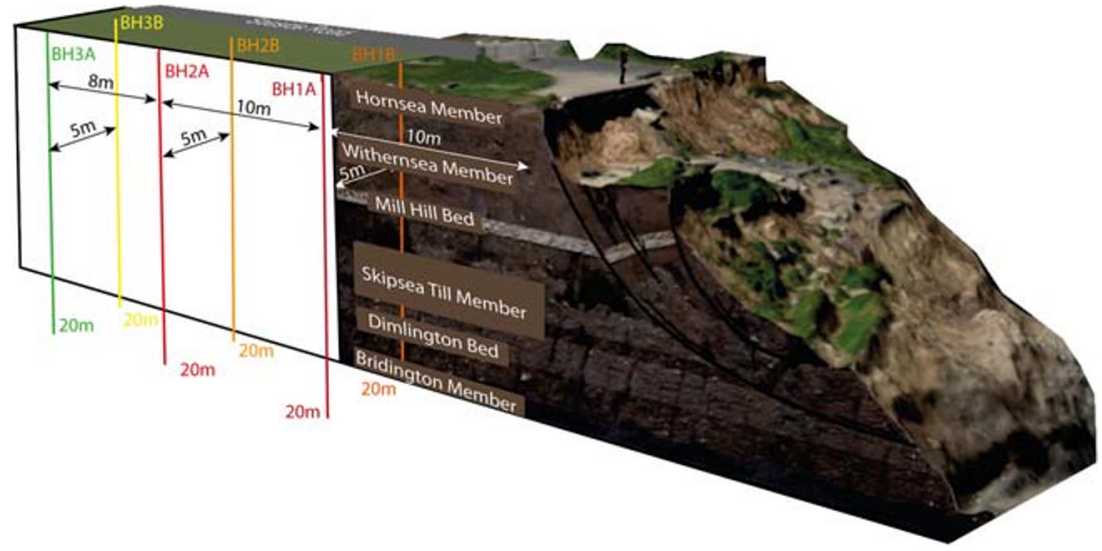

in general, and the news media in particular, allowing landslide events to be understood more readily.

\section{UAV for debris flow mapping and analysis}

Debris flows are "rapid, gravity-induced volume movements consisting of a mixture of water, sediment, wood and anthropogenic debris that propagate along channels incised on mountain slopes and onto debris fans" (Gregoretti et al. 2016). They occur in steep (mean channel gradient $>5 \%$ ) and relatively small $\left(\right.$ area $\left.<25 \mathrm{~km}^{2}\right)$ torrent catchments (Rickenmann and Koschni 2010), transporting up to several hundred thousand cubic meters of debris (Hübl et al. 2009). The high solid-material concentration in the front of the debris flow, combined with high flow velocities, makes them very destructive (Rickenmann 2001). Numerous debris flow events occur every year, substantially affecting the quality of life in mountainous regions and causing extensive damage. Oberndorfer et al. (2007) examined over 5000 debris flow events that occurred in Austria between 1972 and 2004; according to the authors, these events caused total estimated damage of $€ 965$ million and 49 fatalities. In Switzerland, Alpine torrents and debris flows cause an estimated cost of around CHF 65 million every year (Rickenmann 2001).

Promptly mapping the consequences of debris flow events by determining the spatial extent and volume of eroded and deposited material, is highly relevant to scientists and practitioners: Immediately after the event, this data can support search and rescue teams, or provide decision-support for structural and non-structural emergency measures. Subsequently, it may facilitate debris flow hazard management in many ways: foster process understanding (Theule et al. 2015; Pellegrino et al. 2015); benefit numerical simulation modeling (Rickenmann et al. 2006; Han et al. 2015); support planning and implementing mitigation measures, as well as hazard mapping (Rudolf-Miklau 2009) and integral risk management (Ballesteros Cánovas et al. 2016; Aronica et al. 2012).

Conventional techniques to map debris flow events mostly require the surveyor to access the affected area on foot. In the catchment, channel and deposition area, the surveyor measures or estimates sediment redistribution, relative to the preevent terrain height. Erosion depth and deposition height are determined at discrete locations and interpolated for area-wide volume change approximations. This procedure is very timeconsuming and hazardous and may provide only a rough estimation of terrain height changes. Furthermore, the quality of the results strongly depends on the surveyors' experience, skills and knowledge of the pre-event terrain (Scheidl et al. 2008). Therefore, the use of various remote sensing techniques has been reported for debris flow mapping, including: High-resolution satellite imaging (Youssef et al. 2016; Elkadiri et al. 2014), manned-aircraft photography (Dietrich and Krautblatter 2016), airborne laser scanning (ALS) (Kim et al. 2014; Bull et al. 2010; Scheidl et al. 2008) or a combination of the above (Willi et al. 2015). However, compared with other natural hazard events (e.g., floods, earthquakes), debris flows affect relatively small areas (usually $<5 \mathrm{~km}^{2}$ ). Mapping a single debris flow event with one of the techniques mentioned above is hampered by low cost-efficiency; data acquisition is typically only commissioned in the case of large-scale events or a sequence of events (Lindner et al. 2016).

In recent years, the development of UAV has provided a wide range of new possibilities for high-resolution monitoring and mapping (Colomina and Molina 2014; Lucieer et al. 2014). In this contribution, the term UAV refers to aircraft with a typical weight of $<5 \mathrm{~kg}$, flight times of 20-30 min, optimized for easy field deployment, recovery, and transport. In general, UAV can bridge the gap between full-scale, manned aerial, and terrestrial observations (Briese et al. 2013; Rosnell and Honkavaara 2012). They are credited as being able to allow flexible image acquisition at an unprecedented level of 
detail GSD of few centimeters or millimeters (Ryan et al. 2015). Additionally, the development of novel computer vision techniques and their implementation into a wide range of software packages have significantly reduced the requirements for the recorded data (Vander Jagt et al. 2015; Turner et al. 2012). Therefore, UAVs are very well suited for collecting aerial imagery of natural hazard events. This is reflected in a wide range of recent reports on UAV applications for mapping: landslides (Turner et al. 2015; Fernández et al. 2015; Stumpf et al. 2013; Niethammer et al. 2012), rockfall (Giordan et al. 2015; Danzi et al. 2013), glaciers (Boesch et al. 2015; Whitehead et al. 2013), and rock glaciers (Piermattei et al. 2016; Dall'Asta et al. 2015). However, to the knowledge of the authors, very few publications exist that deal with UAV-based debris flow mapping; some examples include Adams et al. (2016), Sotier et al. (2013), and Wen et al. (2011). This paper merges the authors' experience from several UAV-based debris flow mapping missions, conducted in the European Alps between 2012 and 2016, into a practical guideline. In this contribution, the debris flow specific aspects are described for each stage of a typical UAV campaign: (i) mission planning and preparation; (ii) data collection and image acquisition; (iii) data processing and analysis. To conclude, a case study of a UAS debris flow mapping campaign is briefly presented.

\section{Mission planning and preparation}

The Area of Interest (AOI) is set by outlining the region to be mapped with the UAV. In this crucial first step of a UAV debris flow mapping campaign, it is essential to define (i) the location of key debris flow event areas (deposition and erosion hotspots); (ii) the scope of the campaign, i.e., size of the study area and thus time needed for data acquisition and processing; (iii) the mapping priority of all AOIs. If the $\mathrm{AOI}$ is too small or wrong areas are defined, essential parts of the debris flow event may be missed and will thus not be documented or considered in subsequent analyses (e.g., volume-balance calculation). AOI specification should, therefore, be performed in coordination with the civil protection and/or disaster control authorities in charge. Imagery or videos from human-crewed helicopter flights recorded by other agencies might provide essential indications for correctly setting the AOI.

Two distinctly different sub-areas of a debris flow event AOI can be identified using the type of process, which the sub-area is dominated by:

1. Erosion zone: torrent catchment, bordering the deposition zone at the fan apex; the entire catchment (in hydrological terms) contributes to the water volume of the event; material sourced from scouring in the torrent channel, lateral and bank erosion as well as slope failure (Fig. 15, left).

2. Deposition zone: located in valley floor or on the alluvial cone; characterized by widespread deposition of sediment, wood or anthropogenic debris; the majority of direct and indirect damages occur here (Fig. 15, right).

Mapping the entire process area (i.e., erosion and deposition zone) allows reconstruction of the event's volume-balance. This may provide important input for process understanding and for being able to analyze the event trigger and sequence.

When settlements or infrastructure are affected by the debris flow event, communication with emergency services is very important. Be sure to make contact with the leading operational units of the civil protection and disaster relief and inform them about the planned data acquisition. The priority of UAV data acquisition may be ranked rather low if only documentation of the event is carried out, and no real-time data is delivered that would be necessary for search and rescue. Therefore, be prepared to have only a short timeframe for your UAV flight(s), which may be communicated at very short notice. Disastrous debris flow events, in particular, attract a large volume of air traffic (e.g., manned helicopters shuttling members of civil protection agencies, the press, and politicians). Keep the UAV as close as possible and always be prepared to abort data collection safely at short notice.

The choice of the most appropriate UAV platform for debris flow mapping depends on the size of the AOI. To cover small AOIs $\left(<1 \mathrm{~km}^{2}\right)$, e.g., the deposition zone, it is expedient to use rotor UAV; to map larger areas $\left(>1 \mathrm{~km}^{2}\right)$, e.g., the erosion zone, a fixed-wing UAV is better suited. The main priority of flight planning must be safe UAV operation under challenging frame conditions. These include, but are not limited to, (i) poor weather conditions directly following the event (high likelihood of precipitation, limited visibility, overcast sky); (ii) high frequency of air traffic; and (iii) limitations due to clearing up operations in the AOI. Minimum technical requirements for the UAV campaign (e.g., spatial resolution or image overlap), should be defined in the preparation phase but should be conservative and given lower priority. The flight areas (in particular in the deposition zone) should be limited in size while ensuring efficient data acquisition. This provides the pilot with more flexibility in detecting and dealing with potential flight interruptions.

Legislation regarding UAV operation should be scrutinized. Depending on the national law, special rules may apply, and additional certification might be necessary to fly over groups of people or in densely settled areas. The responsible national authorities may be able to provide a certificate of exemption in case of emergencies.

\section{Data collection and image acquisition}

Data collection should take place as soon as possible after the event, to document as much unadulterated process area as possible. Generally, priority should be given to the deposition 
Fig. 15 Post-event view of a debris flow channel (a); the aftermath of a debris flow event in Western Austria (b) (9 June 2015; Stubaier Alps, Austria; Pittracher)
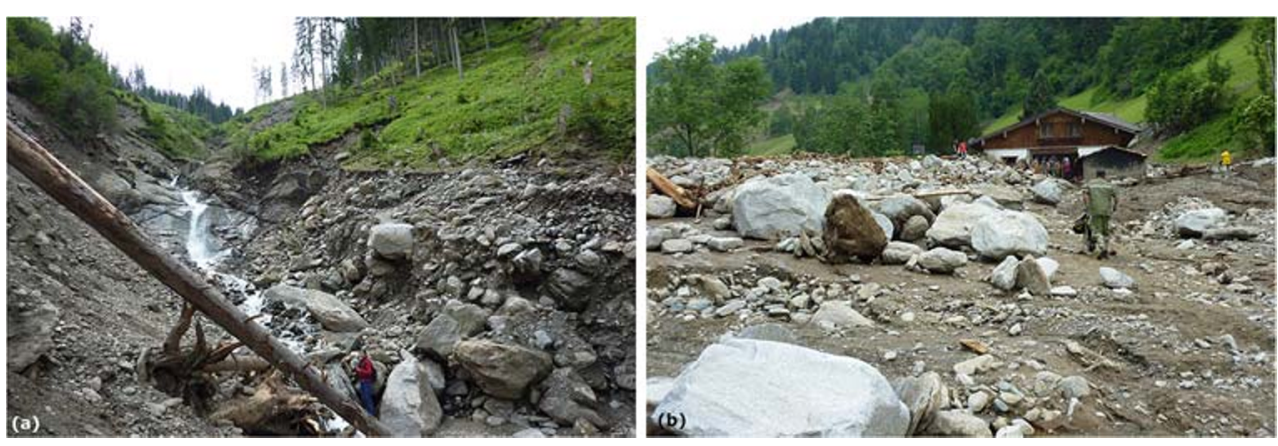

area, as clearing up operations will be carried out soon after the event, especially if the debris flow deposit affected settled areas or roads that need to be cleared. Promptly supplying the emergency services with UAV-based mapping results may, additionally, give valuable support to short-term disaster relief efforts. Furthermore, civil protection agencies can be supplied with current, reliable decision-support from UAV data, for planning and implementing mid- to long-term hazard mitigation measures. Keep in mind that a few high-resolution aerial images or videos from key areas, supplied to the responsible authorities as soon as possible, may often be more helpful than georeferenced orthophotos.

We recommend using ground control, i.e., placing reference points (RP) at predefined locations in the AOI and surveying them with high-quality terrestrial global navigation satellite systems (GNSS) units. This ensures adequate positional accuracy of the photogrammetrically reconstructed terrain heights, which are in turn essential to calculate erosion depths and deposition heights or the event's volume-balance. In case survey-grade (e.g., real-time kinematic) positioning sensors are available on board the UAV to determine location and orientation, the number of these RPs can be limited to 1-3 per flight area (depending on the size and topography of the area). The location of the RPs should be planned before conducting the fieldwork, as navigating debris flow terrain on foot may be difficult.

Accessibility to the site is very likely going to be limited or partially impossible; check with the civil protection agencies in the field as to which locations are safely accessible. In the deposition area, be careful to avoid areas with ongoing search and rescue operations or where heavy machinery is operating. Access to the erosion zone in particular may be limited, as roads leading into the catchment are most likely to be affected by the debris flow event (e.g., due to slope failure or bank erosion).

For image acquisition, a UAV-compatible daylight camera with maximum sensor resolution should be used. This allows the highest possible level of detail in the imagery, which may be crucial to certain parts of the event documentation (e.g., analyzing distribution, size, and magnitude of different grain sizes or wood debris in the deposition). When calculating terrain height change caused by a debris flow event, the level of detail will be less important, as the limiting factor is more likely to be the spatial resolution of the pre-event terrain data. Besides collecting imagery for photogrammetric reconstruction, video sequences offer an additional interesting source of information. This holds especially true for sections of the debris flow channel, where scouring and lateral erosion is likely to create very steep or overhanging banks, which will not be very visible in the final orthophoto.

\section{Data processing and analysis}

Processing the UAV imagery is usually performed with offthe-shelf or custom structure from motion photogrammetry software (for a comprehensive review on available software options, see Nex and Remondino 2014 or Colomina and Molina 2014). Standard outputs are orthophotos and digital surface models (DSM). The latter generally refers to the height of the terrain, buildings or vegetation, captured in the scene (Adams et al. 2016). The DSM is interpolated from a dense point cloud (DPC), generated with multiview stereo reconstruction as part of the photogrammetric workflow (Vander Jagt et al. 2015). Before calculating terrain height change, all objects on or above the terrain should be removed, e.g., by classifying the DPC as ground and non-ground points, and subsequently generating a digital terrain model (DTM).

The use of photogrammetric DTMs is limited in densely forested areas, as only few ground points are recorded. Therefore, masking out the process area before calculating terrain height change may avoid potential errors (Adams et al. 2016). In case different vertical coordinate systems are present in pre- and post-event data, this might cause misalignment of the DTMs and introduce systematic error into the volume-balance calculation. If this is a potential issue, make sure to place RPs in areas undisturbed by the debris flow so that terrain height can be extracted from the pre-event DTM.

\section{Case study}

On 7 June 2015, an intense, almost stationary thunderstorm with hail occurred in the Saigesbach catchment, located in the Sellrain Valley (Stubaier Alps, Austria). It resulted in up to 110-mm precipitation within $6 \mathrm{~h}$, triggering a debris flow, 
which covered parts of the valley floor with a large alluvial cone. Two buildings were totally destroyed and 15 damaged. Three road bridges were damaged or destroyed, the primary road connection was impacted over a length of $300 \mathrm{~m}$ and interrupted for several months; four hectares of green and willow land was affected; no damage to persons occurred, but livestock was lost. The total damage was calculated to be approximately $€ 30$ million (ORF 2015).

The UAV mapping mission was conducted to document the event and provides the total volumetric sediment budget. The deposition area (size, $0.3 \mathrm{~km}^{2}$ ) was mapped on 9 June 2015 with an AustroDrones X18 multicopter, fitted with a Sony Alpha 7R (+35-mm prime lens) that collected a total of 640 images on two flights. The catchment (size, $2.5 \mathrm{~km}^{2}$ ) was mapped on 26 June 2015 with a Multiplex Mentor fixedwing UAV, fitted with a Sony NEX5 (+50/16-mm prime lenses). Four flights were carried out to collect a total of 4000 aerial images. Additionally, 30 RPs were distributed throughout the deposition area and catchment, their location was recorded with terrestrial GNSS (Trimble GeoExplorer XT 2008, expected accuracy $x / y 0.1, z 0.2 \mathrm{~m}$ ).

Pre-event terrain heights were derived from prior airborne laser scanning campaigns (2009 and 2014), with a ground sampling distance of $1 \mathrm{~m}$ (catchment) and $0.5 \mathrm{~m}$ (deposition area). The UAV images were processed in Agisoft Photoscan (version 1.1.6) and the DPC classified into the ground and non-ground points. The resulting orthophotos (Fig. 16a) and DSMs (Fig. 16b) of the valley floor and catchment featured a GSD of $0.02 / 0.05 \mathrm{~m}$ and $0.08 / 0.2 \mathrm{~m}$, respectively, with lower GSD in the catchment. The total debris flow volume-balance calculation showed that $265,000 \mathrm{~m}^{3}\left( \pm 42,000 \mathrm{~m}^{3}\right)$ material was mobilized in the catchment, of which $45,000 \mathrm{~m}^{3}( \pm$ $13,000 \mathrm{~m}^{3}$ ) settled there; of the material that reached the valley floor, 120,000 $\mathrm{m}^{3}\left( \pm 5000 \mathrm{~m}^{3}\right)$ was deposited there, while another $10,000 \mathrm{~m}^{3}\left( \pm 2000 \mathrm{~m}^{3}\right)$ was eroded (Fig. 16c, d). Details of this campaign and its results have been published in Adams et al. (2016).

\section{The use of UAV for rock mass classification and structural analysis}

Rock mass characterization has always been a challenging aspect to analyze the different modes of failure of both natural and human-made slopes. Rock collapses can be due to a series of predisposing and triggering factors, mostly depending on localized geological conditions. According to Zajc et al. (2014), hazardous situations may occur when unfavorable sedimentological characteristics and geological discontinuities (e.g., fractures, faults) of rock masses are made even more critical due to the realization of engineered slope-cuts (e.g., stone extraction, civil infrastructures). At the same time, Zheng et al. (2015) underlain the crucial role played by morphological features, like sharp cuts and steep slopes, for the triggering of rockfalls in mining areas. As demonstrated in the literature, the understanding of geometric relationships between geological discontinuities and slope morphology is essential to evaluate the potential occurrence of rock failures, since the orientation of fracture sets may influence both size and failure mechanisms of rock blocks prone to collapse (Stead and Wolter 2015).

Generally, fracture characterization is carried out in the field by traditional engineering-geological surveys (Priest 1993). Data are traditionally obtained from scan-line mapping using the following technical equipment: (i) geologist's compass with clinometer; (ii) closed case steel tape $50 \mathrm{~m}$; (iii) Schmidt hammer; the output data consists of the arithmetic mean of 10 values of $R$ (rebound index) measured through the same number of percussions on a rock surface preliminarily prepared with a carborundum stone; (iv) Barton comb (profilometer) and comparison profiles, as proposed by Barton and Choubey (1977), for surface roughness determination on rock discontinuities; (v) Vernier caliper for the measurement of rock discontinuities aperture in a centimeter and millimeter scale; (vi) flexometer in steel tape for the measurement of rock discontinuities spacing and trace length of centimetric or higher order.

Measurements may be subjected to different sources of errors, which can result in under- or over-estimation of the fracture geometrical properties (Tuckey and Stead 2016). To limit the impact of those errors, Sturzenegger and Stead (2009) suggested to couple traditional field measurements with remote sensing techniques. Indeed, techniques such as terrestrial laser scanning (TLS) and digital terrestrial photogrammetry (DTP) for rock mass characterization are increasingly being used, especially in engineering contexts where rock slopes subjected to excavation are analyzed (e.g., Kovanič and Blištan 2014; Salvini et al. 2015; Tuckey and Stead 2016). TLS and DTP allow accurate representation of rock outcrops employing stereoscopy, 3D textured point clouds, and interpolated models. A limitation of groundbased remote sensing is related to the survey of complex topography from sub-optimal camera or scanner positions, resulting in occlusion zones (Passalacqua et al. 2015). A solution to this problem is provided by the use of UAV as a platform to acquire either optical photogrammetric images or LiDAR data. There are several photogrammetric studies where UAV is used for the geomorphic feature characterization or mapping of the surface extent in both natural and open-pit mines (Lamb 2000; Chen et al. 2015; Shahbazi et al. 2015; Tong et al. 2015; Esposito et al. 2017). Few of them deal with the use of UAV for fracture characterization of rock slopes affected by human activity. Salvini et al. (2017), for example, used UAV to map fractures in a marble quarry and, subsequently, to build 3D discrete fracture network models. McLeod et al. (2013) explored the feasibility of using UAV- 

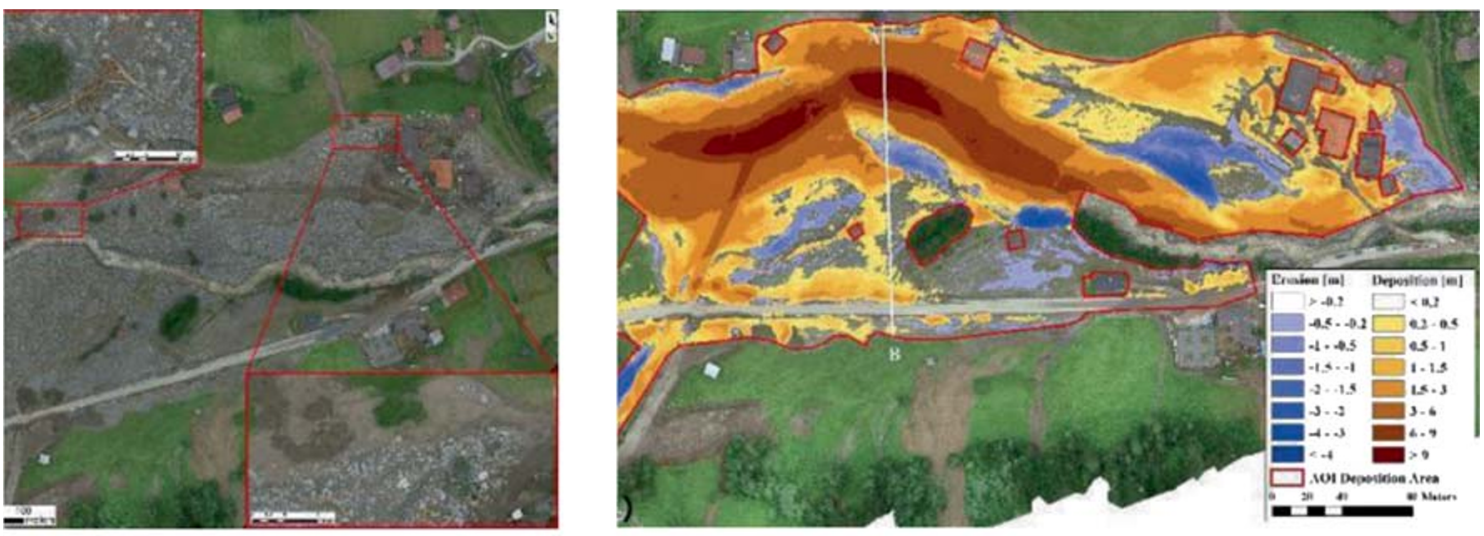

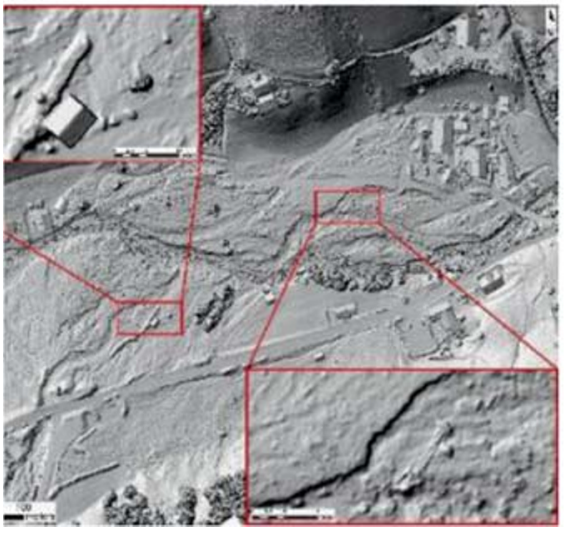

Fig. 16 Results from the photogrammetric processing in the valley floor: orthophoto (a), digital surface model (b), volumetric sediment budget calculation (c). Panel $\mathbf{d}$ shows a cross section through the pre- and post-

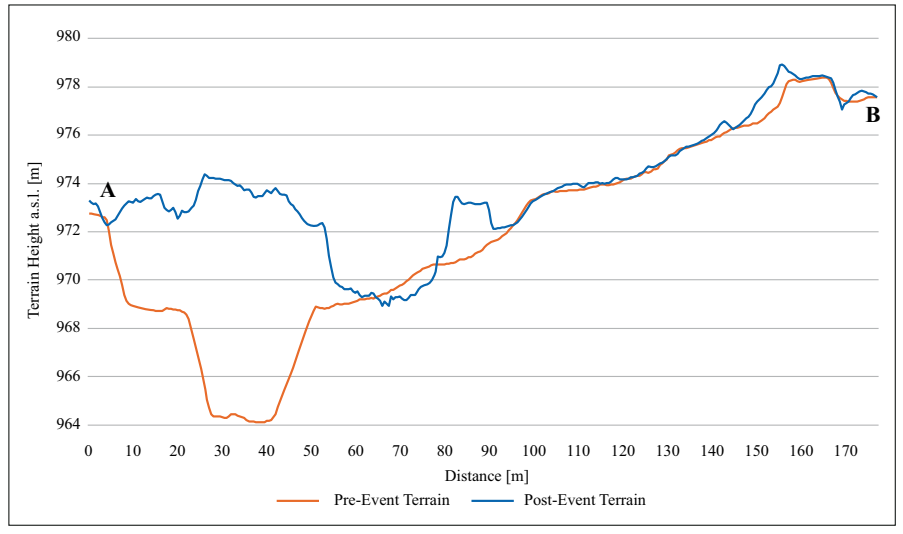

event DTM; the location of the cross sections are indicated by the white lines in (c), (A) and (B) marking the starting and endpoints

In UAV SfM applications, care is needed when georeferencing the 3D model. As stated by Passalacqua et al. (2015), cameras fixed to UAV typically do not have onboard navigation systems with sufficient accuracy for geodetic positioning. The global navigation satellite system (GNSS) and inertial measurement unit (IMU), devices typically mounted on UAV, are used for navigation and flight stabilization purposes and allow only a rough estimation of airborne camera exterior orientation (Gonçalves and Henriques 2015). To obtain accurate and georeferenced 3D models, the use of ground control points (GCPs) surveyed with geodetic GNSS receivers and/or total station (TS) is generally employed (Francioni et al. 2015) and recommended. Nevertheless, the final accuracy is dependent not only on the GCP-related accuracy, density, and distribution within the surveyed area but also on image quality and percentage of overlap between single frames. TS is particularly useful for the acquisition of GCPs on vertical slopes (Menegoni et al. 2019). GCPs measured using TS and GNSS receivers can allow a high level of accuracy in the images exterior orientation, which is particularly important for subsequent fractures and rock block measurements. Therefore, careful planning of an UAV photogrammetric survey plays a crucial role in and for improving engineering-geological investigations. 
providing accurate results necessary for subsequent analysis, such as determination of fracture measurements in terms of orientation (dip direction and dip, Fig. 17), spacing, waviness and trace length.

The latter, in particular, is among the controlling factors that have the most significant influence on the stability condition of a block or slope, but it is challenging to be accurately determined. In this regard, UAV photogrammetric data of high resolution may play a crucial role, improving the level of knowledge of the rock mass. Recent studies by Mastrorocco et al. (2016) have also analyzed the possibility of measuring the joint roughness from RPAS-derived point clouds.

3D data from UAV SfM can be also used to perform a preliminary rockfall hazard assessment knowing the geological setting at different heights. The localized geo-structural conditions may cause different types of failures with different magnitudes. Slope stability analyses are therefore essential to improve safety conditions and management operations. However, a complete analysis of all the slopes characterizing a versant is often problematic, given their spatial extension. For this reason, both geological and geomorphological information of the whole studied area are essential to detect and evaluate the most hazardous situations. UAV-derived data should be therefore integrated with those acquired in the field from a traditional geological and engineering survey; additional info as, for example, fracture resistance, infill, weathering, and water content, can only be measured by direct observation in accessible outcrops. The combined use of these data can allow preliminary $3 \mathrm{D}$ analysis and evaluation of the stability conditions of hazardous aspects that may be identified as posing a risk to a slope.

As demonstrated by Salvini et al. (2018), the application of UAV instrumentation can be extremely successful for the reconstruction of complex morphology in sites where groundbased techniques have limitations due to potential "shadow" effects and several inaccessible setup zones due to safety reasons.

Among the most diffuse apparatuses, also near-infrared and thermal cameras can be mounted on UAV. Near-infrared images can be used to identify minerals so to discretize rock lithologies, to investigate the homogeneity of the rock masses and to assess the humidity and weathering of the rock surface, which may indicate the presence of altered areas prone to rockfall event. The thermal camera can be adopted in areas where, in addition to common impulsive triggers (i.e., heavy rainfalls, dynamic inputs such as earthquakes or anthropic vibrations), consistent thermal excursion exists. Rock masses can react to continuous cyclical thermal inputs, which can operate on wider time-windows configuring as a preparatory factor for rock block failure. Cyclical thermally induced stresses are regarded to operate as microstructural fatigue processes responsible for mechanical weathering of the rock interface able to induce plastic strain and propagation of existing cracks (Fiorucci et al., 2018).

In addition to the described output, UAV can be used for the following measurement and mapping purposes: (i) map faults, folds, and other structures and trace them with high location and orientation accuracy; (ii) calculate block volumes; (iii) create contour maps and cross sections; (iv) detect changes caused by erosion or slope failure using photos acquired at different times.

Apart from these opportunities, possible limitations in the use of UAV can only be related to the need for user experience both in the fields of engineering-geological survey, topographic survey, and data processing. Indeed, the accuracy of the final 3D model can be significantly affected by the quality of data collected (photos, point cloud, and GCPs), data processing, hardware, user expertise, and, lastly, software capability. It is important to remember that UAV is just a machine intended for specialized operations or for experimental, scientific or research activities, which allows an operator to bring by air a payload (such as a camera, LiDAR) to carry out a geomatic survey from an optimal point of view. In recent years, the development of SfM methods, together with rapid technological improvement, has allowed the widespread use of cost-effective UAV for acquiring repeated, detailed, and accurate geometrical information. However, the quality of results in rock mass classification and structural analysis is still necessarily dependent on in situ checks and operator knowledge.
Fig. 17 Example of joint dip and dip direction measurement directly on the UAV-derived point cloud

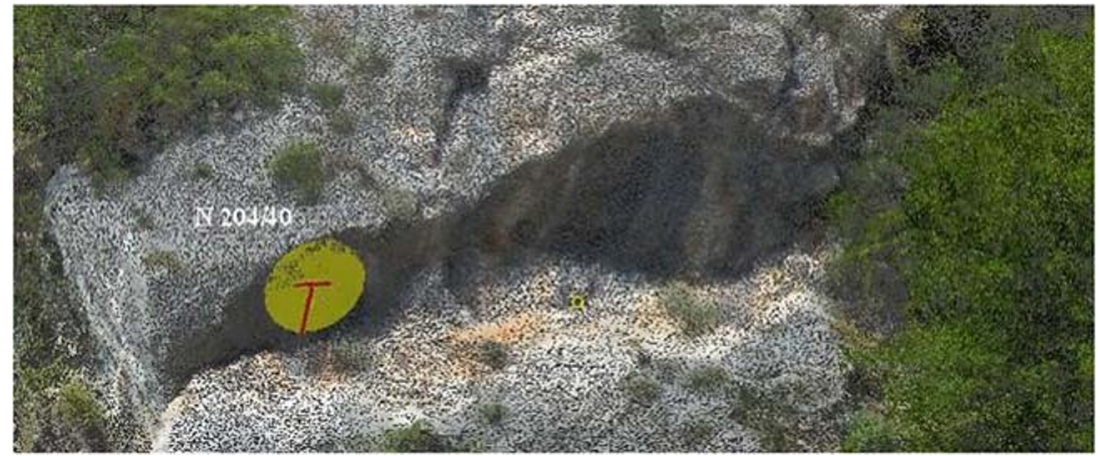




\section{Main applications of UAV in hydrology}

Although UAV has become standard tools for carrying out numerous analyses in fluvial geomorphology (e.g., Witek et al. 2013; Casado et al. 2015; Woodget et al. 2015; Miřijovský and Langhammer 2015; Miřijovský et al. 2015; Woodget et al. 2017; Langhammer et al. 2017a), their use in hydrology is less common. Hydrologic applications of UAV mainly include the following topics: monitoring water bodies, inundation monitoring, water level measurements, flow measurements, hydrodynamic modeling, snow cover monitoring. In this section, these applications are presented with a particular emphasis put on the use of drones to support mathematical simulations in hydrology.

One of the most straightforward applications of UAV in hydrology is monitoring water bodies, including ocean, lakes, and rivers. Such monitoring activities are usually carried out in a planar view. The possibility of utilizing several sensors enables the integration of UAV with other remote sensing and in situ measurements and observations of the oceans (Lomax et al. 2005). Due to limited UAV range, the observations of the oceans are limited to coastal regions. However, recent developments in multi-UAV solutions make ocean monitoring more reliable (Braga et al. 2017). Small inland water bodies can also be monitored by UAV, as demonstrated by Pásler et al. (2016). They compared the potentials of UAV with the skills of satellite Landsat 7 and 8 observations and provided the supportive case study evidence of the UAV potentials in monitoring ponds near Pardubice (Czechia) using the visible light sensors. Such applications include different types of lakes, including those which are difficult to reach, e.g., supra-glacial lakes (Immerzeel et al. 2014). Similarly, UAV
Fig. 18 Hydrograph of the Ścinawka river in Gorzuchów (SW Poland) along with two selected 3-h predictions of water level, issued $3 \mathrm{~h}$ before the UAV observation, based on the vector autoregressive model (VAR) run within the HydroProg system (a), UAV-based orthophoto maps of terrain adjacent to the hydrologic gauge in Gorzuchów for mean stages (b), high flows above warning water level (c), and high flow above emergency water level (d)

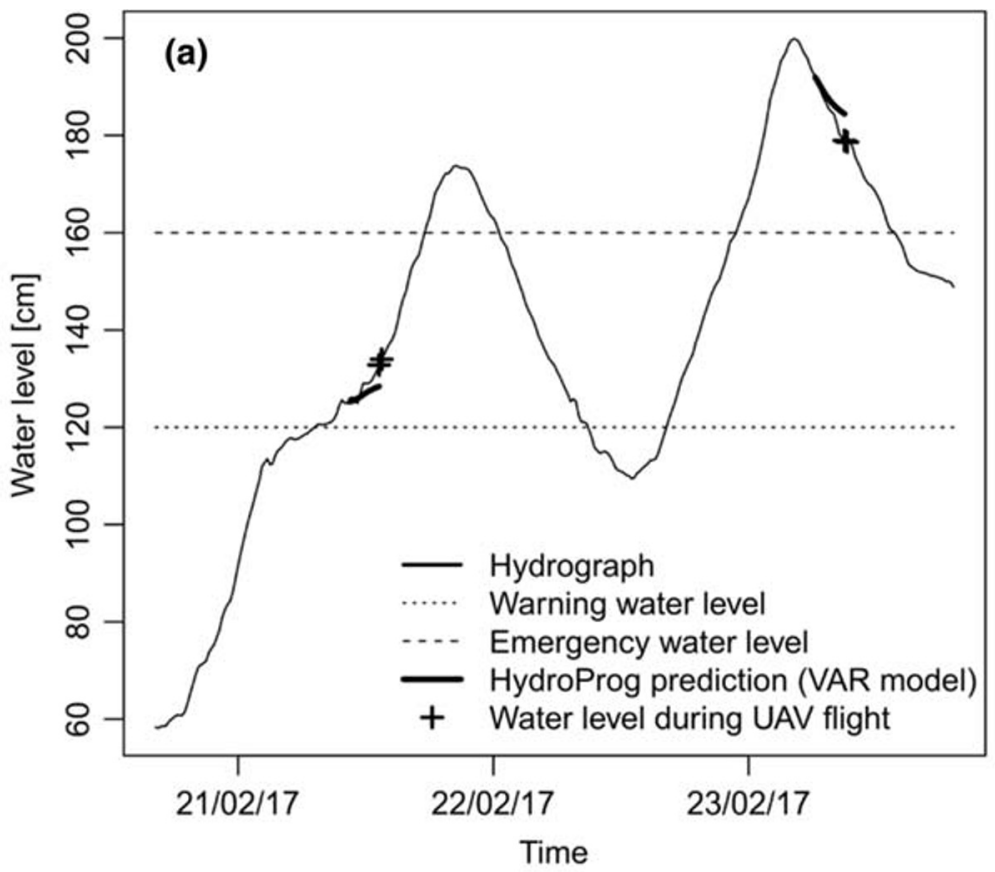

MEAN STAGES (27/09/2013)

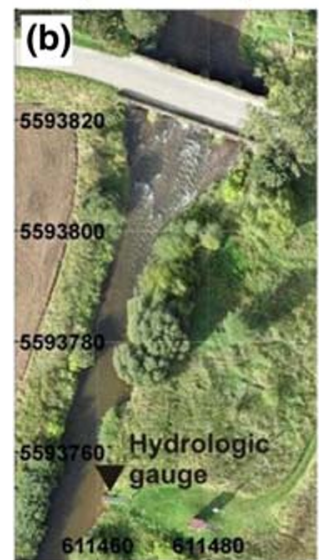

ABOVE WARNING (21/02/2017)

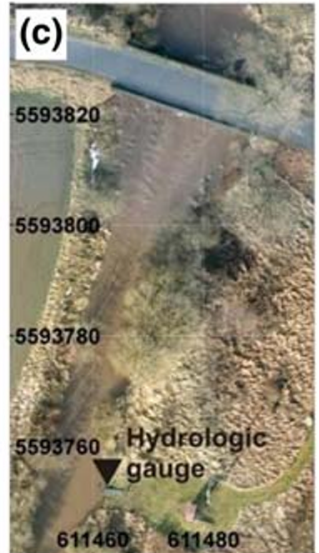

ABOVE EMERGENCY (23/02/2017)

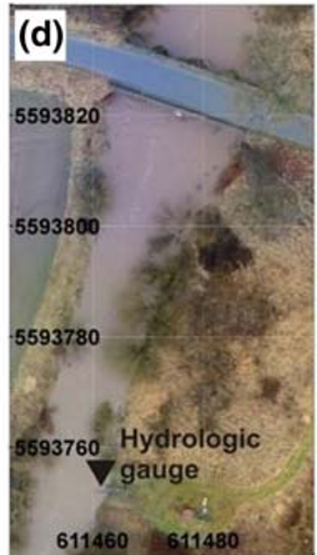


are used to monitor rivers, as exemplified by Flener et al. (2013), Miřijovský et al. (2015), or Woodget et al. (2017). In particular, UAV are useful in observing flood inundation. In this context, it is worth referring to the paper by Feng et al. (2015) and Giordan et al. (2018) who presented the method for mapping flood extent in the urban environment.

Monitoring river in a planar view, including inundation or less pronounced signatures of high flows when no overbank flow occurs, are also important in the river modeling experiments. When the flood extent is modeled, it is necessary to validate the model outputs. The latter is a spatial data (a numerical map) and therefore cannot be easily checked against pointwise marks of where the water reached during the flood. Liu et al. (2014) identified the weaknesses of the traditional flood inundation survey and claimed that, for instance, roads might be inaccessible during severe meteorological events which can constrain collecting information on water extent. Drones may fill this gap when they are deployed in near-realtime during the flood occurrence. Superimposing model simulations onto the corresponding UAV-based orthophoto image enables to validate the model outputs. Initial concepts of this approach were provided by Witek et al. (2014). However, the feasibility study was offered by Niedzielski et al. (2015) who used the hydrodynamic model FloodMap in association with the HydroProg prediction system to determine the water extent forecast, the skills of which was validated using a UAV-based orthophoto. The hydrologic prediction serves as the driver to make a decision on sending the UAV team with the mobile UAV lab to the field to monitor the dynamics of flooding. This concept has been tested in near-real-time (Fig. 18).

Likewise, Langhammer et al. (2015) carried out hydrodynamic modeling with the MIKE SHE approach, and the UAV photogrammetry was also used for model validation. However, the validation was conducted indirectly, i.e., not through the UAV observations of water surface, but through UAV-based observations of morphological changes in a river recorded at dissimilar time steps. The above-mentioned changes are consequences of flood events which have geomorphological effects and clear imprints on river landscape morphology.

Along these lines, observing water surfaces and calculating water surface area using the UAV-acquired imagery remain key activities in the accurate validation of hydrodynamic models. Niedzielski et al. (2016) presented the method for observing statistically significant changes in water surface area and, as a consequence, interpreted these changes in the light of river stage fluctuations. Therefore, oblique imagery taken by UAVs can also serve the purpose of rough water level assessment. Likewise, UAVs may also be used to estimate flow characteristics at low cost (Detert and Weitbrecht 2015; Bolognesi et al. 2017; Detert et al. 2017).

The UAV-based investigations into rivers go beyond monitoring and measurement activities, which of course are valuable when validating hydrologic and hydrodynamic models, and are employed to build the models themselves. For instance, Tamminga et al. (2015) made use of a quadcopter UAV, collected aerial images and produced a 5$\mathrm{cm}$ digital three-dimensional terrain model, with a correction for submerged topography. It was used to run the River2D hydrodynamic model to improve habitat mapping. As a digression, it is worth noting here that the UAV-based habitat mapping in a microscale has recently been shown as a method that enables to go beyond mesoscale, often subjective habitat mapping approaches (Woodget et al. 2016). Another example of using UAVs for mathematical simulations in hydrology is presented by Langhammer et al. (2017b) who reconstructed the stream channel in three dimensions using high-resolution UAV-acquired aerial images and arrived at the resolution of $1.5 \mathrm{~cm} / \mathrm{px}$. Such a level of details enabled to utilize the UAVbased digital surface model (DSM) as one of the datasets to calibrate the MIKE 21 hydrodynamic model.

Flood predictions are also issued for snow-melt episodes. To assess such hazards, the rapid estimation of snow depth (HS) and, more importantly, snow water equivalent (SWE) is needed. For large- and mediumsize basins, satellite observations serve well the purpose of snow cover monitoring. However, satellites offer a too low spatial resolution for quantitative assessment of snow-melt flood risk in small basins. This gap can be filled by UAV which, along with advanced image processing methods, may be used to collect highresolution data (Vander Jagt et al. 2015; De Michele et al. 2016; Bühler et al. 2016). If the information on high-resolution variability is available automatically and in near-real-time, it can be promptly used to infer the possible magnitude of snow-melt episodes (Adams et al. 2018) or, more importantly, can serve as one of two input variables to get SWE estimates (Miziński and Niedzielski 2017). Such UAV-based data can subsequently be used by mathematical models to calculate predictions of snow-melt high flows.

The most common approach to process UAV-acquired oblique aerial images is the structure from motion (SfM) algorithm which enables to produce dense point cloud and, subsequently, DSM, and orthophoto, the resolution of which is very high (Westoby et al. 2012). The successful use of UAV in hydrology, where changes occur rapidly, requires reproducibility of the DSM reconstructions (Fig. 18). To ensure reproducibility different methods can be employed (separately or in combination), for instance, the appropriate use of GCP measured by the GNSS receiver (Clapuyt et al. 2016), the appropriate flight strategy (James and Robson 2014), the use of real-time kinematic (RTK) solution (Harder et al. 2016), or automated georeferencing to known land cover objects such as trees (Miziński and Niedzielski 2017). 


\section{The use of UAV for glacier monitoring and zglacial outburst flood risk mitigation}

Glacial environment is characterized by a very high dynamicity because of its intrinsic sensitivity to temperature, to climate changes, and to the natural ductile and fragile deformations that occur in ice. One of the main consequences of this aspect is the likelihood of very rapid topographic changes that can be clearly noticed on seasonal scale, but that can be detected at almost daily if supported by a high-resolution topography analysis. The multi-temporal approach can be very useful for the study of the evolution of glaciers, and the use of UAV can be a good solution for the acquisition of several dataset with a good cost-benefit ratio aimed to the acquisition of a high temporal frequency multi-temporal topographic survey (Ryan et al. 2015).

\section{The Grand Croux Centrale Glacier case study ( Aosta Valley, Italy)}

The Grand Croux Centrale Lake is a proglacial lake that has started forming since year 2000 on the left snout of the Grand Croux Centrale Glacier, reference to Fig. 19, located in the Valnontey Valley (Aosta Valley Region, NW Italy). The lake gave evidence of subglacial outburst flood (GLOF) in 2016, when local authorities documented it and more than 60 people had to be evacuated from the bottom valley area, where their houses could be reached by the flood wave. After this first recent event, regular observations of the lake formation started by means of Sentinel 2B satellite optical images monitoring. Even though the lake did not form again in 2017, observation of Planetscope satellite optical images in 2018 was useful for the identification of the lake formation in late spring. Thus, an UAV survey was performed to assess the lake dimension. The results of the survey demonstrated a consistent lake area expansion with respect to 2016 limit (Table 14). Local government decided to undertake specific monitoring actions considering the following critical elements: (i) the real possibility of a new sudden emptying of the lake, (ii) the higher impact of the flood due to the improvement of the water volume with respect to 2016 event, and (iii) the higher probability of a new GLOF during the summer season, when the touristic frequentation of the valley is at its peak. Monitoring actions consisted at first in a bathymetric survey that allowed a first estimation of the total water volume $42000 \mathrm{~m}^{3}$, and the subsequent installation of a pressure sensor in order to receive an alert in case of a sudden water level decrease. A GLOF numerical simulation was performed adopting the HEC-RAS software. These first results of this simulation were fundamental for the definition of the potential area exposed to the flooding risks downstream to the lake by evaluating flooded areas vulnerability. The risk assessment analysis allowed the local authorities to define actions for the population safety. First, a detailed topographic survey by means of UAV photogrammetry and RTK GPS was performed on the lake area and the adjacent ice dam. This permitted the proper installation of water pumping system. A ground-penetrating radar (GPR) survey of the ice dam was performed to assess ice thicknesses; the snow depths of the studied area were measured to estimate the snow water equivalent (SWE) availability.

The water pumping procedure was activated to reduce the GLOF risk level. When the safety water level was reached, another UAV survey of the dried lake area was carried on to support the design of a drainage channel excavation for the permanent lake water level management. The water level reduction by means of water pumping was proven to be efficient, and prevented any GLOF event during the summer, but it cannot be considered a permanent solution. The creation of a
Fig. 19 Grand Croux Lake area expansion from 2005 to 2018. The flowpath of the subglacial outburst flood is indicated as well as the location of the prospected drainage channel excavation. Glacier retreat is highlighted, as further regression could lead to total ice dam failure

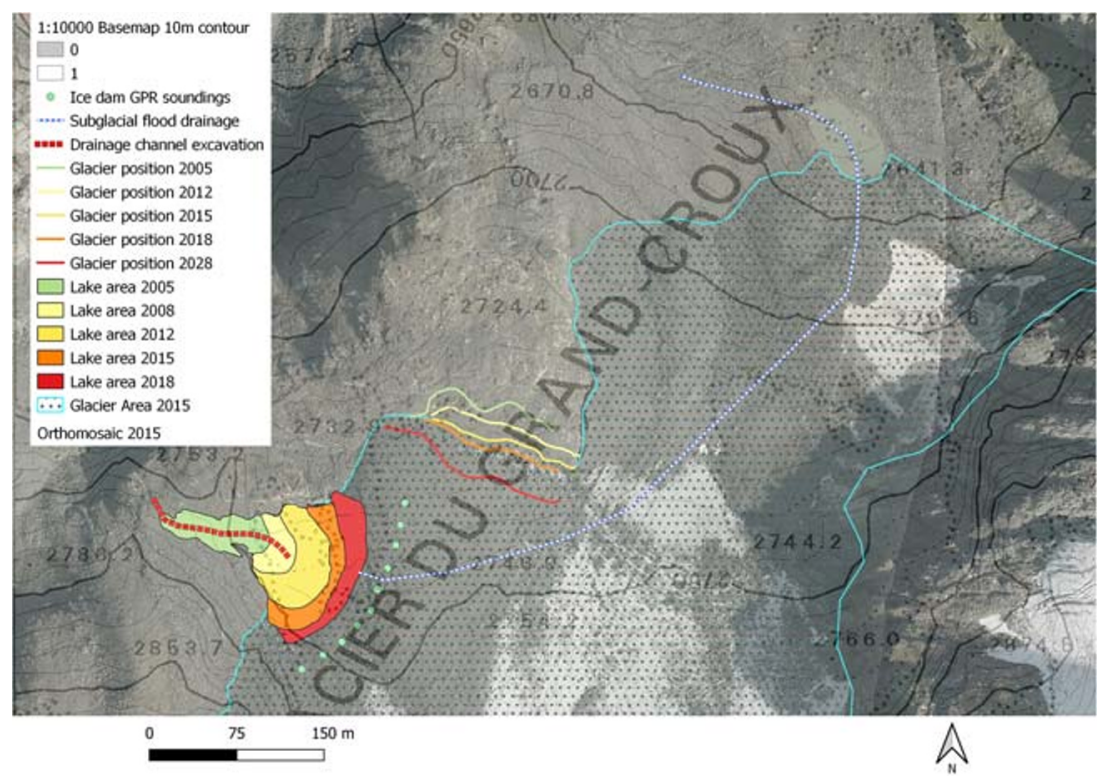


Table 14 Grand Croux Lake area measurements and subsequent expansion rates for the considered timespans. The expansion of the lake starts with a reduced rate, due to the shallower water towards the west part, and becomes almost linear as the deeper lake area is reached towards the eastern part

\begin{tabular}{lll}
\hline Year & Lake area $\left(\mathrm{m}^{2}\right)$ & Expansion rate $\left(\mathrm{m}^{2} /\right.$ year $)$ \\
\hline 2005 & 2258.90 & $/$ \\
2008 & 3235.85 & 325.65 \\
2012 & 6331.53 & 773.92 \\
2015 & 8377.48 & 681.98 \\
2018 & $10,555.54$ & 726.02 \\
\hline
\end{tabular}

drainage channel that hamper the possibility to the lake to reach again a critical volume of water was considered a better solution. The excavation was subsequently finalized in October, and the water level was lowered permanently by $3.4 \mathrm{~m}$ from the original level (with a volume reduction of more than $21,000 \mathrm{~m}^{3}$ ). Multi-temporal UAV surveys performed from June to the end of the field activities gave a detailed insight on the evolution of the lake ( 7 surveys from June to October with an average orthomosaic resolution of $1.5 \mathrm{~cm} /$ pixel). Thus, evolution scenarios were provided by combining the GPR data with the expansion rates of the lake.

\section{Materials and method}

The study site is located at an altitude of $2800 \mathrm{~m}$ above sea level, at a 4-h walking distance from the nearest road. The major problem of this specific site was determined by the need of helicopter transportation for people and materials. Moreover, the payload of helicopters compared from sea level would drop by $50 \%$ at $2800 \mathrm{~m}$ in summer conditions. As an example for the complications linked to the high altitude operations, the excavating machine that was chosen for the excavation of the drainage channel, the lightest available with a vertical movement of the arm of at least $4 \mathrm{~m}$ had to be unmounted into pieces lighter than $600 \mathrm{~kg}$ to be transported using the available helicopter. The study site is inside a National Park that implies the presence of additional restrictions for timing, dates and flight paths of helicopters and UAVs rides. The UAV platform used for 2018 surveys was different. The first survey was done using a DJI Inspire 1 equipped with a DJI FC350 Zenmuse $\times 3$ camera with $6.17 \times 4.55-\mathrm{mm}$ sensor, and an automated flight track. The DJI Inspire 1 survey was planned at $100 \mathrm{~m}$ above ground with automatic flight over selected waypoints. The flight controller managed the flight elevation using the available 2008 airborne Lidar DTM. This first fly result pointed out a significant glacier volume reduction with respect to 2008 DTM, and also the topography of the lake surroundings became more regular allowing a lower fixed altitude for following flights. GCPs distribution was planned to be as more homogeneous as possible, but they had to be set on bedrock outcrops, as all the boulders of morainic origin could possibly result unstable. After the first flight, all GCPs were removed but fixed GCPs have been later sprayed with acrylic paint to be used without repositioning. A set of 11 principal GCPs were painted as red/ white 4 sections squares, additional 22 secondary GCPs were painted as smaller red dots, to be used in case of disappearing of principal GCPs under snow or mud. The position of GCPs was carried out with two GNSS Trimble R10 antennas in RTK-VRS configuration.

After the elaboration of the first survey, the Fondazione Montagna Sicura researchers planned to repeat other surveys with a smaller UAV. The selected system was a DJI Spark multicopter, modified with carbon parts to enter in a special category (under $300 \mathrm{gr}$ ) of the Italian UAV regulation. The use of a small drone that could fit into a backpack limited the logistic complexity of the survey operation. Using a DJI Spark, fixed altitude strips would give more flight time on a single battery respect to the terrain following option because of less energy use related to the minor altitudinal changes along the flight paths. The camera acquisition was defined using a 3-s interval setting, with an average flight velocity $2.78 \mathrm{~m} / \mathrm{s}$, and considering an average forward overlap of $82 \%$; the single image average footprint was $63 \times 47 \mathrm{~m}$ and mean GSD was determined subsequently an average of $1.59 \mathrm{~cm} /$ pixel on the single images. The resolution of $2 \mathrm{~cm} /$ pixel was considered enough for the glacier dynamics analysis. Manual flight mode was chosen to manage the presence of a steep flank of the lateral moraine of the Grand Croux glacier that is very close to the flight path. The frequent presence of helicopters in the area of interest required an immediate landing procedure.

Structure from Motion (SFM) technology was used for process the UAV-acquired image dataset. In the SFM reconstruction process. As long as lake surface would be frozen, the reconstruction of lake area worked correctly, but when the water surface was reconstructed was ice-free some problems in the point cloud reconstruction required the post-processing reconstruction of the lake surface. Absolute error of the GNSS position of the GCPs was under $1.5 \mathrm{~cm} X Y$ and under $2 \mathrm{~cm} Z$ for all the points and could be considered acceptable for the purpose of the surveys. Total Images shot on a single survey varied from 300 to 600 , depending on the time available for the survey, single subparallel strips were chosen for the more rapid surveys. Older available cartography and elevation models of the area used for a multi-temporal analysis are the 1999, 2005, 2012 and 2015 orthophotogrammetric surveys and the 2008 airborne LiDAR (2-m resolution). These datasets are all freely downloadable from the Aosta Valley Region WebGis http://www.geonavsct.partout.it/pub/ GeoCartoSCT/index.html. 


\section{Results}

Nine fully processed UAV photogrammetric surveys were performed between July and October 2018. The repeated surveys gave the opportunity to obtain a great amount of information, which were used for the solution of different technical problems as the best location of water pumps or the analysis of the long-term dynamics of the glacier to understand future behavior of the Grand Croux glacial lake.

The first result helpful in understanding recent dynamics and the risk situation of the Grand Croux glacial lake was the measurement of the lake area of 2018 on the orthomosaic rendered by the UAV flights; a first insight was the measure of lake expansion since 2015, date of the last regional aerial survey. Combined with older data from the 1999, 2005, 2008, 2012 and 2015 surveys, an expansion rate could be also determined. On the other hand, frontal retreat of the ice margin that forms the ice dam could be estimated as well. The lake expansion ratio subsequent to glacier melting and calving individuating a clear trend, the future projection of the lake expansion could be extrapolated (Fig. 20).

With the realization of a bathymetric survey by means of GPR sounding on an inflatable vessel, the calculation of water volume present in the lake was possible; interpolation of radar tracks was made on lake contour obtained by UAV orthomosaic of July 22, 2018. The total volume present in the lake was estimated in $42.000 \mathrm{~m}^{3}$. Given the Clague and Mathews (1973) relationship between glacial lake volume and outburst flood debit, an actual and future magnitude of the subglacial outburst flood could be determined; moreover, assumptions from the 2016 flood event coupled with assumptions from Desloges (Desloges et al. 1989) gave more data for the determination of GLOF peak discharges. Starting from data acquired from 2005 dataset, an estimation of the water increment was calculated and a 2028 projection was estimated. The 2028 projection with a potential flood of more than

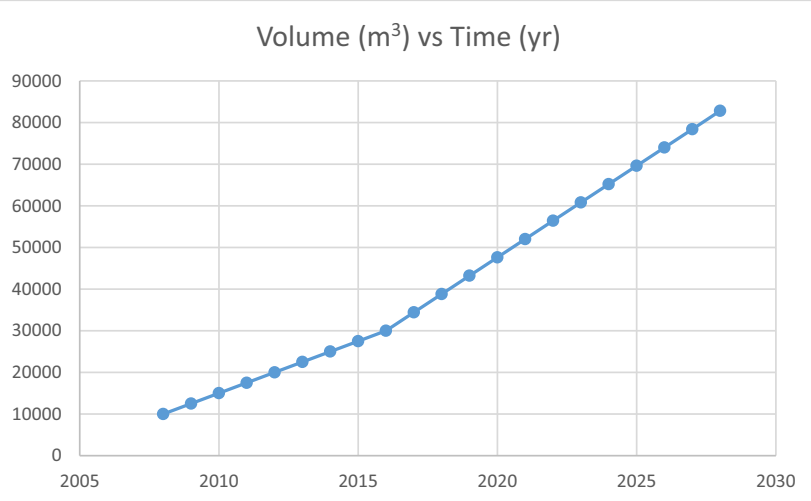

Fig. 20 Bathymetric surveys coupled with GPR data and 2018 UAVderived lake area expansion data, which confirmed the ongoing almost linear trend in the expansion rate (average of $727.31 \mathrm{~m}^{3} /$ year), gave the possibility to assess future lake volumes
$100 \mathrm{~m}^{3} / \mathrm{s}$ water debit supported the decision-makers' evaluation to plan an active intervention to limit the water volume present in the lake.

The first stage of the emergency management was the lake lowering with the use of a series of 10 fuel-powered motor pumps. A detailed UAV topographic survey of the area surrounding the lake already available was a key feature in the decision of the positioning of the pumps, taking into account pipe length and water level to pump altitude difference. This gave the maximum possible efficiency to the pumping system. As the lake water level was lowered, new UAV surveys could be carried out, mapping details and elevation models of the areas that were covered by water just few days before. With an extended topographical survey, the feasibility of the excavation of a permanent drainage channel was possible. The project of a 4-m-deep excavation was subsequently planned.

During the excavation operations, some major calving events took place. These ice falls could be dangerous because of the possible activation of water wave when the block fall down in the water lake. The processing of UAV updated elevation models and orthomosaics was useful for an indication on the volume of the unstable ice portions. The volume of unstable sectors was considered not so big to overflow the protection dam and create a wave that could reach the bottom valley, but could be critical for workers that had to excavate the drainage system. Workers were warned to limit the permanence to the strictly necessary time near the lake and in the drainage trench. Rapid escape routes out of the excavation were identified and adopted. The finished drainage channel lowered the lake level by $3.4 \mathrm{~m}$ reducing the original volume of 42,000 to $21,000 \mathrm{~m}^{3}$.

Processing of the full series of elevation models and orthomosaics gave more insights on glacier dynamics. A trend of elevation change on the ice dam surface could be calculated by means of DEM differencing both for the summer 2018 season and for the long-term analysis by differencing with the 2008 airborne LiDAR data (Fig. 21).

Three different zones with different behaviors have been individuated: (i) a frontal area (1) undergoing intense melting and retreat; (ii) an area (2) which is in contact with water that undergoes very intense melting of the whole thickness of the glacier, enhanced by water thermokarst erosion and calving events; (iii) an overlying flat and debris-covered surface (3) having more homogeneous behaviors (very low standard deviation of elevation difference data). Analysis of elevation changes in this area give a long-term mean value of $-1.076 \mathrm{~m}$ per year averaged on the whole area and on the 20082018 timespan. Analysis on the short term and actual evolution of 2018 give a value of $-1.210 \mathrm{~m}$ on the 3 month timespan between the July 26, 2018, and the October 26 UAV survey. The result could be according to the actual climate evolution causing increased glacial 
Fig. 21 Surface elevation changes 2008-2018 calculated by DEM differencing (2008 Lidar2018 UAV SfM)

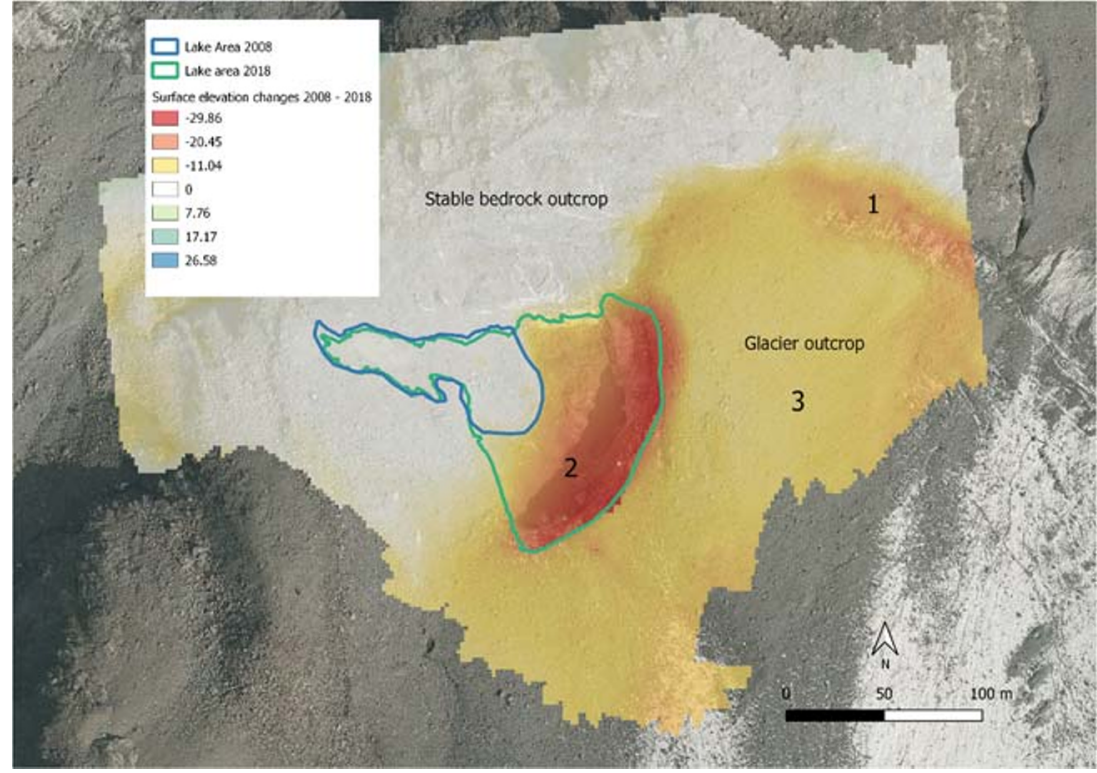

ablation happening at altitudes lower than $3500 \mathrm{~m}$ on alpine glaciers (Zemp et al. 2015)

Surface velocities of the Grand Croux Glacier could be inferred by image correlation (Bhardwaj et al. 2016) between the 2015 Orthophotographs and the 2018 UAV surveys. The movements were too small to be detected on the 3 months timespan of the UAV surveys only as on the 3 years cumulated displacement (2015-2018) velocities varied from 0.66 to $2.8 \mathrm{~m} /$ year horizontal displacement ( 5 to $20 \mathrm{~cm} / \mathrm{month}$ ). The upper (3) area is of great importance as the lowering of this part to a critical threshold of $+10 \%$ of the water column height could lead to hydrostatic uplift of the glacier tongue regardless of its wideness and cause outburst floods of higher magnitude compared with the ones actually happening at Grand Croux Glacier, linked to subglacial drainage system expansion towards the lake.

\section{The smart management of building sites in a post-seismic scenario using UAV photogrammetry}

In this last section, we present and discuss the use of UAV for the management of buildings reconstruction after an earthquake. In particular, we present the use of the UAV photogrammetry technique to support the contemporary reconstruction of several buildings in the historical center of Villa Sant'Angelo. Villa Sant'Angelo is one of the villages strongly damaged by the earthquake that struck the L'Aquila area (Abruzzo region, central Italy) in 2009 (Chiarabba et al. 2009; Manconi et al. 2012). The reconstruction activity in an ancient village is a critical task that should consider many different elements. Architectural, the safety of work activities and environmental aspects are of course the most important, so the reconstruction of many buildings destroyed or seriously damaged by the same event in a small area with several access limitations also requires a good optimization. The case of Villa Sant'Angelo can be considered a good example where the use of innovative solutions supported good planning of building site, which is a crucial aspect for the correct execution of required works.

During the building planning phase, many elements have to be considered and defined: (i) the choice of the most suitable machinery for the size and duration of the work, (ii) the rational organization of the available resources (workforce and machinery), (iii) the arrangement of the spaces, (iv) the site traffic, (v) the achievement of required quality and safety standards. To achieve these objectives, the organization of site logistics is fundamental. Furthermore, the designer must keep in mind that the work requirements often determine the variation of the site configuration, according to the so-called development stages. They correspond to different configuration modes that the building site assumes in certain time intervals, and it is possible to have homogeneous development stages even if the qualitative and / or quantitative consistency of the working cycles changes within them.

External constraints assume fundamental importance when the intervention involves the recovery of an existing building in a historical center. The singularity of the recovery site lies in the peculiarities that influence the decision-making process and management of the work activities such as, in particular:

- peculiarities and dimensions, sometimes limited, of the spaces available inside and outside the building, usable for its rational organization; 
Fig. 22 Test area: a the historical center of Villa Sant'Angelo (AQ) and the identification of the aggregate with black circle; $\mathbf{b}$ the structural units into which the aggregate 12 is divided
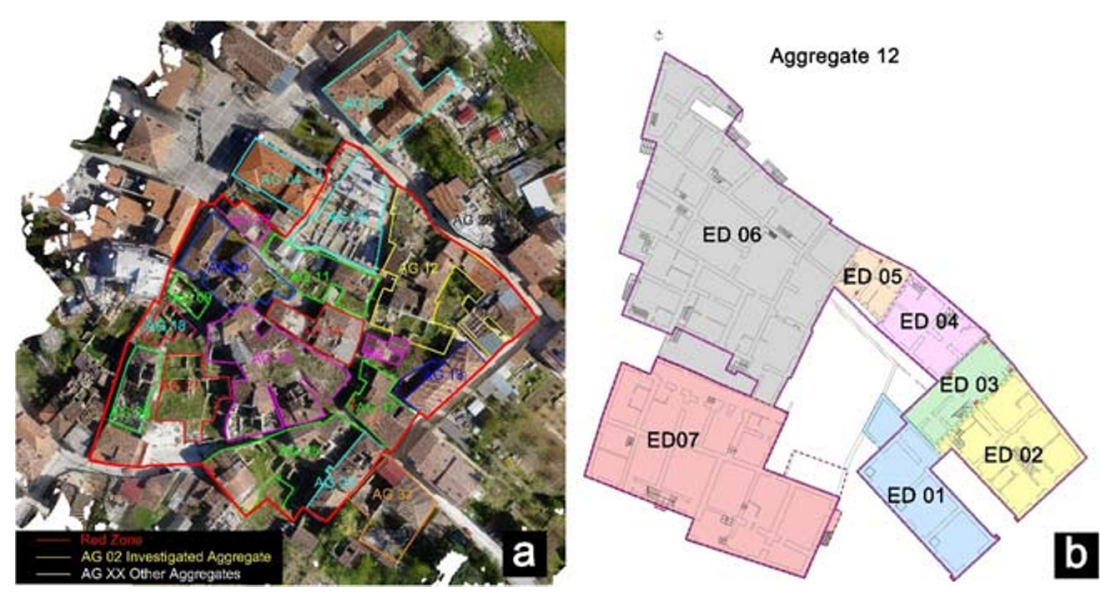

- difficulty in storing, traveling distances, both for the evacuation of waste materials, the access to supply materials, and the movement of people, materials and vehicles;

- obstruction and dimensional impediment caused by adjacent buildings;

- presence of neighboring building sites;

- presence of users and activities both in the building to be recovered and in the immediate vicinity;

- quality and complex interdependence of the various operational phases;

- the crucial importance of temporary works, safety, and service (Alicandro et al. 2019).

Another essential element is the evolution of the building construction activities, which cannot be considered a static part but an evolutionary process that has to be followed, updating the relative building construction plan.

For these reasons, an analysis of the surrounding context and areas, as well as continuous monitoring of the changes that the building site undergoes are essential elements for a correct evaluation of all the variables involved to achieve quality and safety. A right solution for the acquisition of high-resolution images of the building site is the use of UAV. The possibility to have a high resolution and metric survey of the building site area highlights the issues to manage during the work phases and facilitates the analysis of the road network and the small areas dedicated to service and material storage. Furthermore, the use of UAV photogrammetry guarantees the safety for operators engaged in the survey, the possibility to study inaccessible or dangerous areas and to obtain a metric survey and high-resolution data (Dominici et al. 2017). Given the presence of numerous variables and peculiarities, the use of the UAV photogrammetry allows the general analysis in the site (for example for the execution of the metric structural survey of the ruins), and establishes the aspects connected to the theme of the construction site logistics (such as for example the entrances to the construction site, the size of the roads, the presence of obstructions, the existence of neighboring construction sites with interfering cranes, the analysis of the open spaces). A synthesis of these analyses highlights the criticalities of the site, useful to plan the project design of the building site. The aspects assessed were multiple. In particular, however, the study has focused on the smart management of all elements and issues involved in the organization of the building site.

Thus, this work has outlined that UAV photogrammetry can be a great help and, above all, solid support in the building site management and its post-earthquake reconstruction efforts.

\section{Villa Sant'Angelo case study}

Villa Sant'Angelo is an ancient minor center located in Italy in the Province of L'Aquila that, together with its hamlet Tussillo, has about 427 inhabitants. Initially, its origins had been traced back to the Middle Ages, but archaeological excavations carried out in 2005 brought to light archaeological finds attributable to Roman buildings dating back to the Imperial age. In the Middle Ages, the new center was established, together with Tussillo, that had its maximum development in the thirteenth century. Following the earthquake of 1461, the village was rebuilt in Renaissance style, and the noble palaces were built. In 2009, the earthquake that occurred in the Province of L'Aquila damaged again Villa Sant'Angelo. A large part of the minor center was reduced to ruins, so all the buildings in the historic area were classified as condemned. For this reason, precisely because of the problematic conditions of travel and visibility of the center and the studied area, a metric survey was required of the historical center and its surroundings to understand the real condition due to collapses, ruins, and rubble. The investigated area was labeled "uninhabitable area" (also called "red zone") after the 2009 earthquake and was divided into 20 aggregate (URSC 2019), as outlined in Fig. 22a. At the time of the survey in 2017, the reconstruction phase was partially started, and not many building sites were activated. Some cranes were presents in the area; few rubbles removed and many roads not made safe. Inside the red zone, we focused the study on aggregate 12 
Table 15 GCPs and CPs residuals

\begin{tabular}{llllll}
\hline GCPs & Error (m) & Error (pix) & CPs & Error (m) & Error (pix) \\
\hline 8 & 0.08 & 1.19 & 19 & 0.03 & 1.19 \\
\hline
\end{tabular}

(Fig. 22a-AG12). Inside aggregate 12, seven structural units have been identified and defined according to the technicalconstructive characteristics and the structural behavior of the aggregate itself. Subsequently, depending on the damage level of each unit defined in 2009 by the firefighters, the project of reconstruction was developed. In particular, the planned works are as follows: ED 02 and ED 04 required a to structural reinforcement; ED 01, ED 03, ED 05, ED 06, and ED 07 should be demolished and reconstructed with the reinforced concrete frame structure. As mentioned above, the survey of the level of damages of the structures was conducted immediately after the earthquake in a traditional way, since in 2009 the UAV photogrammetry techniques were not very common. Instead, today several pieces of research are focused on the detection and assessment damages in a post-disaster scenario with these techniques (Calantropio et al. 2018; Duarte et al. 2019; Mavroulis et al. 2019; Vetrivel et al. 2018).
Fig. 23 UAV photogrammetry output. a Summary of the criticalities from UAV photogrammetry survey. $\mathbf{b}$ Facilities and service installation. c Access analysis. d Building site crane interference

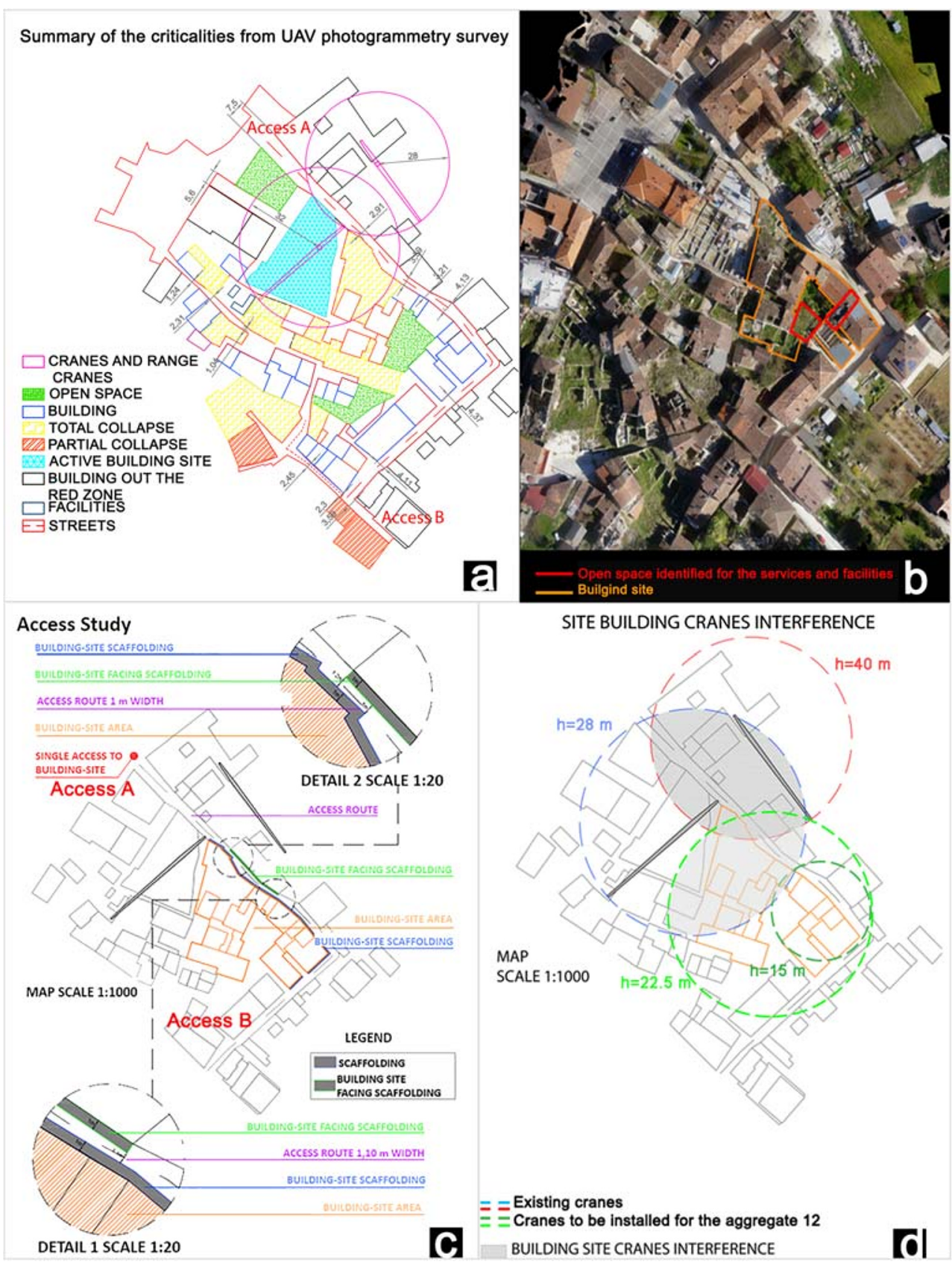




\section{UAV photogrammetry survey}

The main phase of the survey and the elaboration of UAV photogrammetry data is described in this section. The main steps of the UAV survey are (i) the planning phase, (ii) the acquisition phase, and (iii) the elaboration phase as described in Dominici et al. (2018). The flight planning includes all activities aimed to define the waypoints from which the UAV will take the picture during the acquisition phase. Starting from the knowledge of the relationships between the characteristics of the sensor (focal length and sensor size) and the Ground Sample Distance (GSD), the flight altitude was set to $50 \mathrm{~m}$, considering the presence of cranes. The image overlay was set to $90 \%$ for the longitudinal side and $80 \%$ for the transversal side. To obtain a detailed view of the cranes, two flights were planned in the opposite direction. Therefore, 350 images and $27 \mathrm{GCPs} / \mathrm{CPs}$ (ground control points/check points) were acquired. The data were elaborated using Agisoft Photoscan, a software that combines photogrammetry and structure from motion (SFM) algorithms (Barazzetti et al. 2011; Westoby et al. 2012). Table 15 shows the final residuals on GCPs and CPs of the elaboration. The principal outputs of the elaboration are the georeferenced 3D model, the orthomosaic, and the digital elevation model.

\section{Results}

The photogrammetry output allows analyzing several aspects related to the optimization of the investigated building site. All information, starting from the 3D model, have been extracted and summarized in Fig. 23. In particular, the availability of a detailed survey has been used for the identification of main critical elements that have to be considered during the building works management (Fig. 23a): (i) the access to the building site, (ii) the areas to stock rubbles and ruins, (iii) the presence of two cranes and their possible interference, (iv) the presence of different active building sites, and (v) the presence of collapsed buildings.

One of the analyzed elements is the identification of possible accesses to the aggregate 12. Figure 23 a shows the possible accesses to the site and, in particular, the possibility of accessing using only access A. In fact, access B is not available due to the presence of a dangerous building. In Fig. 23c, a detailed analysis of the access is shown, including also the study of the width of the roads, reduced by the presence of scaffolding and support structures of the partially collapsed buildings.

Another critical aspect investigated is the presence of cranes in the surrounding at the time of the survey. Figure $23 \mathrm{~d}$ shows an interference analysis that supports the best cranes installation positions. To project the crane installation in the building site for the aggregate 12, Fig. 23 d shows the location of the cranes already installed, their arms overlapping areas, their height and the two cranes that have to be added.
The UAV photogrammetry survey has highlighted the complexity of the buildings activities and the presence of different critical points related to this specific case study, with the presence of narrow streets, collapsed buildings and the need of work simultaneously on different sites. The limited operational space also causes various problems to the material storage and disposal, which is worsened by the presence of neighboring buildings. A relevant factor that should also be evaluated is the presence of provisional works, temporary safety structures, cranes, and all elements that are essential in the organization of the building site. For example, the limited space and the absence of suitable free areas have led to the arrangement of two service areas, one located in the internal courtyard of the building aggregate and the other positioned at the ED3 structural unit, after its demolition (Fig. 23b). This logistic choice has strongly influenced the planning of the works and has been carried out following the results of the on-site analysis and the criticalities in the positioning of the auxiliary site factors.

The case study briefly illustrated aims to show that UAV photogrammetry can be solid support in the preparation of surveys and analyses in areas affected by violent earthquakes but, in general, this consideration is also adequate for other types of post-disaster scenario. Furthermore, the UAV photogrammetry could also be used in the reconstruction implementation phase. In this regards, the authors are also considering the possibility of applying the methodology to the whole village to monitor and support the development stages of each construction site. The new research will aim to prevent problems, interference, and criticalities to increase the safety and rational organization of the entire reconstruction process.

\section{Conclusions}

This paper represents the result of the work of the C35 IAEG Commission on the topic of the use of UAV for engineering geology applications. The Commission work is aimed to present an overview of unmanned aerial vehicles and a representative collection of case studies that show how these systems can be very in several engineering geology activities and environments. UAVs represent a cheap and fast solution for the on-demand acquisition of detailed images of an area of interest and the creation of detailed 3D models and orthophoto. The use of UAV required a good background of data processing (photogrammetry and structure from motion) and a good drone pilot ability for the management of the flight mission in particular in a complex environment. These two skills guarantee a good possibility of the acquisition of a good dataset, which should also be correctly planned considering the final engineering geology question that should be solved. The paper cannot be considered an exhaustive document that can be used 
for the improvement of these skills if the reader is a beginner, but an introduction to the most important key elements that should be considered by users that are considering the possibility to use UAV in their activities. If required, the large bibliographic review presented in this paper allows readers to a more detailed analysis of the sequence of actions and procedures that should be adopted to guarantee a correct level of safety and to collect a good dataset that can assure a positive result. As every new instrument, even in the case of $\mathrm{UAV}$, it is important a correct and rigorous approach, because an underestimation of the real level of complexity of these systems could imply clamorous errors in the generation of $3 \mathrm{D}$ models that are the base for further study and analysis. A correct approach, on the contrary, creates the right condition for the proper use of these systems and great support in many engineering geology applications.

Acknowledgments Authors want to thank the Editors and Reviewers of the Bulletin of Engineering Geology and the Environment for their important revisions and improvement of the presented work.

"The use of UAVs on landslides" section: The author would like to thank colleagues: Colm Jordan, Lee Jones, Matthew Kirkham, David Morgan, David Boon, Catherine Pennington, Simon Holyoake, Vanessa Banks and former colleagues Edward Haslam, Christopher Wardle and Paul Witney. The Natural Environment Research Council (NERC) supported this research. This paper is published with the permission of the Executive Director of the British Geological Survey, BGS@UKRI[2018].

"Main applications of UAV in hydrology" section: The research was financed by the National Science Centre, Poland, through the grant no. 2011/01/D/ST10/04171. The author is indebted to the authorities of the County Office in Kłodzko for making the data of the Local Flood Monitoring System (Lokalny System Osłony Przeciwpowodziowej LSOP) available for research purposes. The HydroProg prototype is based on the following open-source solutions: R, PostgreSQL, and MySQL. Last but not least, the UAV operators, Ms. Matylda WitekKasprzak and Dr. Joanna Remisz, are acknowledged.

Authors' contributions Daniele Giordan is the chairman of IAEG Commission C35, he supervised the redaction of this paper, and he is the co-author of the "Introduction," "UAV payload sensors," "UAV for 3D model generation: operative rules, regulation, data collection, and processing," and "Conclusions" sections; Marc S. Adams is the coauthor of the "UAV for debris flow mapping and analysis" section; Irene Aicardi is the author of the "UAV main components analysis and comparison" section; Maria Alicandro is the co-author of the "The smart management of building sites in a post-seismic scenario using UAV photogrammetry" section; Paolo Allasia is the co-author of the "UAV payload sensors" section; Marco Baldo is the co-author of the "UAV payload sensors" section; Pierluigi De Berardinis is the co-author of the "The smart management of building sites in a post-seismic scenario using UAV photogrammetry" section; Donatella Dominici is the co-author of the "The smart management of building sites in a post-seismic scenario using UAV photogrammetry" section; Danilo Godone is the co-author of the "UAV payload sensors" and "UAV for 3D model generation: operative rules, regulation, data collection, and processing" sections; Peter Hobbs is the author of the "The use of UAVs on landslides" section and he is the co-author of the "UAV for 3D model generation: operative rules, regulation, data collection, and processing" section; Veronika Lechner is the co-author of the "UAV for debris flow mapping and analysis" section;
Tomasz Niedzielski is the author of the "Main applications of UAV in hydrology" section; Marco Piras is the co-author of the "Introduction," "UAV payload sensors," "UAV for 3D model generation: operative rules, regulation, data collection, and processing," and "Conclusions" sections; Marianna Rotilio is the co-author of the "The smart management of building sites in a post-seismic scenario using UAV photogrammetry" section; Riccardo Salvini is the author of the "The use of UAV for rock mass classification and structural analysis" section; Valerio Segor is the co-author of the "The use of UAV for glacier monitoring and glacial outburst flood risk mitigation" section; Bernadette Sotier is the coauthor of the "UAV for debris flow mapping and analysis" section; and Fabrizio Troilo is the co-author of the "The use of UAV for glacier monitoring and glacial outburst flood risk mitigation" section.

Open Access This article is licensed under a Creative Commons Attribution 4.0 International License, which permits use, sharing, adaptation, distribution and reproduction in any medium or format, as long as you give appropriate credit to the original author(s) and the source, provide a link to the Creative Commons licence, and indicate if changes were made. The images or other third party material in this article are included in the article's Creative Commons licence, unless indicated otherwise in a credit line to the material. If material is not included in the article's Creative Commons licence and your intended use is not permitted by statutory regulation or exceeds the permitted use, you will need to obtain permission directly from the copyright holder. To view a copy of this licence, visit http://creativecommons.org/licenses/by/4.0/.

\section{References}

Adams MS, Fromm R, Lechner V (2016) High-resolution debris flow volume mapping with unmanned aerial systems (UAS) and photogrammetric techniques. The International Archives of the Photogrammetry, Remote Sensing and Spatial Information Sciences, Volume XLI-B1, XXIII ISPRS Congress, 12-19 July 2016, Prague, Czech Republic.

Adams MS, Bühler Y, Fromm R (2018) Multitemporal accuracy and precision assessment of unmanned aerial system photogrammetry for slope-scale snow depth maps in Alpine terrain. Pure and Applied Geophysics, 175(9), 3303-3324.

Agisoft (2018) PhotoScan user manual: professional edition, Version 1.4, pp.118.

Aicardi I, Chiabrando F, Grasso N, Lingua AM, Noardo F, Spanò A (2016a) UAV photogrammetry with oblique images: first analysis on data acquisition and processing. International Archives of the Photogrammetry, Remote Sensing \& Spatial Information Sciences, 41.

Aicardi I, Nyapwere N, Nex F, Gerke M, Lingua AM, Koeva MN (2016b) Co-registration of multitemporal uav image datasets for monitoring applications: a new approach. International Archives of the Photogrammetry, Remote Sensing \& Spatial Information Sciences, 41.

Ajayi OG, Salubi AA, Angbas AF, Odigure MG (2017) Generation of accurate digital elevation models from UAV acquired low percentage overlapping images. Int J Remote Sens 38(8-10):3113-3134

Alicandro M, Rotilio M (2019) UAV photogrammetry for resilience management in reconstruction plan of urban historical centres after seismic events. A case study. The International Archives of the Photogrammetry, Remote Sensing and Spatial Information Sciences, Volume XLII-2/W11, 2019 GEORES 2019 - 2nd 
International Conference of Geomatics and Restoration, 8-10 May 2019, Milan, Italy, 55-61

Allasia P, Baldo M, Giordan D, Godone D, Wrzesniak A, Lollino G (2018) Near real time monitoring systems and periodic surveys using a multi sensors UAV: the case of Ponzano landslide. IAEG/AEG Annual Meeting Proceedings, San Francisco, California, 2018 - Volume 1,303-10. Cham: Springer International Publishing.

Amici S, Turci M, Giammanco S, Spampinato L, Giulietti F (2013) UAV thermal infrared remote sensing of an Italian mud volcano. Adv Remote Sens 2(December):358-364

Aronica GT, Biondi G, Brigandì G, Cascone E, Lanza S, Randazzo G (2012) Assessment and mapping of debris-flow risk in a small catchment in eastern Sicily through integrated numerical simulations and GIS. Physics and Chemistry of the Earth, Parts A/B/C 49:52-63

Ballesteros Cánovas JA, Stoffel M, Corona C, Schraml K, Gobiet A, Tani S, Sinabell F, Fuchs S, Kaitna R (2016) Debris-flow risk analysis in a managed torrent based on a stochastic life-cycle performance. Sci Total Environ 557-558:142-153

Baltsavias EP (1999) Airborne laser scanning: basic relations and formulas. ISPRS J Photogrammetry Remote Sens 54(2-3):199-214

Barazzetti L, Forlani G, Remondino F, Roncella R, Scaioni M (2011) Experiences and achievements in automated image sequence orientation for close-range photogrammetric projects. In: Remondino F., Shortis MR. (Eds.) Videometrics, range imaging, and applications XI, Proc. of SPIE Vol. 8085, 1-13. DOI https://doi.org/10.1117/12. 890116.

Barton NR, Choubey V (1977) The shear strength of rock joints in theory and practice. Rock Mech. 10(1-2):1-54

Bemis SP, Micklethwaite S, Turner D, James MR, Akciz S, Thiele ST, Bangash HA (2014) Ground-based and UAV-based photogrammetry: a multi-scale, high-resolution mapping tool for structural geology and paleoseismology. Journal of Structural Geology. Pergamon

Bhardwaj A, Sam L, Akanksha F, Martín-Torres J, Kumar R (2016) UAVs as remote sensing platform in glaciology: present applications and future prospects. Remote Sens Environ 175:196-204

Boccardo P, Chiabrando F, Dutto F, Tonolo FG, Lingua AM (2015) UAV deployment exercise for mapping purposes: evaluation of emergency response applications. Sensors 15(7):15717-15737

Boesch R, Bühler Y, Ginzler C, Adams MS, Fromm R, Graf A (2015) Optimizing channel weights for digital surface models with snow coverage. ISPRS Archives, XL-3/W3.

Bolognesi M, Farina G, Alvisi S, Franchini M, Pellegrinelli A, Russo P (2017) Measurement of surface velocity in open channels using a lightweight remotely piloted aircraft system. Geomatics, Natural Hazards and Risk 8:73-86

Boon DP, Chambers JE, Hobbs PRN, Kirkham M, Merritt AJ, Dashwood C, Pennington C, Wilby PR (2015) A combined geomorphological and geophysical approach to characterising relict landslide hazard on the Jurassic Escarpments of Great Britain. Geomorphology 248: 296-330

Braga J, Aguiar AP, De Sousa JB (2017) Coordinated multi-UAV exploration strategy for large areas with communication constrains. [In:] ROBOT 2017: Third Iberian Robotics Conference, Springer, 149160

Braunstein ML (1990) Structure from motion. Human performance models for computer-aided engineering, January, 89-105.

Briese C, Fortner R, Sager P, Pfeifer N (2013) Vom Modellflughobby zu unbemannten Flugsystemen für die Geodatenerfassung. Österreichische Zeitschrift für Vermessung und Geoinformation (VGI) 101(2+3):64-74

Bühler Y, Adams MS, Bösch R, Stoffel A (2016) Mapping snow depth in alpine terrain with unmanned aerial systems (UASs): potential and limitations. Cryosphere 10:1075-1088

Bull JM, Miller H, Gravley DM, Costello D, Hikuroa DCH, Dix JK (2010) Assessing debris flows using LIDAR differencing: 18
May 2005 Matata event, New Zealand. Geomorphology 124(1-2): $75-84$

Bulusu N, Heidemann J, Estrin D (2000) GPS-less low-cost outdoor localization for very small devices. IEEE Personal Commun 7(5): 28-34

Calantropio A, Chiabrando F, Sammartano G, Spanò A, Teppati Losè L (2018) UAV strategies validation and remote sensing data for damage assessment in post-disaster scenarios. The International Archives of the Photogrammetry, Remote Sensing and Spatial Information Sciences, Volume XLII- 3/W4, 2018 GeoInformation For Disaster Management (Gi4DM), 18-21 March 2018. Istanbul, Turkey, pp 121-128

Carbonneau PE, Dietrich JT (2017) Cost-effective non-metric photogrammetry from consumer-grade SUAS: implications for direct georeferencing of structure from motion photogrammetry. Earth Surface Processes and Landforms 42(3):473-486

Casado MR, Gonzalez RB, Kriechbaumer T, Veal A (2015) Automated identification of river hydromorphological features using UAV high resolution aerial imagery. Sensors 15:27969-27989

Casella V, Franzini M, Forlani G, Galetto R, Manzino A, Radicioni F, Sona G, Villa B (2004) Initial results of the Italian project on direct georeferencing in aerial photogrammetry. International Archives of Photogrammetry and Remote Sensing, XX Th ISPRS Congress, Comm. III, 35:881-886.

Cetas TC (1978) Practical thermometry with a thermographic cameracalibration, transmittance, and emittance measurements. Review of Scientific Instruments 49:245

Chao H, Cao Y, Chen Y (2010) Autopilots for small unmanned aerial vehicles: a survey. International Journal of Control, Automation, and Systems. 8(1):36-44

Chen J, Li K, Chang KJ, Sofia G, Tarolli P (2015) Open-pit mining geomorphic feature characterization. Int. J. Appl. Earth Obs. 42: $76-86$

Chesley JT, Leier AL, White S, Torres R (2017) Using unmanned aerial vehicles and structure-from-motion photogrammetry to characterize sedimentary outcrops: an example from the Morrison Formation, Utah, USA. Sediment Geol 354:1-8

Chiabrando F, Lingua AM, Piras M (2013) Direct photogrammetry using UAV: tests and first results. ISPRS Arch 1:W2

Chiarabba C, Amato A, Anselmi M, Baccheschi P, Bianchi I, Cattaneo M, Cecere G, Chiaraluce L, Ciaccio MG, De Gori P, De Luca G, Di Bona M, Di Stefano R, Faenza L, Govoni A, Improta L, Lucente FP, Marchetti A, Margheriti L, Mele F, Michelini A, Monachesi G, Moretti M, Pastori M, Piana Agostinetti N, Piccinini D, Roselli P, Seccia D, Valoroso L (2009) The 2009 L'Aquila (central Italy) MW6.3 earthquake: Main shock and aftershocks. Geophysical Research Letters, 36, L18308, 1-6

Cignetti M, Godone D, Wrzesniak A, Giordan D (2019) Structure from motion multisource application for landslide characterization and monitoring: the Champlas du Col case study, Sestriere, NorthWestern Italy. Sensors 19:2364

Clague J, Mathews W (1973) The magnitude of Jökulhlaups. J Glaciol 12(66):501-504

Clapuyt F, Vanacker V, Van Oost K (2016) Reproducibility of UAV-based earth topography reconstructions based on structure-from-motion algorithms. Geomorphology 260:4-15

Clarke TA, Fryer JG (1998) The development of camera calibration methods and models. Photogrammetric Record 16(91):51-66

Colomina I, Molina P (2014) Unmanned aerial systems for photogrammetry and remote sensing: a review. ISPRS Journal of Photogrammetry and Remote Sensing 92:79-97

Cooper MAR, Robson S (2001) Theory of close range photogrammetry. In: Atkinson $\mathrm{KB}$ (ed) Close range photogrammetry and machine vision. Whittles Publishing, Caithness, p 371

Cracknell AP (2017) UAV's: regulations and law enforcement. International Journal of Remote Sensing 38(8-10):3054-3067 
Cramer M (2001) Performance of GPS/inertial solutions in photogrammetry. Photogrammetric Week:49-62

Cunliffe AM, Anderson K, DeBell L, Duffy JP (2017) A UK Civil Aviation Authority (CAA)-approved operations manual for safe deployment of lightweight drones in research. International Journal of Remote Sensing 38(8-10):2737-2744

Daftry S, Hoppe C, Bischof H (2015) Building with drones: accurate 3D facade reconstruction using MAVs. 2015 IEEE International Conference on Robotics and Automation (ICRA), Seattle, WA, 3487-3494

Dall'Asta E, Delaloye R, Diotri F, Forlani G, Fornari M, Morra di Cella U, Pogliotti P, Roncella R, Santise M (2015) Use of UAS in a high mountain landscape: the case of Gran Sommetta rock glacier (AO). ISPRS International Archives of the Photogrammetry XL-3(W3): 391-397

Danzi M, Di Crescenzo G, Ramondini M, Santo A (2013) Use of unmanned aerial vehicles (UAVs) for photogrammetric surveys in rockfall instability studies. Rendiconti online Della Società Geologica Italiana 24:82-85

De Agostino M, Manzino AM, Piras M (2010) Performances comparison of different MEMS-based IMUs. IEEE/ION Position, Location and Navigation Symposium, 187-201.

De Michele C, Avanzi F, Passoni D, Barzaghi R, Pinto L, Dosso P, Ghezzi A, Gianatti R, Della VG (2016) Using a fixed-wing UAS to map snow depth distribution: an evaluation at peak accumulation. Cryosphere 10:511-522

Desloges J, Jones D, Ricker K (1989) Estimates of peak discharge from the drainage of ice-dammed Ape Lake, British Columbia, Canada. J Glaciol 35(121):349-354

Detert M, Weitbrecht V (2015) A low-cost airborne velocimetry system: proof of concept. J Hydraulic Res 53:532-539

Detert M, Johnson ED, Weitbrecht V (2017) Proof-of-concept for lowcost and non-contact synoptic airborne river flow measurements. Int J Remote Sens 38:2780-2807

Dewitte OJ, Jasselette C, Cornet Y, Van Den Eeckhaut M, Collignon A, Poesen J, Demoulin A (2008) Tracking landslide displacements by multi-temporal DTMs: a combined aerial stereophotogrammetric and LIDAR approach in Western Belgium. Eng Geol 99(1-2):11-22

Dietrich A, Krautblatter M (2016) Evidence for enhanced debris-flow activity in the Northern Calcareous Alps since the 1980s (Plansee, Austria). Geomorphology 287:144-158

Dominici D, Alicandro M, Rosciano E, Massimi V (2017) Multiscale documentation and monitoring of l'Aquila historical centre using UAV photogrammetry. International Archives of the Photogrammetry, Remote Sensing and Spatial Information Sciences - ISPRS ArchivesVolume 42, Issue 5W1, 12 May 2017, 365-371.

Dominici D, De Berardinis P, Rotilio M, Alicandro M (2018) Photogrammetry from UAV in the recovery interventions: from the pre-planning phase to the construction site. Geomedia 22(1):6-10

Dron A (2017) EU moves forward on UAV regulation. Air Transport World, Nov 2017. http://atwonline.com

Duarte D, Nex F, Kerle N, Vosselman G (2019) Damage detection on building façades using multi-temporal aerial oblique imagery ISPRS Annals of the Photogrammetry, Remote Sensing and Spatial Information Sciences, Volume IV-2/W5, 2019 ISPRS Geospatial Week 2019, 10 14 June 2019. Enschede, The Netherlands, pp 29-36

Eisenbeiß H. (2009) UAV photogrammetry. Institute of Geodesy and Photogrammetry, Eidgenössische Technische Hochschule Zürich, pp. 203.

Eitel JUH, Keefe RF, Long DS, Davis AS, Vierling LA (2010) Active ground optical remote sensing for improved monitoring of seedling stress in nurseries. Sensors 10:2843-2850

Eling C, Wieland M, Hess C, Klingbeil L, Kuhlmann H (2015) Development and evaluation of a UAV based mapping system for remote sensing and surveying applications. Int. Arch. Photogramm. Remote. Sens. Spat. Inf. Sci. XL-1/W4, 233-239.

Elkadiri R, Sultan M, Youssef AM, Elbayoumi T, Chase R, Bulkhi AB, Al-Katheeri MM (2014) A remote sensing-based approach for debris-flow susceptibility assessment using artificial neural networks and logistic regression modeling. IEEE Journal of Selected Topics in Applied Earth Observations and Remote Sensing 7(12): 4818-4835

Eltner A, Kaiser A, Castillo C, Rock G, Neuring F, Abellan A (2015) Image-based surface reconstruction in geomorphometry - merits, limits and developments. Earth Surf. Dynam. 4:359-389

Esposito G, Mastrorocco G, Salvini R, Oliveti M, Starita P (2017) Application of UAV photogrammetry for the multi-temporal estimation of surface extent and volumetric excavation in the Sa Pigada Bianca open-pit mine, Sardinia, Italy. Environ. Earth Sci. 76(103):1-16

Feng Q, Liu J, Gong J (2015) Urban flood mapping based on unmanned aerial vehicle remote sensing and random forest classifier - a case of Yuyao, China. Water 7:1437-1455

Fernández T, Pérez JL, Cardenal FJ, López A, Gómez JM, Colomo C, Delgado J, Sánchez M (2015) Use of a light UAV and photogrammetric techniques to study the evolution of a landslide in Jaén (southern Spain). ISPRS Archives XL-3(W3):241-248

Fiorucci F, Cardinali M, Carlà R, Rossi M, Mondini AC, Santurri L, Ardizzone F, Guzzetti F (2011) Seasonal landslide mapping and estimation of landslide mobilization rates using aerial and satellite images. Geomorphology 129(1-2):59-70

Fiorucci F, Giordan D, Santangelo M, Dutto F, Rossi M, Guzzetti F (2018a) Criteria for the optimal selection of remote sensing optical images to map event landslides. Nat Hazards Earth Syst Sci 18:405417

Fiorucci M, Marmoni GM, Martino S, Mazzanti P (2018b) Thermal response of jointed rock masses inferred from infrared thermographic surveying (Acuto Test-Site, Italy). Sensors 18(7):2221

Flener C, Vaaja M, Jaakkola A, Krooks A, Kaartinen H, Kukko A, Kasvi E, Hyyppä H, Hyyppä J, Alho P (2013) Seamless mapping of river channels at high resolution using mobile LiDAR and UAV-photography. Remote Sensing 5:6382-6407

Forster A, Culshaw M (2004) Implications of climate change for hazardous ground conditions in the UK. Geology Today 20(2):61-67

Francioni M, Salvini R, Stead D, Giovannini R, Riccucci S, Vanneschi C, Gullì D (2015) An integrated remote sensing-GIS approach for the analysis of an open pit in the Carrara marble district, Italy: slope stability assessment through kinematic and numerical methods. Comput Geotech 67:46-63

Gabrlik P, la Cour-Harbo A, Kalvodova P, Zalud L, Janata P (2018) Calibration and accuracy assessment in a direct georeferencing system for UAS photogrammetry. Int J Remote Sens 39(15-16):49314959

Gao Y, Wojciechowski A (2004) High precision kinematic positioning using single dual-frequency GPS receiver. The International Archives of the Photogrammetry, Remote Sensing and Spatial Information Sciences, 44(XXX), 4pp.

Gherdevich D, Gonizzi Barsanti S, Degrassi D (2012) The historic and archaeological itineraries for the discovery of Friuli during the Lombard period Davide Computer Applications and Quantitative Methods in Archaeology (CAA) 2012 conference, University of Southampton 26-30 March 2012, 1-16.

Giordan D, Manconi A, Facello A, Baldo F, dell'Anese M, Allasia P, Dutto F (2015) Brief communication: the use of an unmanned aerial vehicle in a rockfall emergency scenario. Nat Hazards Earth Syst Sci 15:163-169

Giordan D, Hayakawa Y, Nex F, Remondino F, Tarolli P (2018) Review article: the use of remotely piloted aircraft systems (RPASs) for natural hazards monitoring and management. Nat. Hazards Earth Syst. Sci. 18:1079-1096 
Gomez C, Purdie H (2016) UAV-based photogrammetry and geocomputing for hazards and disaster risk monitoring - a review. Geoenvironmental Disasters 3:1-11

Gonçalves JA, Henriques R (2015) UAV photogrammetry for topographic monitoring of coastal areas, ISPRS J. Photogramm., 104, 101-111.

Gonzalez L, Glen AM, Pluig E, Johnson S, Mengersen K, Gaston K (2016) Unmanned aerial vehicles (UAVs) and artificial intelligence revolutionizing wildlife monitoring and conservation. Sensors 16(1):97

Gregoretti C, Degetto M, Boreggio M (2016) GIS-based cell model for simulating debris flow runout on a fan. J Hydrol 534:326-340

Guo Q, Su Y, Hu T, Zhao T, Wu F, Li Y, Liu J, Chen L, Xu G, Lin G, Zheng Y, Lin Y, Xiangcheng M, Fei L, Xugao W (2017) An Integrated UAVborne lidar system for 3D habitat mapping in three forest ecosystems across China. Int J Remote Sens 38(8-10):2954-2972

Guzzetti F, Mondini AC, Cardinali M, Fiorucci F, Santangelo M, Chang KT (2012) Landslide inventory maps: new tools for an old problem. Earth-Sci Rev 112(1-2):42-66

Han Z, Chena G, Lia Y, Tangc C, Xub L, Hea Y, Huangc X, Wanga W (2015) Numerical simulation of debris-flow behavior incorporating a dynamic method for estimating the entrainment. Eng Geol 190:52-64

Harder P, Schirmer M, Pomeroy J, Helgason W (2016) Accuracy of snow depth estimation in mountain and prairie environments by an unmanned aerial vehicle. Cryosphere 10:2559-2571

Harwin S, Lucieer A (2012) Assessing the accuracy of georeferenced point clouds produced via multi-view stereopsis from unmanned aerial vehicle (UAV) Imagery. Remote Sensing 4:1573-1599

Hemayed E (2003) A survey of camera self-calibration. In: IEEE Conference on Advanced Video and Signal Based Surveillance, 22-22 July 2003, Miami, FL, USA.

Hobbs PRN, Gibson AD, Jones L, Pennington CVL, Jenkins G, Pearson SG, Freeborough KA (2010) Monitoring coastal change using terrestrial LiDAR. 117-127 In: Elevation models for geoscience. Fleming, C, Marsh, S H, and Giles, J R A (editors). Geological Society, London, Special Publications 345, 117-127.

Hobbs PRN, Jones LD, Kirkham MP, Pennington CVL, Jenkins GO, Dashwood C, Haslam EP, Freeborough KA, Lawley RS (2013) Slope dynamics project report: Holderness Coast - Aldbrough, survey \& monitoring, 2001 - 2013 British Geological Survey, Open Report No. OR/11/063.

Hobbs PRN, Jones LD, Kirkham MP, Pennington CVL, Morgan DJR, Dashwood C, Banks VJ, Reeves HJ (2020) Coastal landslide monitoring at Aldbrough, East Riding of Yorkshire, UK. Quarterly J Eng Geol Hydrogeol 53(1):88-100

Hübl J, Keiler M, Fuchs S (2009) Risikomanagement für alpine Naturgefahren. Wildbach- und Lawinenverbau 73(163):60-74

Hungr O, Lerouil S, Picarelli L (2014) The Varnes classification of landslide types, an update. Landslides 11(2):167-194

Immerzeel WW, Kraaijenbrink PDA, Shea JM, Shrestha AB, Pellicciotti F, Bierkens MFP, de Jong SM (2014) High-resolution monitoring of Himalayan glacier dynamics using unmanned aerial vehicles. Remote Sensing of Environment 150:93-103

James MR, Robson S (2012) Straightforward reconstruction of 3D surfaces and topography with a camera: accuracy and geoscience application. Journal of Geophysical Research 117(F03017):1-17

James MR, Robson S (2014) Mitigating systematic error in topographic models derived from UAV and ground-based image networks. Earth Surf Process Landforms 39:1413-1420. https://doi.org/10.1002/esp. 3609

James MR, Robson S, d'Oleire-Oltmanns S, Niethammer U (2017) Optimising UAV topographic surveys processed with structurefrom-motion: ground control quality, quantity and bundle adjustment. Geomorphology 280:51-66

Jordan C, Dijkstra T, Hobbs P, King N, Purser G, Rochelle C, Traut K (2016) Research and application of small unmanned aerial vehicles for terrestrial \& atmospheric geoscience at the British Geological
Survey. Small UAS for Environmental Research Conference. Univ. of Worcester, 28th-29th June 2016.

Juul M (2015) Civil drones in the European Union. EPRS, European Parliamentary Research Service, PE571.305, 8pp. http://www. europarl.europa.eu/RegData/etudes/BRIE/2015/571305/EPRS BRI\%282015\%29571305_EN.pdf

Kalman RE (1960) A new approach to linear filtering and prediction problems. Journal of basic Engineering 82(1):35-45

Kim H, Lee SW, Yune CY, Kim G (2014) Volume estimation of small scale debris flows based on observations of topographic changes using airborne LiDAR DEMs. Journal of Mountain Science 11(3): 578-559

Kovanič L, Blišt’an P (2014) Quarry wall stability assessment using TLS method. Advanced Materials Research Vols. 1044-1045:603-606

Kraus K (2007) Photogrammetry geometry from images and laser scans. Walter de Gruyter, Berlin, Germany, pp. 461.

Lamb AD (2000) Earth observation technology applied to mining related environmental issues. Min. Tech. 109:153-156

Langhammer J, Hartvich F, Kliment Z, Jeníček M, Bernsteinová Kaiglová J, Vlček L, Su Y, Štych P, Miřijovský J (2015) The impact of disturbance on the dynamics of fluvial processes in mountain landscapes. Silva Gabreta 21(1):105-116

Langhammer J, Lendzioch T, Miřijovský J, Hartvich F (2017a) UAVbased optical granulometry as tool for detecting changes in structure of flood depositions. Remote Sensing 9:240

Langhammer J, Bernsteinová J, Miřijovský J (2017b) Building a highprecision 2D hydrodynamic flood model using UAV photogrammetry and sensor network monitoring. Water 9:861

Lato M, Hutchinson J, Diederichs M, Ball D, Harrap R (2009) Engineering monitoring of rockfall hazards along transportation corridors: using mobile terrestrial LiDAR. Natural Hazards and Earth System Science 9(3):935-946

Li F, Mistele B, Hu Y, Chen X, Schmidhalter U (2013) Comparing hyperspectral index optimization algorithms to estimate aerial $\mathrm{N}$ uptake using multi-temporal winter wheat datasets from contrasting climatic and geographic zones in China and Germany. Agricultural and Forest Meteorology 180:44-57

Lindner G, Schraml K, Mansberger R, Hübl J (2016) UAV monitoring and documentation of a large landslide. Applied Geomatics 8(1):1-11

Liu P, Chen AY, Huang Y-N, Han J-Y, Lai J-S, Kang S-C, Wu T-H, Wen M-C, Tsai M-H (2014) A review of rotorcraft unmanned aerial vehicle (UAV) developments and applications in civil engineering. Smart Structures and Systems 13:1065-1094

Lomax AS, Corso W, Etro JF (2005) Employing unmanned aerial vehicles $(\mathrm{UAVs})$ as an element of the Integrated Ocean Observing System. Proceedings of OCEANS 2005 MTS/IEEE, 17-23 September 2005, Washington, DC, USA.

Lucieer A, De Jong SM, Turner D (2014) Mapping landslide displacements using structure from motion (SfM) and image correlation of multi-temporal UAV photography. Progress in Physical Geography 38(1):97-116

Mademlis I, Karakostas J, Nikolaidis N (2018) UAV cinematography constraints imposed by visual target trackers. 25th IEEE International Conference on Image Processing (ICIP), no. May (October) 76-80.

Madjid MYA, Vandeginste V, Hampson G, Jordan CJ, Booth AD (2018) Drones in carbonate geology: opportunities and challenges, and application in diagenetic dolomite geobody mapping. Mar Pet Geol 91:723-734

Mancini F, Dubbini M, Gattelli M, Stecchi F, Fabbri S, Gabbianelli G (2013) Using unmanned aerial vehicles (UAV) for high-resolution reconstruction of topography: the structure from motion approach on coastal environments. Remote Sensing 5(12):6880-6898

Manconi A, Giordan D, Allasia P, Baldo M, Lollino G (2012) Surface displacements following the Mw 6.3 L'Aquila earthquake: One year 
of continuous monitoring via robotized total station. Ital J Geosci 131(3):403-409

Mastrorocco G, Salvini R, Esposito G, Seddaiu M (2016) 3D point cloud analysis for surface roughness measurement: application of UAV photogrammetry. X Convegno Nazionale dei Giovani Ricercatori di Geologia Applicata AIGA, Bologna February 18-19, 2016. Rend. Online Soc. Geol. It., 313-316.

Mateos RM, Azanon JM, Roldan FJ, Notti D, Perez-Pena V, Galve JP, Perez-Garcia JL, Colomo CM, Gomez-Lopez JM, Montserrat O, Devantery N, Lamas-Fernandez F, Fernandez-Chacon F (2017) The combined use of PSInSAR and UAV photogrammetry techniques for the analysis of the kinematics of a coastal landslide affecting an urban area (SE Spain). Landslides 14, pp743-754.

Mavroulis S, Andreadakis E, Spyrou NI, Antoniou V, Skourtsos E, Papadimitriou P, Kasssaras I, Kaviris G, Tselentis GA, Voulgaris N, Carydis P, Lekkas E (2019) UAV and GIS based rapid earthquake-induced building damage assessment and methodology for EMS-98 isoseismal map drawing: The June 12, 2017 MW 6.3 Lesvos (Northeastern Aegean, Greece) earthquake. Int J Disaster Risk Reduct 37:1-20

McLeod T, Samson C, Labrie M, Shehata K, Mah J, Lai P, Wang L, Elder JH (2013) Using video acquired from an unmanned aerial vehicle (UAV) to measure fracture orientation in an open-pit mine. Geomatica 67:173-180

Menegoni N, Giordan D, Perotti C, Tannant DD (2019) Detection and geometric characterization of rock mass discontinuities using a $3 \mathrm{D}$ high-resolution digital outcrop model generated from RPAS imagery - Ormea rock slope, Italy. Eng Geol 252:145-163

Mian O, Lutes J, Lipa G, Hutton JJ, Gavelle E, Borghini S (2015) Direct georeferencing on small unmanned aerial platforms for improved reliabiitily and accuracy of mapping without the need for ground control points. Int. Arch. Photogramm. Remote. Sens. Spat. Inf. Sci. XL-1/W4, 397-402.

Micheletti N, Chandler JH, Lane SN (2015) Structure from motion (SFM) photogrammetry. In: Clarke LE, Nield JM (eds) Geomorphological techniques. British Society for Geomorphology, London, p 2, 12 pp

Miller R, Amidi O (1998) 3-D site mapping with the CMU autonomous helicopter. Proceedings of the 5th International Conference on Intelligent Autonomous Systems (IAS-5), no. June: 765-774.

Miller PE, Mills JP, Edwards SJ, Bryan P, Marsh S, Hobbs P, Mitchell H (2007) A robust surface matching technique for integrated monitoring of coastal geohazards. Marine Geodesy 30(1-2):109-123

Miřijovský J, Langhammer J (2015) Multitemporal monitoring of the morphodynamics of a mid-mountain stream using UAS photogrammetry. Remote Sensing 7:8586-8609

Miřijovský J, Šulc Michalková M, Petyniak O, Máčka Z, Trizna M (2015) Spatiotemporal evolution of a unique preserved meandering system in Central Europe - the Morava River near Litovel. Catena 127:300-311

Miziński B, Niedzielski T (2017) Fully-automated estimation of snow depth in near real time with the use of unmanned aerial vehicles without utilizing ground control points. Cold Regions Sci Technol 138:63-72

Mondini AC, Guzzetti F, Reichenbach P, Rossi M, Cardinali M, Ardizzone F (2011) Semi-automatic recognition and mapping of rainfall induced shallow landslides using optical satellite images. Remote Sens Environ 115(7):1743-1757

Nageli T, Meier L, Domahidi A, Alonso-Mora J, Hilliges O (2017) Realtime planning for automated multi-view drone cinematography. ACM Trans Graph 36(4):Article 132, 10 pp

NASA (2015) A report overview of the civil UAV capability assessment.

Nex F, Remondino F (2014) UAV for 3D mapping applications: a review, Appl. Geomatics, 6, 1-15

Niedzielski T, Miziński B, Yu D (2015) Hydrological forecasting in real time: an experimental integrated approach. In: Jasiewicz J, Zwoliński Z, Mitasova H, Hengl T (eds.), Geomorphometry for geosciences, Bogucki Wydawnictwo Naukowe, Adam Mickiewicz University in Poznań - Institute of Geoecology and Geoinformation, Poznań, 97-101.

Niedzielski T, Witek M, Spallek W (2016) Observing river stages using unmanned aerial vehicles. Hydrol Earth Syst Sci 20:3193-3205

Nieminski NM, Graham SA (2017) Modeling stratigraphic architecture using small unmanned aerial vehicles and photogrammetry: examples from the Miocene East Coast Basin, New Zealand. J Sediment Res 87:126-132

Niethammer U, James MR, Rothmund S, Travelletti J, Joswig M (2012) UAV-based remote sensing of the Super-Sauze landslide: evaluation and results. Eng Geol 128:2-11

Nikolakopoulos KG, Koukouvelas IK (2018) UAVs for the rapid assessment of the damages in the coastal zone after a storm. Proc. SPIE 10773, Sixth International Conference on Remote Sensing and Geoinformation of the Environment, 107731S.

Nikolakopoulos KG, Kavoura K, Depountis N, Kyriou A, Argyropoulos N, Koukouvelas IK, Sabatakakis N (2017a) Preliminary results from active landslide monitoring using multidisciplinary surveys. European Journal of Remote Sensing 50:280-299

Nikolakopoulos KG, Soura K, Koukouvelas IK, Argyropoulos NG (2017b) UAV vs classical aerial photogrammetry for archaeological studies. Journal of Archaeological Science: Reports 14:758-773

Nikolakopoulos K, Kyriou A, Koukouvelas I, Zygouri V, Apostolopoulos D (2019) Combination of aerial, satellite, and UAV photogrammetry for mapping the diachronic coastline evolution: the case of Lefkada Island. ISPRS Int J Geo-Inf 2019(8):489

Nishar A, Richards S, Breen D, Robertson J, Breen B (2016) Thermal infrared imaging of geothermal environments and by an unmanned aerial vehicle (UAV): a case study of the Wairakei - Tauhara Geothermal Field, Taupo, New Zealand. Renewable Energy 86: 1256-1264

O’Banion MS, Olsen MJ, Rault C, Wartman J, Cunningham K (2018) Suitability of structure from motion for rock slope assessment. The Photogrammetric Record, Wiley Online Library 33(162):217-242

Oberndorfer S, Fuchs S, Rickenmann D, Andrecs P (2007) Vulnerabilitätsanalyse und monitäre Schadensbewertung von Wildbachereignissen in Österreich. BFW-Berichte, 139, Vienna.

ORF (2015) News report from the Austrian Broadcasting Corporation (ORF) on 9 June 2015 (http://tirol.orf.at/news/stories/2715184; accessed 28 March 2016).

Pajares G (2015) Overview and current status of remote sensing applications based on unmanned aerial vehicles (UAVs). Photogrammetric Engineering and Remote Sensing 81(4):281-330

Pásler M, Komárková J, Sedlák P (2016) Comparison of possibilities of UAV and Landsat in observation of small inland water bodies. In: 2015 International Conference on Information Society (i-Society), 9-11 November 2015, London, UK.

Passalacqua P, Belmont P, Staley D, Simley J, Arrowsmith JR, Bodee C, Crosby C, DeLongg S, Glenn N, Kelly S, Lague D, Sangireddy H, Schaffrath K, Tarboton D, Wasklewicz T, Wheaton J (2015) Analyzing high resolution topography for advancing the understanding of mass and energy transfer through landscapes: a review. Earth-Sci. Rev. 148:174-193

Pellegrino AM, Scotto di Santolo A, Schippa L (2015) An integrated procedure to evaluate rheological parameters to model debris flows. Engineering Geology 196:88-98

Pennington CVL, Freeborough KA, Dashwood C, Dijkstra TA, Lawrie KIG (2015) The National Landslide Database of Great Britain: acquisition, communication and the role of social media. Geomorphology 249:44-51

Peppa MV, Mills JP, Moore P, Miller PE, Chambers JE (2016) Accuracy assessment of a UAV-based landslide monitoring system. The International Archives of the Photogrammetry, Remote Sensing and Spatial Information Sciences, Vol. XLI-B5, 2016, XXIII ISPRS Congress, pp895-902. Gottingen: Copernicus GmbH. 
Peppa MV, Mills JP, Moore P, Miller PE, Chambers JE (2017) Brief communication: landslide motion from cross correlation of UAVderived morphological attributes. Nat. Hazards Earth Syst. Sci. 17: 2143-2150

Piermattei L, Carturan L, de Blasi F, Tarolli P, Dalla Fontana G, Vettore A, Pfeifer N (2016) Suitability of ground-based SfM-MVS for monitoring glacial and periglacial processes. Earth Surface Dynamics 4: 425-443

Piras M, Dabove P (2016) Comparison of two different mass-market IMU generations: bias analyses and real time applications. 2016 IEEE/ION Position, Location and Navigation Symposium (PLANS), $34-41$.

Piras M, Grasso N, Jabbar AA (2017a) UAV photogrammetric solution using a raspberry pi camera module and smart devices: test and results. The International Archives of Photogrammetry, Remote Sensing and Spatial Information Sciences 42:289

Piras M, Taddia G, Forno MG, Gattiglio M, Aicardi I, Dabove P, Lingua A (2017b) Detailed geological mapping in mountain areas using an unmanned aerial vehicle: application to the Rodoretto Valley, NW Italian Alps. Geomatics, Natural Hazards and Risk 8(1):137-149

Poulton CVL, Lee JR, Hobbs PRN, Jones L, Hall M (2006) Preliminary investigation into monitoring coastal erosion using terrestrial laser scanning: case study at Happisburgh, Norfolk. The Bulletin of the Geological Society of Norfolk 56:45-64

Priest S (1993) Discontinuity analysis for rock engineering. Journal of Chemical Information and Modeling 53(9):1689-1699

Przybilla H, Wester-Ebbinghaus W (1979) Bildflug mit ferngelenktem Kleinflugzeug. Bildmessung und Luftbildwessen 47:137-142

Pupillo G, Naldi G, Mattana A, Monari J, Poloni M, Perini F, Schiaffino M, Bianchi G, Bolli P, Lingua AM, Aicardi I, Bendea H, Maschio P, Piras M, Virone G, Paonessa F, Farooqui Z, Tibaldi A, Addamo G, Peverini OA, Tascone R, Wijnholds SJ (2015) Medicina Array Demonstrator: calibration and radiation pattern characterization using a UAV-mounted radio-frequency source. Experimental Astronomy 39:405-421

Quinn JD, Rosser NJ, Murphy W, Lawrence JA (2010) Identifying the behavioural characteristics of clay cliffs using intensive monitoring and geotechnical numerical modelling. Geomorphology 120(3-4):107-122

Remondino F, Barazzetti L, Nex F, Scaioni M, Sarazzi D (2012) UAV photogrammetry for mapping and 3D modeling - current status and future perspectives. ISPRS - International Archives of the Photogrammetry, Remote Sensing and Spatial Information Sciences XXXVIII-1/: 25-31. https://doi.org/10.5194/ isprsarchives-XXXVIII-1-C22-25-2011.

Rickenmann D (2001) Murgänge in den Alpen und Methoden zur Gefahrenbeurteilung. Proceedings 31, IWASA, Internationales Wasserbau-Symposium, Aachen.

Rickenmann D, Koschni A (2010) Sediment loads due to fluvial transport and debris flows during the 2005 flood events in Switzerland. Hydrological Processes 24:993-1007

Rickenmann D, Laigle D, McArdell BW, Hübl J (2006) Comparison of 2D debris-flow simulation models with field events. Comput Geosci 10:241-264

Rinaudo F, Chiabrando F, Lingua AM, Spanò A (2012) Archaeological site monitoring: UAV photogrammetry can be an answer. Paper presented at the International Archives of the Photogrammetry, Remote Sensing and Spatial Information Sciences - ISPRS Archives, 39, 583-588.

Rosnell T, Honkavaara E (2012) Point cloud generation from aerial image data acquired by a quadricopter type micro unmanned aerial vehicle and a digital still camera. Sensors 12:453-480

Rossi P, Mancini F, Dubbini M, Mazzone F, Capra A (2017) Combining nadir and oblique UAV imagery to reconstruct quarry topography: methodology and feasibility analysis. Eur J Remote Sens 50:211-221

Rudol P, Doherty P (2008) Human body detection and geolocalization for UAV search and rescue missions using color and thermal imagery.
IEEE Aerospace Conference Proceedings, 1-8. IEEE. https://doi. org/10.1109/AERO.2008.4526559.

Rudolf-Miklau F (2009) Naturgefahren-Management in Österreich: Vorsorge - Bewältigung - Information. LexisNexis ARD Orac, Vienna.

Ryan JC, Hubbard AL, Box JE, Todd J, Christoffersen P, Carr JR Holt TO, Snooke N (2015) UAV photogrammetry and structure from motion to assess calving dynamics at Store Glacier, a large outlet draining the Greenland Ice Sheet. Cryosphere 9(1): 1-11.

Saari H, Antila T, Holmlund C, Makynen J, Ojala K, Toivanen H, Pellikka I,Tuominen S, Pesonen L, Heikkila J (2011) Unmanned aerial vehicle (UAV) operated spectral camera system for forest and agriculture applications. In: Proceedings of SPIE, 8174.

Salvini R, Vanneschi C, Riccucci S, Francioni M, Gullì D (2015) Application of an integrated geotechnical and topographic monitoring system in the Lorano marble quarry (Apuan Alps, Italy). Geomorphology 241:209-223

Salvini R, Mastrorocco G, Seddaiu M, Rossi D, Vanneschi C (2017) The use of an unmanned aerial vehicle for fracture mapping within a marble quarry (Carrara, Italy): photogrammetry and discrete fracture network modeling. Geom. Nat. Haz. Risk 8(1):34-52

Salvini R, Mastrorocco G, Esposito G, Di Bartolo S, Coggan J, Vanneschi C (2018) Use of a remotely piloted aircraft system for hazard assessment in a rocky mining area (Lucca, Italy). Nat Hazards Earth Syst Sci 18(1):287-302

Sankey T, Donager J, McVay J, Sankey JB (2017) UAV lidar and hyperspectral fusion for forest monitoring in the Southwestern USA. Remote Sens Environ 195:30-43. https://doi.org/10.1016/j. rse.2017.04.007

Sankey T, McVay J, Swetnam TL, McClaran MP, Heilman P, Nichols M (2018) UAV hyperspectral and lidar data and their fusion for arid and semi-arid land vegetation monitoring. Remote Sensing in Ecology and Conservation 4(1):20-33

Sassa K (2017) The 2017 Ljubljana Declaration on landslide risk reduction and the Kyoto 2020 Commitment for global promotion of understanding and reducing landslide disaster risk. Landslides 14 : 1289-1296

Scheidl C, Rickenmann D, Chiari M (2008) The use of airborne LiDAR data for the analysis of debris flow events in Switzerland. Natural Hazards Earth System Sciences 8:1113-1127

Schulz WH (2007) Landslide susceptibility revealed by LIDAR imagery and historical records, Seattle, Washington. Engineering Geology 89:67-87

Semsch E, Jakob M, Pavlicek D, Pechoucek M (2009) Autonomous UAV surveillance in complex urban environments. In: Web Intelligence and Intelligent Agent Technologies, WI-IAT'09. IEEE/WIC/ACM International Joint Conferences, 2, 82-85.

Shahbazi M, Sohn G, Théau J, Ménard P (2015) UAV-based point cloud generation for open-pit mine modeling. Int Arch Photogramm Remote Sens Spat Inf Sci 40:313-320

Shapiro M, Westervelt J (1994) r. mapcalc: an algebra for GIS and image processing; Technical Report; Construction Engineering Research Lab (ARMY): Champaign, IL, USA.

Sotier B, Graf A, Kammerlander J (2013) Einsatz von UAV im alpinen Gelände: Erfahrungsbericht und Anwendungsbeispiel aus der Naturgefahrenpraxis. Österreichische Zeitschrift für Vermessung und Geoinformation (VGI), 101 (2013), 2+3, 110- 118.

Spetsakis ME, Aloimonos J (1991) A multi-frame approach to visual motion perception. Int J Comput Vision 6:245-255

Stead D, Wolter A (2015) A critical review of rock slope failure mechanisms: the importance of structural geology. J Struct Geol 74:1-23

Stempfhuber W, Buchholz M (2011) A precise, low-cost RTK GNSS system for UAV applications. In: International Archives of the Photogrammetry, Remote Sensing and Spatial Information Sciences, Zurich, XXXVIII-1/C22. 
Stöcker C, Bennett R, Nex F, Gerke M, Zevenbergen J (2017) Review of the current state of UAV regulations. Remote Sensing 9(5):459. https://doi.org/10.3390/rs9050459

Stumpf A, Malet J-P, Kerle N, Niethammer U, Rothmund S (2013) Image-based mapping of surface fissures for the investigation of landslide dynamics. Geomorphology 186:12-27

Stumpf A, Malet JP, Allemand P, Pierrot-Deseilligny M, Skupinski G (2014) Ground-based multi-view photogrammetry for the monitoring of landslide deformation and erosion. Geomorphology 321:130 145

Sturzenegger M, Stead D (2009) Close-range terrestrial digital photogrammetry and terrestrial laser scanning for discontinuity characterization on rock cuts. Eng. Geol. 106:163-182

Tamminga AD, Eaton BC, Hugenholtz CH (2015) UAS based remote sensing of fluvial change following an extreme flood event, Earth Surf. Proc. Land., 40, 1464-1476, https://doi.org/10.1002/esp.3728

Tannant DD (2015) Review of photogrammetry-based techniques for characterization and hazard assessment of rock faces. Int. J. Geohazards Environ. 2015(1), 76-87.

Theule J, Liébault F, Laigle D, Loye A, Jaboyedoff M (2015) Channel scour and fill by debris flows and bedload transport. Geomorphology 243:92-105

Tong XH, Liu XF, Chen P, Liu SJ, Luan KF, Li LY, Liu S, Liu XL, Xie H, Jin YM, Hong ZH (2015) Integration of UAV-based photogrammetry and terrestrial laser scanning for the three-dimensional mapping and monitoring of open-pit mine areas. Rem Sens 7:6635-6662

Tuckey Z, Stead D (2016) Improvements to field and remote sensing methods for mapping discontinuity persistence and intact rock bridges in rock slopes. Eng Geol 208:136-153

Turner D, Lucieer A, Watson C (2010) Development of an unmanned aerial vehicle (UAV) for hyper resolution vineyard mapping based on visible, multispectral, and thermal imagery. Proceedings of 34th International Symposium on Remote Sensing of Environment, 4.

Turner D, Lucieer A, Watson C (2012) An automated technique for generating georectified mosaics from ultrahigh resolution unmanned aerial vehicle (UAV) imagery, structure from motion (SfM) point clouds. Remote Sens 4:1392-1410

Turner D, Lucieer A, Wallace L (2014) Direct georeferencing of ultrahigh-resolution UAV imagery. IEEE Trans Geosci Remote Sensing 52(5):2738-2745

Turner D, Lucieer A, de Jong SM (2015) Time series analysis of landslide dynamics using an unmanned aerial vehicle (UAV). Remote Sens 7: $1736-1757$

UAS Yearbook (2011) UAS: the global perspective - 9th Edition June 2011 - Blyenburgh \& Co

Uhlemann S, Smith A, Chambers J, Dixon N, Dijkstra T, Haslam E, Meldrum P, Merritt A, Gunn D, Mackay J (2016) Assessment of ground-based monitoring techniques applied to landslide investigations. Geomorphology 253:438-451

URSC (2019) Piano Generale di Cantierizzazione di Villa Sant'Angelo. Ufficio Speciale per la Ricostruzione dei Comuni del Cratere http:// www.usrc.it/home/news/357-piano-generale-di-cantierizzazione-divilla-sant-angelo Accessed 23 Jul 2019

UST (2018) Memsense develops high performance inertial measurement units for unmanned systems. Unmanned Systems Technologies. May 2018.

Vander Jagt B, Lucieer A, Wallace L, Turner D, Durand M (2015) Snow depth retrieval with UAS using photogrammetric techniques. Geosciences 5:264-285

Vasterling M, Meyer U (2013) Challenges and opportunities for UAVborne thermal imaging. Remote Sensing and Digital Image Processing 17:69-92

Vetrivel A, Gerke M, Kerle N, Nex F, Vosselman G (2018) Disaster damage detection through synergistic use of deep learning and 3D point cloud features derived from very high resolution oblique aerial images, and multiple-kernel-learning. ISPRS J Photogramm Remote Sens 140:45-59

Wefelscheid C, Hansch R, Hellwich O (2011) “Three-dimensional building reconstruction using images obtained by unmanned aerial vehicles". In: Proceedings of the International Conference on Unmanned Aerial Vehicle in Geomatics (UAV-g), Zurich, Switzerland.

Wehr A, Lohr U (1999) Airborne laser scanning - an introduction and overview. ISPRS J Photogrammetry Remote Sens 54(2-3):68-82

Wen Q, He H, Wang X, Wu W, Wang L, Xu F, Wang P, Tang T, Lei Y (2011) UAV remote sensing hazard assessment in Zhouqu debris flow disaster. Proc. SPIE, Remote Sensing of the Ocean, Sea Ice, Coastal Waters, and Large Water Regions, 8175.

Westoby MJ, Brasington J, Glasser NF, Hambrey MJ, Reynolds MJ (2012) Structure-from-motion photogrammetry: a low-cost, effective tool for geoscience applications. Geomorphology 179:300-314

Whitehead K, Moorman BJ, Hugenholtz CH (2013) Brief communication: low-cost, on-demand aerial photogrammetry for glaciological measurement. The Cryosphere 7:1879-1884

Wilkinson MW, Jones RR, Woods CE, Gilment SR, McCaffrey KJW, Kokkalas S, Long JJ (2016) A comparison of terrestrial laser scanning and structure-from-motion photogrammetry as methods for digital outcrop acquisition. Geosphere 12:1865-1880

Willi C, Graf C, Deubelbeiss Y, Keiler M (2015) Methods for detecting channel bed surface changes in a mountain torrent - experiences from the Dorfbach torrent. Geogr. Helv. 70:265-279

Witek M, Jeziorska J, Niedzielski T (2013) Możliwości wykorzystania bezzałogowej fotogrametrii lotniczej do identyfikacji przekształceń antropogenicznych w korytach rzecznych / Possibilities of using unmanned air photogrammetry to identify anthropogenic transformations in river channel. Landform Analysis 24:115-126

Witek M, Jeziorska J, Niedzielski T (2014) Experimental approach to verify prognoses of floods using the unmanned aerial vehicle. Meteorology Hydrology and Water Management - Research and Operational Applications 2:3-11

Woodget AS, Carbonneau PE, Visser F, Maddock IP (2015) Quantifying submerged fluvial topography using hyperspatial resolution UAS imagery and structure from motion photogrammetry. Earth Surface Processes and Landforms 40:47-64

Woodget AS, Visser F, Maddock IP, Carbonneau PE (2016) The accuracy and reliability of traditional surface flow type mapping: is it time for a new method of characterizing physical river habitat? River Research and Applications 32:1902-1914

Woodget AS, Austrums R, Maddock IP, Habit E (2017) Drones and digital photogrammetry: from classifications to continuums for monitoring river habitat and hydromorphology. WIREs Water 4(e1222)

Youssef AM, Al-Kathery M, Pradhan B, El-sahly T (2016) Debris flow impact assessment along the Al-Raith Road, Kingdom of Saudi Arabia, using remote sensing data and field investigations. Geomatics, Natural Hazards and Risk 7(2):620-638

Zajc M, Pogačnik Z, Gosar A (2014) Ground penetrating radar and structural geological mapping investigation of karst and tectonic features in flyschoid rocks as geological hazard for exploitation. Int J Rock Mech Min 67:78-87

Zemp M, Frey H, Gärtner-Roer I, Nussbaumer SU, Hoelzle M, Frank P, Haeberli W, Denzinger F, Ahlstrøm AP, Anderson B, Bajracharya S, Baroni C, Braun L, Cáceres B, Casassa G, Cobos G, Davila RL, Delgado Granados U, Demuth MN, Espizua L, Fischer A, Fujita K, Gadek B, Ghazanfar A, Hagen JO, Holmlund P, Karimi N, Li Z, Pelto M, Pitte P, Popovnin VV, Potocarrero CA, Prinz R, Sangewar CV, Severskiy I, Sigurdsson O, Soruco A, Usubaliev R, Christian V (2015) Historically unprecedented global glacier decline in the early 21st century. J Glaciol 61:745-762

Zhang C, Kovacs JM (2012) The application of small unmanned aerial systems for precision agriculture: a review. Precision Agric. 13:693-712 
Zhang J, Liu L, Wang B, Chen X, Wang Q, Zheng T (2012) High speed automatic power line detection and tracking for a UAV-based inspection. In: International Conference on Industrial Control and Electronics Engineering (ICICEE), pp 266-269

Zheng D, Frost JD, Huang RQ, Liu FZ (2015) Failure process and modes of rockfall induced by underground mining: a case study of Kaiyang Phosphorite Mine rockfalls. Eng Geol 197:145-147
Zongjian L (2008) UAV for mapping — low altitude photogrammetric survey. ISPRS - International Archives of the Photogrammetry, Remote Sensing and Spatial Information Sciences XXXVII B1: $1183-1186$ 